Keywords: SCIX, Rotary

Filter, Filtration

Retention: Permanent

\title{
Testing of the Dual Rotary Filter System
}

\author{
D. T. Herman \\ M. D. Fowley \\ D. B. Stefanko
}

August 2011

Savannah River National Laboratory Savannah River Nuclear Solutions, LLC Aiken, SC 29808

Prepared for the U.S. Department of Energy under contract number DE-AC09-08SR22470.

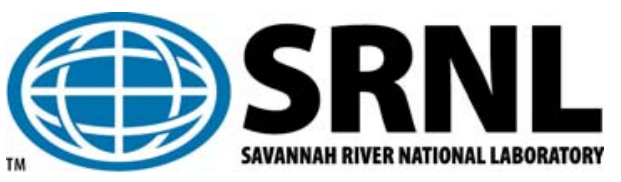


SRNL-STI-2011-00466

Revision 0

\section{DISCLAIMER}

This work was prepared under an agreement with and funded by the U.S. Government. Neither the U.S. Government or its employees, nor any of its contractors, subcontractors or their employees, makes any express or implied:

1. warranty or assumes any legal liability for the accuracy, completeness, or for the use or results of such use of any information, product, or process disclosed; or

2. representation that such use or results of such use would not infringe privately owned rights; or

3. endorsement or recommendation of any specifically identified commercial product, process, or service.

Any views and opinions of authors expressed in this work do not necessarily state or reflect those of the United States Government, or its contractors, or subcontractors.

\section{Printed in the United States of America \\ Prepared for \\ U.S. Department of Energy}




\section{REVIEWS AND APPROVALS}

\section{AUTHORS}

D. T. Herman

Date

Advanced Characterization and Processing Group

M. D. Fowley

Date

Process Engineering Technology

D. B. Stefanko

Date

Advanced Characterization and Processing Group

DESIGN CHECK

C. A. Nash

Date

Advanced Characterization and Processing Group

\section{APPROVALS}

F. M. Pennebaker, Manager

Date

Advanced Characterization and Processing Group

S. L. Marra, Manager

Date

Environmental \& Chemical Process Technology Research Programs

T.H. Huff, Manager

Date

SCIX Engineering 


\section{EXECUTIVE SUMMARY}

The Savannah River National Laboratory (SRNL) installed and tested two hydraulically connected SpinTek rotary microfilter (RMF) units to determine the behavior of a multiple filter system. Both units were successfully controlled by a control scheme written in DELTA-V architecture by Savannah River Remediation (SRR) Process Control Engineering personnel. The control system was tuned to provide satisfactory response to changing conditions during the operation of the multi-filter system. Stability was maintained through the startup and shutdown of one of the filter units while the second was still in operation.

The installation configuration originally proposed by the Small Colum Ion Exchange (SCIX) project of independent filter and motor mountings may be susceptible to vibration. Significant stiffening of the filter and motor mounts was required to minimize the vibration. Alignment of the motor to the filter was a challenge in this test configuration. The deployment configuration must be easy to manipulate and allow for fine adjustment.

An analysis of the vibration signature of the test system identified critical speeds. Whether it corresponds to the resonance frequency of a rotor radial vibration mode that was excited by rotor unbalance is uncertain based upon the measurements. A relative motion series should be completed on the filter with the final shaft configuration to determine if the resonances exist in the final filter design.

The instrumentation selected for deployment, including the concentrate discharge control valve and flow meters, performed well. Automation of the valve control integrated well with the control scheme and when used in concert with the other control variables, allowed automated control of the dual RMF system. The one area of concern with the instrumentation was the condition resulting when the filtrate flow meter operated with less than three gpm. This low flow was at the lower range of performance for the flow meter. This should not be an issue in deployment where the desired flow rate will be within the normal operating range of the meter.

Testing demonstrated that the use of a flexible line for the filtrate discharge is highly desired at the outlet of the rotary union to transition to the system piping. Isolating the vibration from the rotary union will significantly improve the lifetime of the seals.

Methods to monitor and isolate individual filters should be considered during deployment. The ability to diagnose issues and isolate individual filters would allow isolation prior to failure. Thus, filters may be cleaned or repaired instead of requiring complete replacement if the condition were to continue unnoticed. Isolating the filtrate line of each filter during startup will minimize the premature buildup of solids on the filter disks. Several tests have shown that the method of filter startup can improve performance lifetime of the filters.

The installation must factor in an air inlet for the draining of a filter that does not involve a reverse flow through the filter disks. The reverse flow may cause deformation of the disks or may damage other components of the filters themselves. 


\section{TABLE OF CONTENTS}

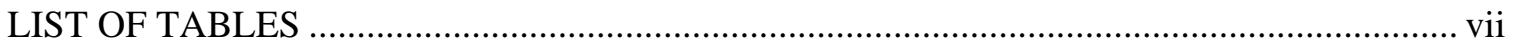

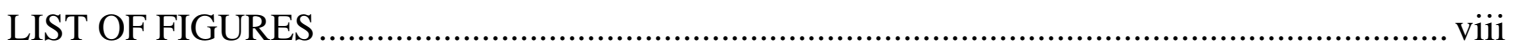

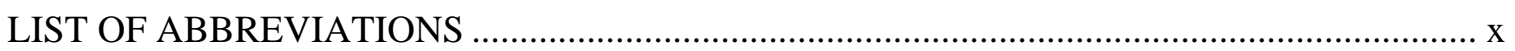

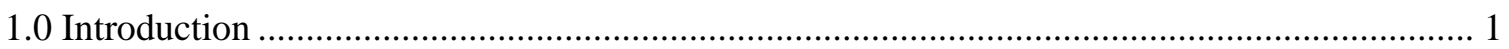

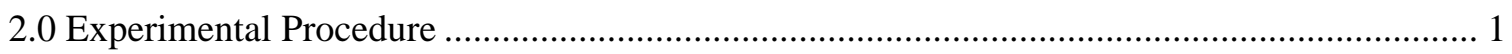

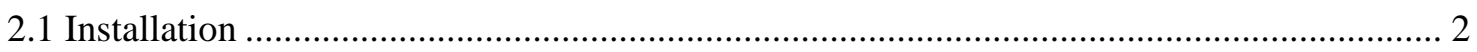

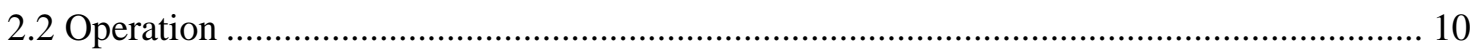

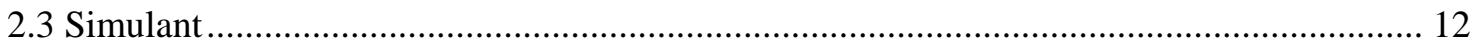

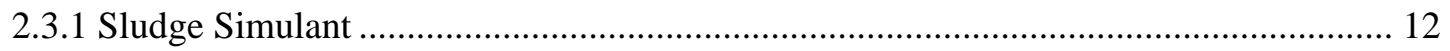

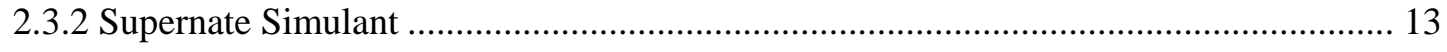

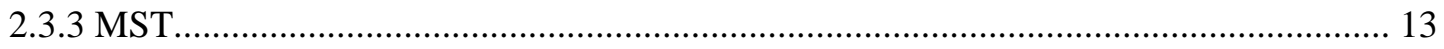

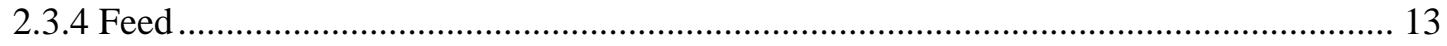

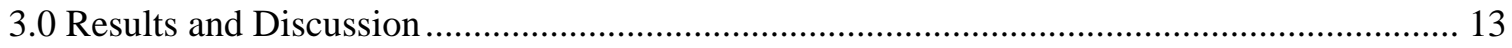

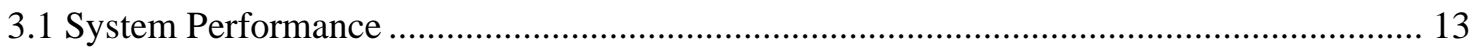

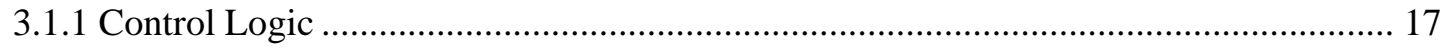

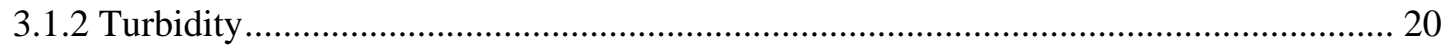

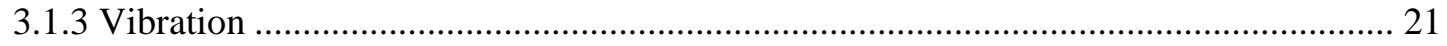

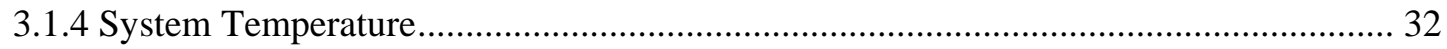

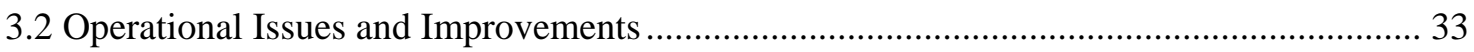

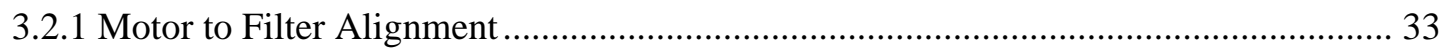

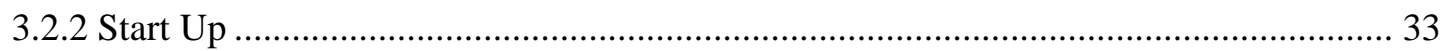

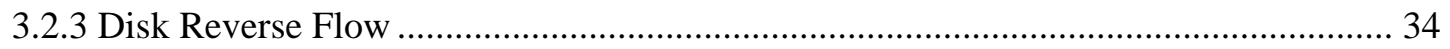

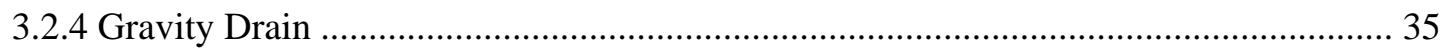

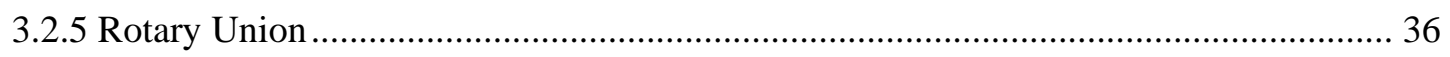

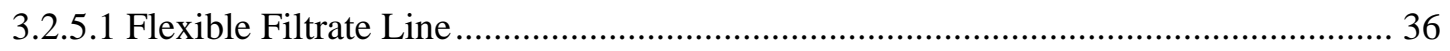




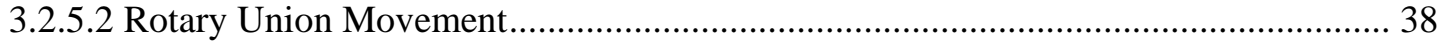

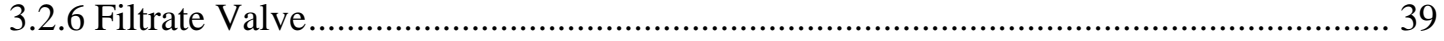

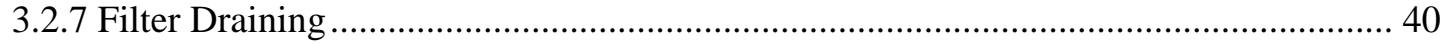

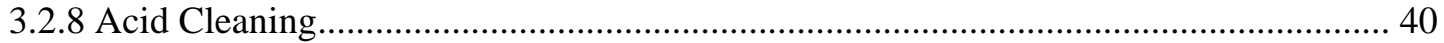

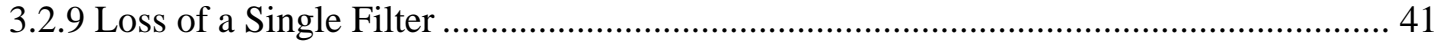

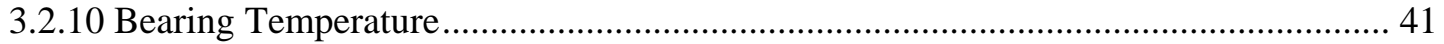

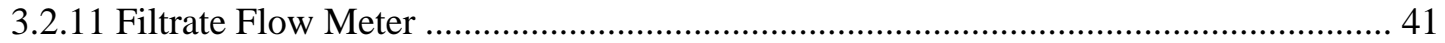

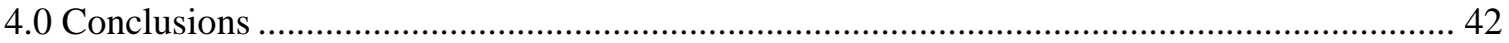

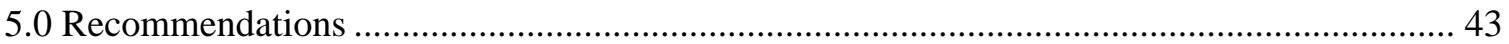




\section{LIST OF TABLES}

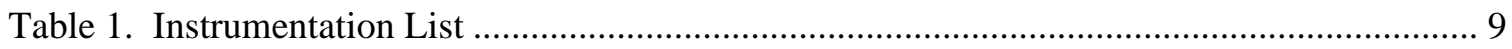

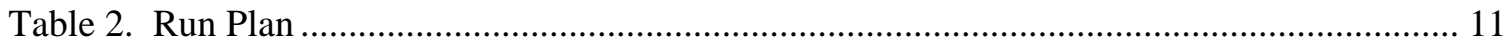

Table 3. Concentration of Anion/Cation Content of Sludge Batch 6 Feed Simulant.................... 12

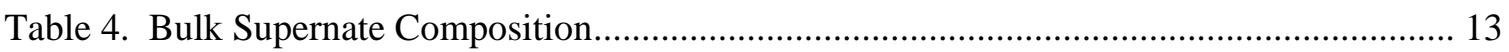

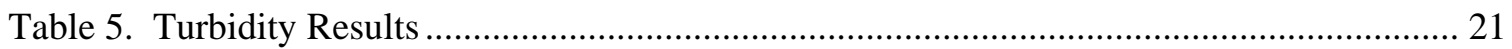

Table 6. Filter \#2 Filtration Improvement from Acid Cleaning ................................................. 40 


\section{LIST OF FIGURES}

Figure 1. Dual Filter/Motor Support Design ............................................................................ 2

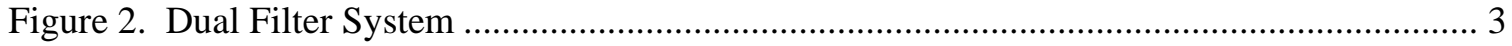

Figure 3. Simplified Process Instrumentation Diagram - SRR Configuration .............................. 4

Figure 4. Process Instrumentation Diagram Showing Additional SRNL Instrumentation............. 5

Figure 5. SRNL Process Diagram for Dual Filter Test ….......................................................... 6

Figure 6. Particle Size Distribution of Initial Feed.................................................................... 13

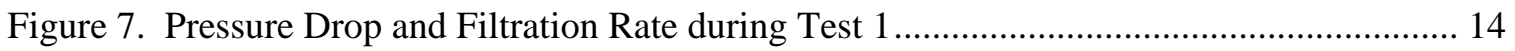

Figure 8. Pressure Drop and Filtrate Flow during Test 2 ......................................................... 15

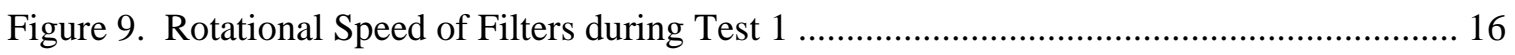

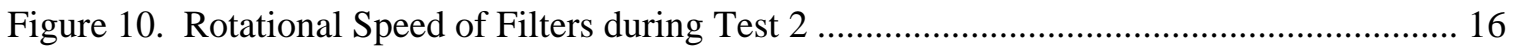

Figure 11. Test 2 Filter 2 - Effect of Increasing Rotor Speed................................................... 17

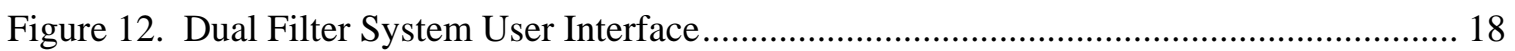

Figure 13. DCS Response to Parameter Change Prior to Tuning................................................ 19

Figure 14. DCS Response to Parameter Change after Tuning .................................................... 20

Figure 15. Vibration Monitoring Point for Dual Rotary Microfilter System .............................. 22

Figure 16. Cascade Plot of Motor Vibration for Filter \#1 …....................................................... 23

Figure 17. Cascade Plot of Rotary Union Vibrations for Filter \#1 …........................................ 24

Figure 18. Cascade Plot of Gas Seal Housing Vibrations for Filter \#1 ....................................... 24

Figure 19. Cascade Plot of Rotor Housing Vibrations for Filter \#1 .......................................... 25

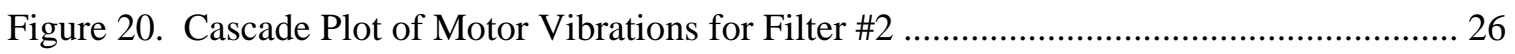

Figure 21. Cascade Plot of Rotary Union Vibrations for Filter \#2 …......................................... 26

Figure 22. Cascade Plot of Gas Seal Housing Vibrations for Filter \#2 ….................................. 27

Figure 23. Cascade Plot of Rotor Housing Vibrations for Filter \#2 _........................................ 27

Figure 24. Polar Plot of Lower Motor Showing System Resonances in the X Direction ............ 28

Figure 25. Polar Plot of Lower Motor Showing System Resonances in the Y Direction ............ 29

Figure 26. Polar Plot of Rotary Union Showing System Resonances in the X-Direction............ 29 
Figure 27. Polar Plot of Rotary Union Showing System Resonances in the Y Direction............ 30

Figure 28. Polar Plot of Gas Seal Housing Showing System Resonances in the X Direction ..... 30

Figure 29. Polar Plot of Gas Seal Housing Showing System Resonances in the Y Direction ..... 31

Figure 30. Polar Plot of Rotor Can Housing Showing System Resonances in the X Direction... 31

Figure 31. Polar Plot of Rotor Can Housing Showing System Resonances in the Y Direction... 32

Figure 32. Filter Disk from Reverse Pressure Testing ............................................................... 34

Figure 33. Disk from Filter 2 (old filter) with Evidence of Reverse Flow .................................. 35

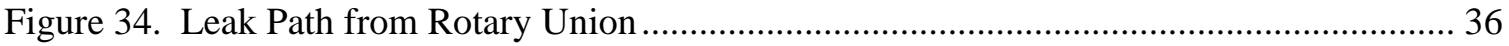

Figure 35. Rotary Joint of Filter \# 2 with Evidence of Salt and Carbon Discharge ...................... 37

Figure 36. Flexible Lines between Rotary Unions and Filtrate Piping ...................................... 38

Figure 37. Rotary Union Connection Showing Blocked Shaft Discharge .................................. 39

Figure 38. Filter Main Bearing Temperatures for the First 40 Hours of Test 2 .......................... 41

Figure 39. Filtrate Flow Rate Discrepancy of 1-1/2" Meter........................................................ 42 


\section{LIST OF ABBREVIATIONS}

$\begin{array}{ll}\text { ARP } & \text { Actinide Removal Process } \\ \text { CPVC } & \text { chlorinated polyvinyl chloride } \\ \text { DI } & \text { de-ionized } \\ \text { DOE } & \text { Department of Energy } \\ \text { EM } & \text { Environmental Management } \\ \text { EPDM } & \text { Ethylene-Propylene Diene Monomer } \\ \text { gpm } & \text { gallons per minute } \\ \text { I/O } & \text { input/output } \\ \text { kVA } & \text { kilovolt-ampere } \\ \text { kW } & \text { Kilowatt } \\ \text { M } & \text { Molar } \\ \text { MST } & \text { Monosodium titanate } \\ \text { NTU } & \text { Nephelometric Turbidity Unit } \\ \text { PSD } & \text { particle size distribution } \\ \text { psid } & \text { pound per square inch differential } \\ \text { psig } & \text { pound per square inch gauge } \\ \text { rPm } & \text { revolutions per minute } \\ \text { RCRA } & \text { Resource Conservation and Recovery Act } \\ \text { RMF } & \text { rotary microfilter } \\ \text { SB6 } & \text { Sludge Batch 6 } \\ \text { SCIX } & \text { Small Column Ion Exchange } \\ \text { SRNL } & \text { Savannah River National Laboratory } \\ \text { SRR } & \text { Savannah River Remediation } \\ \text { SRS } & \text { Savannah River Site } \\ \text { TTR } & \text { Task Technical Request } \\ \text { VFD } & \text { variable frequency drive } \\ \text { wt \% } & \end{array}$




\subsection{Introduction}

The SpinTek rotary microfilter has been developed by SpinTek Filtration ${ }^{\circledR}$ and SRNL under the Department of Energy (DOE) Office of Environmental Management (EM) for the purpose of deployment into radioactive service in the DOE complex. Under funding provided by DOE-EM, testing has been completed on a laboratory scale single disk unit ${ }^{\mathrm{i}}$, three disk pilot scale units ${ }^{\mathrm{ii}}$, first generation full scale twenty-five disk units ${ }^{\mathrm{iii}, \mathrm{iv}}$, and a 1000-hour endurance test ${ }^{\mathrm{v}}$ on a second generation filter unit. All testing has been accomplished with single units of various sizes.

SRR requested that SRNL install and test multiple full scale filter units to determine the hydraulic behavior and to allow SRR to develop control logic for operation of the filters during deployment with the SCIX system. ${ }^{\text {vi }}$ The purposes of the tests described in this report were to determine the effects of multiple units operating in parallel and to develop a multi-filter control system. The control system tested in these experiments will be the platform for deployment. The development of the control system is documented in a separate report. ${ }^{\mathrm{vii}}$

\subsection{Experimental Procedure}

SRNL installed two rotary microfilter units hydraulically connected in a parallel flow configuration. A series of operational tasks were performed with the dual filter setup. SRR Process Control Engineering provided the single-loop, digital control system for testing and developed the operational algorithms. The objectives of the task were met through testing the control logic with water, salt simulant and simulated sludge. The two simulant tests were planned and conducted to meet the minimum requirements of the task. Each test was conducted for a minimum of 100 hours of filter operation. Solids in the form of simulated Sludge Batch 6 (SB6) and Monosodium titanate (MST) were added to the salt simulant during the test.

The two primary objectives of the tests were to determine how to start multiple filters essentially simultaneously and to determine how to start a second filter after the first filter had been at steady state operation. A follow-on test was the converse situation where one filter was removed from service after both had been running at steady state.

The first test challenged the control system to rapidly adapt to the numerous dynamic changes occurring during startup. The control system must maintain operational parameters (minimum pressure) required by the vendor during these changes. The second test also challenged the rapid response of the control system due to changes in flow and pressure dynamics. The difficulty in this case was that the second filter to be brought online was significantly "cleaner" than the filter that had been running at a quasi-steady state. The cleaner filter provided a significant flow path that had to be accommodated by the control system.

The shutdown of one of the filters after both had been operating had similar logic control issues, where the control system must adjust demand with the loss of one of the filters. Rapid changes to system parameters by the control system can result in loss of operational integrity.

During this testing, vibration measurements were obtained on the filters to look for resonances and aid in the design of the filter deployment configuration. 


\subsection{Installation}

Two rotary filters were installed in a hydraulically parallel configuration using as much of the equipment and instrumentation as possible that is intended for Tank $41 \mathrm{H}$ deployment for the SCIX process. To simulate the hydraulic aspects of the tank-top configuration, the filters were placed on a second-level mezzanine with the feed tank on the first level. This configuration provided similar flow conditions like those for the actual waste tank, which in SRNL testing proved to be an important operating consideration.

An original intent of the installation was to verify the proposed tank-top support configuration of the filters and filter motors. The bank of filters and their respective motors were to be independently supported since they were isolated by the required shielding between them. To this intent, the SRNL main support structure for the filters was fabricated using unistrut and was set in a secondary container on the mezzanine. The filter motors were hung above the filters from an existing I-beam frame that was part of the mezzanine. This configuration is shown in Figure 1.

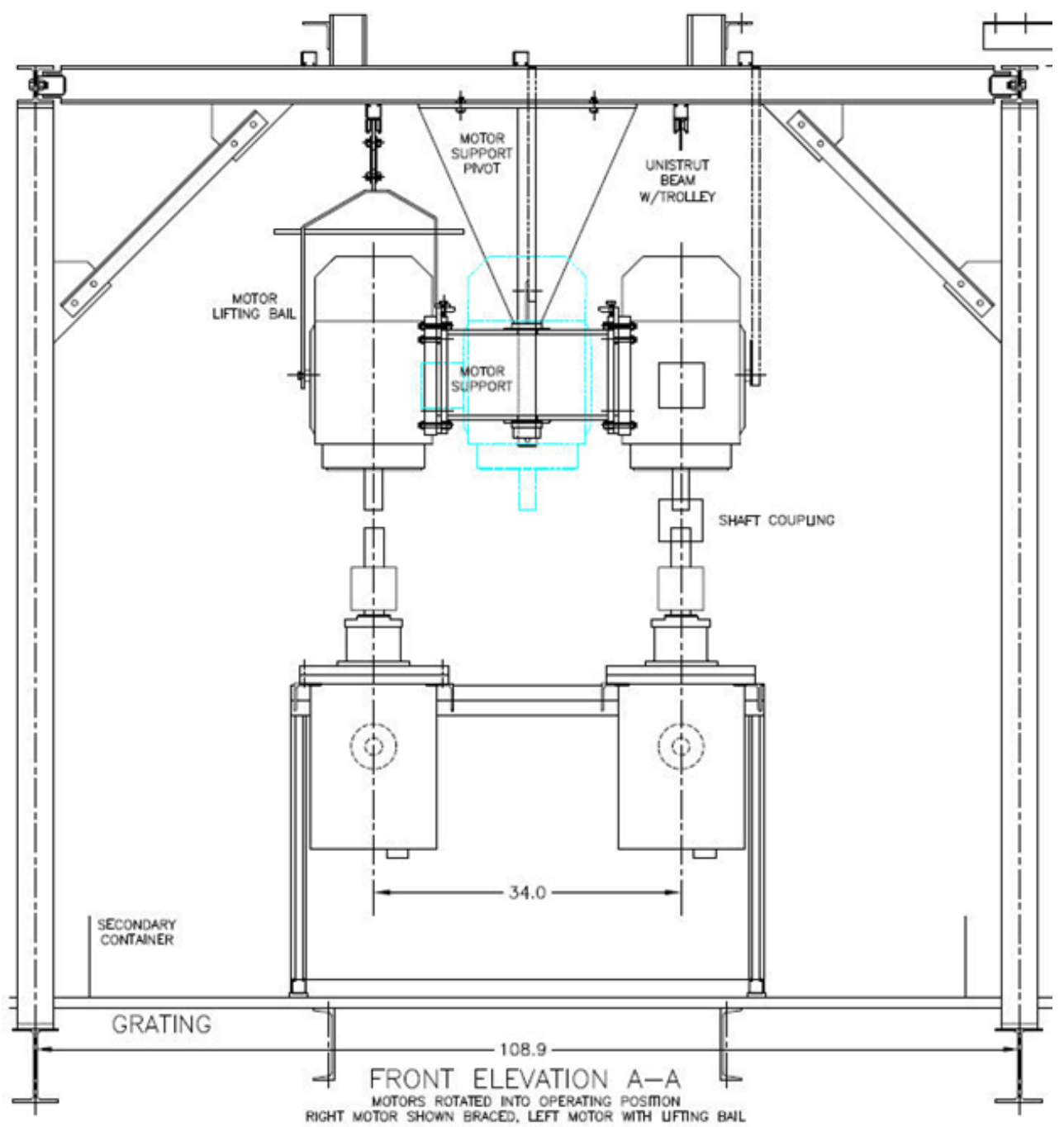

Figure 1. Dual Filter/Motor Support Design 
This original mounting configuration proved to be insufficient due to excessive vibration. Additional support structures were required to stiffen the structure for continued operation at tolerable vibration levels. A photo of the final reinforced filter setup is shown in Figure 2.

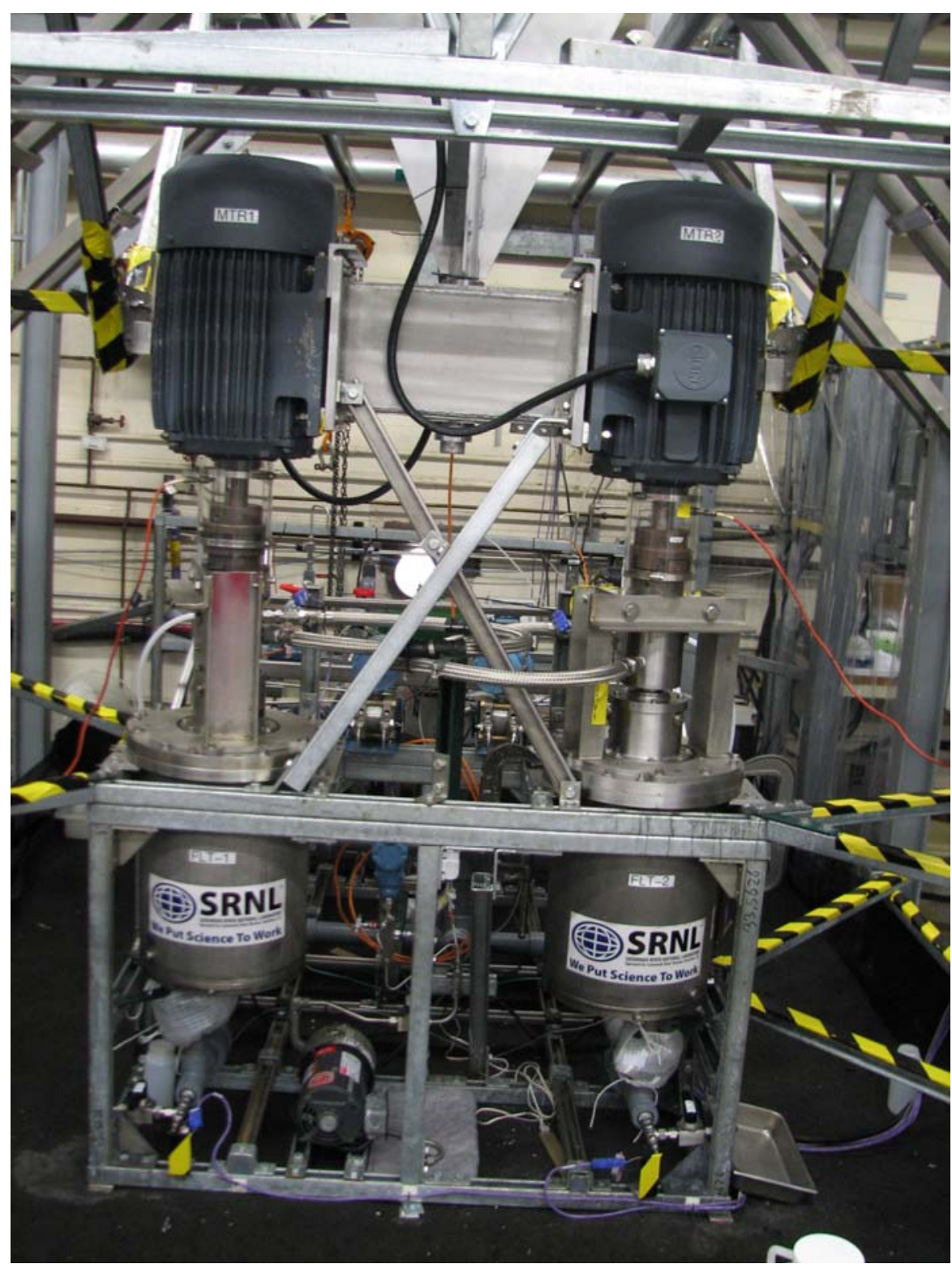

\section{Figure 2. Dual Filter System}

Not shown are additional supports that were added to stiffen the floor from below and tie the mezzanine to the main building structure. The motor mounts were eventually tied to the filter mount structure via the cross braces visible in Figure 2.

\subsubsection{Equipment}

The dual filter test installation in SRNL contained the pertinent equipment and instrumentation specified in the SRR process sketch M-M6-H-SK001 included in the Task Technical Request ${ }^{\mathrm{vi}}$ (TTR) (Figure 3). Additional equipment and instrumentation were included in the final SRNL 
test configuration to provide information regarding the operation of individual filters and to facilitate secondary activities such as cleaning and sampling. The additional instrumentation was not intended to provide input to the control system for filter operation.

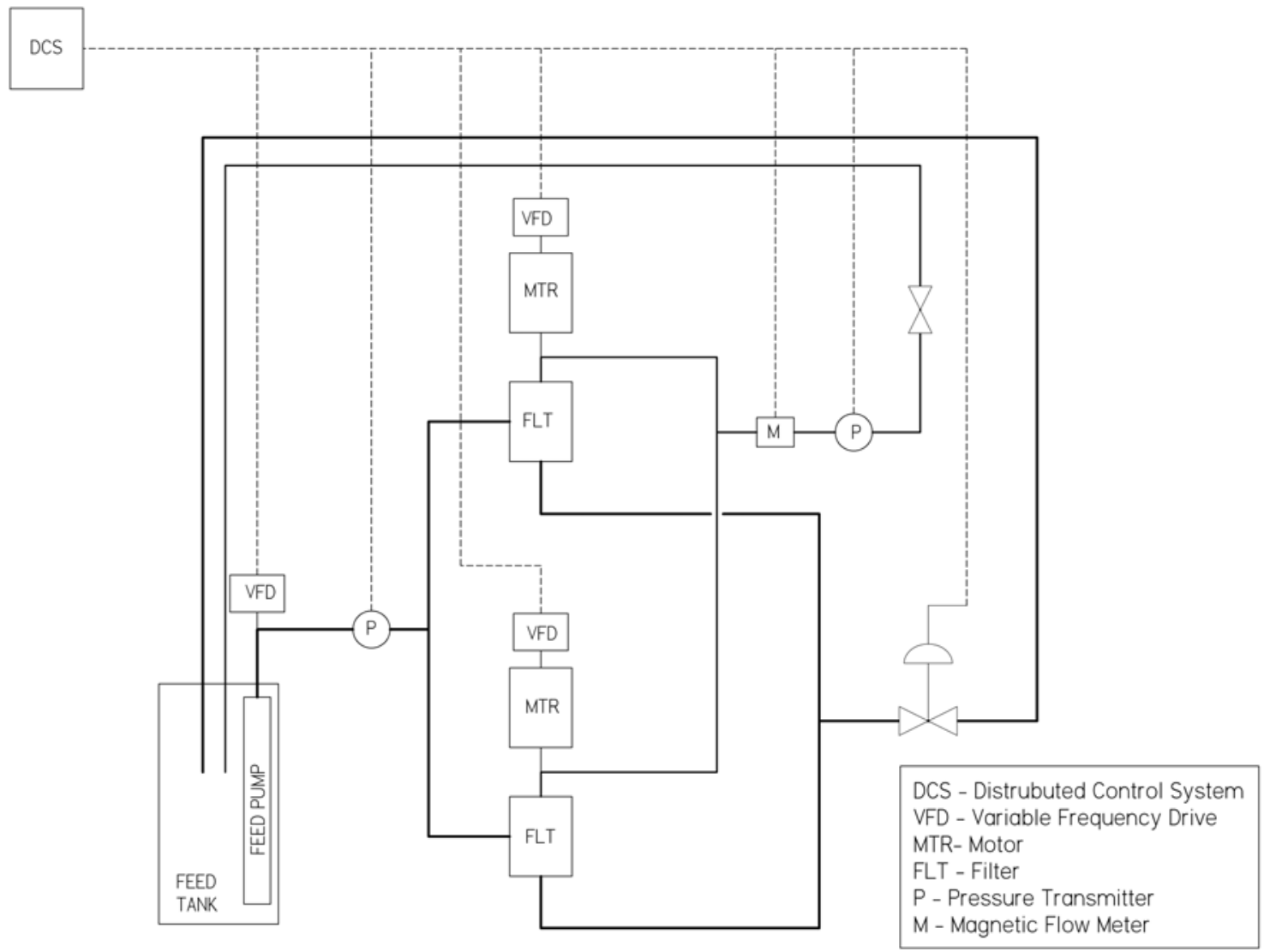

Figure 3. Simplified Process Instrumentation Diagram - SRR Configuration

Figure 4 highlights the additional instrumentation added by SRNL in red. Additional flow meters were added to each filtrate and concentrate line to determine the individual flow rates. Pressure drop measurement was also added across each filter from feed to filtrate. 


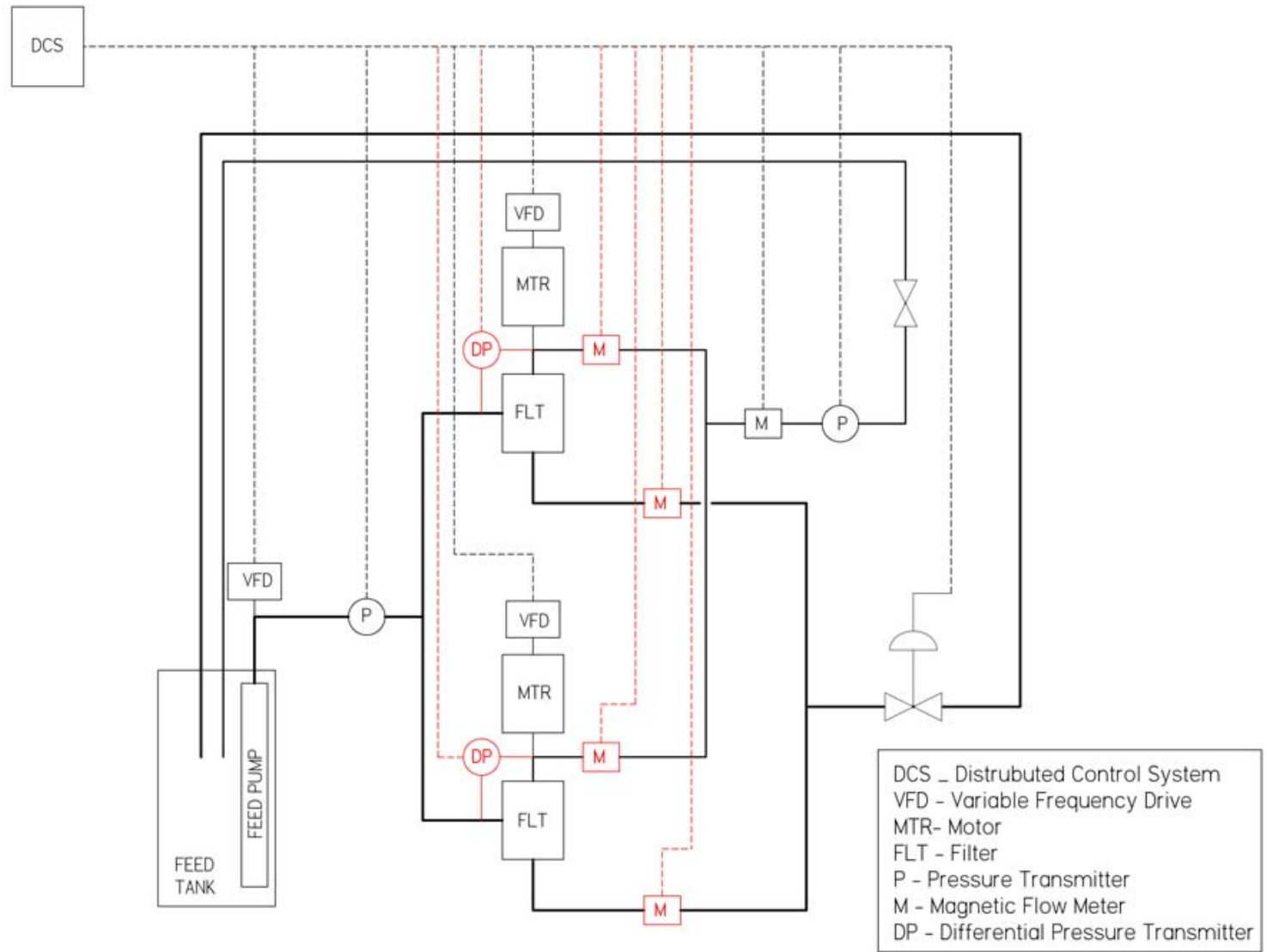

Figure 4. Process Instrumentation Diagram Showing Additional SRNL Instrumentation

The complete SRNL process diagram for the dual filter test is shown in Figure 5. 
SRNL-STI-2011-00466

Revision 0

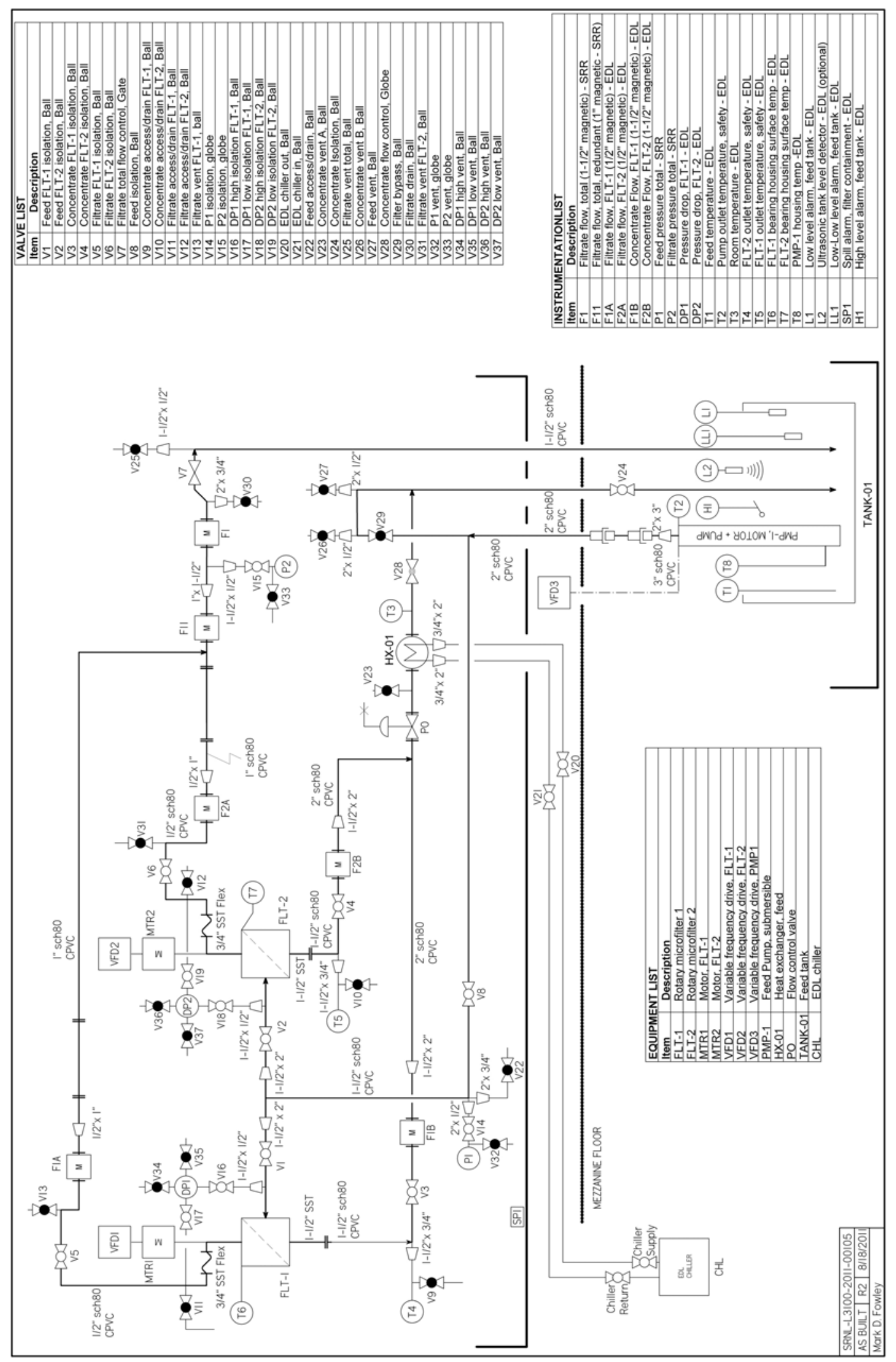

Figure 5. SRNL Process Diagram for Dual Filter Test 
The test piping was a closed loop system, as indicated in Figure 5. The concentrate and filtrate returned to the feed tank to allow continuous operation with a small feed volume. As shown in the process diagram, filter feed is provided by a submersible pump in the 180-gallon feed tank. The flow rate of the feed pump and the feed tank size provided rapid turnover of the tank and assured adequate mixing. The feed line split into two separate lines prior to entering the inlets on the side of each filter. The individual feed lines were similar in construction to provide an equal hydraulic resistance in the lines. Concentrate discharged from the bottom of the filter housing. The concentrate lines converged prior to entering the feed tank and were similar in construction to provide equal hydraulic resistance. The combined concentrate line contained the air-driven control valve to provide back pressure to the filters and a tube in shell heat exchanger to provide temperature control. Filtrate discharged from the rotary union of each filter. The filtrate lines converged prior to entering the feed tank and were similar in construction to provide equal resistance. A manual gate valve in the filtrate line downstream of the total flow meter provided back pressure in the filtrate line.

Major test components included the filters and their motors, the submersible feed pump, the variable frequency drives (VFDs) for the filter and pump motors, the feed tank, the air-driven control valve, and the heat exchanger and chiller.

Two 25-disk SpinTek rotary filters were used in the tests. Filter \#1 was originally purchased in $2005^{\text {viii }}$ and upgraded for this testing. Filter \#2 was the filter that recently completed the 1000hour endurance test at the vendor facility ${ }^{\mathrm{ix}}$. The upgrades to Filter $\# 1$ included a Stellite on nitronic 60 journal bearing, a new 28LD shaft air seal, and a rebuilt rotary union (new seals and new bearings). The original shaft was shortened to the same length as the shaft on Filter \#2 to provide filter/motor assemblies with similar stack-up dimensions for the installation. Filter \#2 also utilized a new Stellite on nitronic 60 journal bearing and a new 28LD air seal. The primary differences between the two units after the upgrades were the assembly tolerances of the rotors (Filter \#2 from the 1000-hour test had tighter tolerances) and the internal shaft restrictions. Due to these differences, Filter \#1 was expected to have greater vibration and possibly have a lower filtration rate due to higher internal hydraulic resistance. It was believed that the differences in the two filters would provide valuable input on system control when both filters could have different responses to changes in parameters.

Each filter was powered by a 20-hp, alternating current (AC) electric motor with a maximum rotation speed of 1175 revolutions per minute (RPM). Rotational speed for each was controlled by an Allen-Bradley VFD; the motor for Filter \#1 unit used a model Powerflex 70 and Filter \#2 used a model Powerflex 700. Two different VFD models were used due to availability. Feed to the filters was provided by a Grundfos model 150S150-6 submersible pump in a 180-gallon supply tank. The motor speed of the pump was controlled by an Allen-Bradley model 1336 Plus II VFD. A 20 kVA isolation transformer was used with each Allen-Bradley VFD. ${ }^{a}$

The control valve was a 2" air actuated globe valve from Fisher Controls model NPS 2 EZ 667 size 45 with a DVC6010 communication module. The heat exchanger was a Graham Heliflow tube in shell design with a total duty of $36,400 \mathrm{BTU} / \mathrm{hr}$ or $10.7 \mathrm{~kW}$. Cooling fluid for the heat exchanger was provided by a GC Industries Icewagon rated at $16 \mathrm{~kW}$ cooling capacity. A secondary cooling system was added to assist with temperature control in the feed tank. The secondary system consisted of two coils in the feed tank made from stainless steel tubing. One coil was 1/2" diameter tubing and the other was 3/8" diameter tubing, each approximately 20 feet

\footnotetext{
a The isolation transformers were required for use with the Allen Bradley VFDs when wired in a Delta configuration to maintain the Underwriters Laboratory Listing of the drives.
} 
long. Chilled water was provided by a NESLAB portable chiller, model HX150, rated at $4.5 \mathrm{~kW}$ cooling capacity.

\subsubsection{Motor/Filter Alignment}

Alignment between the individual motors and filters was aided by an Easy Laser D480 shaft alignment system. Due to lack of axial space on the filter shaft, the alignment was performed between the motor shaft and the filter coupling. Positional adjustment of the filters and motors to attain alignment was accomplished by the addition of shims on respective support structures. The majority of adjustments were made to the filter instead of the motor due to the complexity of the structural members attached to the motors.

\subsubsection{Control System}

The control system for the dual filter test used a personal computer based DELTA-V architecture supplied by SRR Process Controls Engineering. SRR personnel programmed the system. The control system communicated with equipment and instrumentation through either digital or analog input/output (I/O). The VFDs, control valve and two pressure transmitters communicated through the digital Foundation Fieldbus protocol. The remaining components communicated through analog 4-20 milliamp loops.

The purpose of the control system was to maintain a specific filtrate flow rate over a range of operating conditions with the valve position and the feed pump speed as control variables. Target filtrate flow was anticipated to be approximately four gpm for the two filters. However, filtration rate was not the primary objective of this testing, and several target flows were used during testing to probe variations in system response.

\subsubsection{Instrumentation}

The instrumentation in the SRNL dual filter test is listed in Table 1. SRR required measurement only of the combined filtrate flow rate, the feed pressure in the combined line prior to the filters, and the filtrate pressure after the lines converged (the feed pressure and filtrate pressure would provide differential pressure across the filter bank). Additional flow and pressure measurements were incorporated by SRNL to provide operational data for each filter. Flow was measured by magnetic flow meters in the separate concentrate lines and the separate filtrate lines. The differential pressure was measured across each filter.

Temperature was measured in several locations to obtain operational data and maintain safe operation. Feed temperature was measured in the feed tank. Room temperature was measured in the vicinity of the test equipment. The metal surface temperature at the feed pump outlet was monitored to prevent exceeding the pressure limitation of the chlorinated polyvinyl chloride (CPVC) pipe de-rated by heat from the pump. Likewise, the concentrate temperature was measured at the outlet of the filters. The metal surface temperature of the main bearing housing for each filter was monitored to indicate bearing problems.

The feed tank had several level detection devices to assure safe operation. Two low-level switches (low and low-low) indicated loss of feed. A high level switch indicated an unintended addition of a fluid to the feed tank (i.e., fluid from one of the cooling systems). And finally, a level detector was employed to provide tank level measurement and to verify switch enunciation. 
SRNL-STI-2011-00466

Revision 0

Table 1. Instrumentation List

\begin{tabular}{|c|c|c|c|c|}
\hline Description & Instrumentation & Range & M\&TE\# & Tolerance \\
\hline Feed Tank Temp, T1 & Omega Type E Thermocouple & $0-100 \mathrm{C}$ & TR-40054 & $1.70 \mathrm{C}$ \\
\hline Pump Outlet Temp, T2 & Omega Type E Thermocouple & $0-100 \mathrm{C}$ & TR-40081 & $1.70 \mathrm{C}$ \\
\hline Room Temp, T3 & Omega Type E Thermocouple & $0-100 \mathrm{C}$ & TR-40080 & $1.70 \mathrm{C}$ \\
\hline FLT-2 Outlet Temp, T4 & Omega Type E Thermocouple & $0-100 \mathrm{C}$ & TR-40084 & $1.70 \mathrm{C}$ \\
\hline FLT-1 Outlet Tempe, T5 & Omega Type E Thermocouple & $0-100 \mathrm{C}$ & TR-40083 & $1.70 \mathrm{C}$ \\
\hline FLT-1 Bearing Temp, T6 & Omega Type E Thermocouple & $0-100 \mathrm{C}$ & TR-40105 & $1.70 \mathrm{C}$ \\
\hline FLT-2 Bearing Temp, T7 & Omega Type E Thermocouple & $0-100 \mathrm{C}$ & TR-40106 & $1.70 \mathrm{C}$ \\
\hline PMP-1 Housing Temp, T8 & Omega Type E Thermocouple & $0-100 \mathrm{C}$ & TR-40095 & $1.70 \mathrm{C}$ \\
\hline Filtrate Flow, FLT-1, F1A & Fischer-Porter Magnetic Flow Meter & 0-15 gpm & TR-40067 & $0.25 \mathrm{gpm}$ \\
\hline Filtrate Flow, FLT-2, F2A & Fischer-Porter Magnetic Flow Meter & 0-15 gpm & TR-40078 & $0.25 \mathrm{gpm}$ \\
\hline Concentrate Flow, FLT-1< F1B & Fischer-Porter Magnetic Flow Meter & $0-100 \mathrm{gpm}$ & TR-40077 & $1.00 \mathrm{gpm}$ \\
\hline Concentrate Flow, FLT-2, F2B & Fischer-Porter Magnetic Flow Meter & 0-100 gpm & TR-40076 & $1.00 \mathrm{gpm}$ \\
\hline Pressure Drop, FLT-1, DP1 & Rosemount Differential Pressure Transducer & $0-70$ psid & TR-40074 & $0.35 \mathrm{psid}$ \\
\hline Pressure Drop, FLT-2, DP2 & Rosemount Differential Pressure Transducer & $0-70$ psid & TR-40075 & $0.35 \mathrm{psid}$ \\
\hline Filtrate Flow, Total, F1 & Krohne Magnetic Flow Meter & $0-25 \mathrm{gpm}$ & TR-40110 & $0.5 \mathrm{gpm}$ \\
\hline Feed Pressure, Total, P1 & Rosemount Gage Pressure Transmitter & $0-150$ psig & TR-40112 & $0.75 p s i g$ \\
\hline Filtrate Pressure, Total, P2 & Rosemount Gage Pressure Transmitter & $0-150$ psig & TR-40113 & $0.75 p s i g$ \\
\hline SPDT level switch, L1 & Gems Electro-optic Liquid Level Switch & N/A & N/A & N/A \\
\hline SPDT level switch, LL1 & Gems Electro-optic Liquid Level Switch & N/A & N/A & N/A \\
\hline SPST level switch, H1 & Madison Liquid Level Switch & N/A & N/A & N/A \\
\hline Ultrasonic level transmitter, L2 & Omega Ultrasonic Level Transmitter & $0.3-6 \mathrm{ft}$ & N/A & N/A \\
\hline Spill detector, SP1 & Floodstop Spill Detector & N/A & N/A & N/A \\
\hline Turbidity Meter & HF Scientific Micro 100 Turbidimeter & $0-1000 \mathrm{NTU}$ & N/A & $0.1 \pm 4 \% \mathrm{RDG}$ \\
\hline
\end{tabular}

\subsubsection{Ancillary Equipment}

The piping system was constructed using CPVC pipe of varying sizes (1/2” to 3”) to emulate the system shown in the SRR process sketch. Quarter-turn isolation valves were added to the piping system to accommodate cleaning, sampling and various other activities.

Filter cleaning was performed before and after tests using a separate closed loop system. The system consisted of a separate feed tank for the cleaning solution (nitric acid in this testing), small pump, associated piping and insolation valves. Cleaning occurred by pumping a solution from the cleaning solution tank into the filters via the feed line, where it passed through the filter membranes and exited the filtrate line. The discharge from the filtrate line was routed back to the cleaning solution tank. The feed and filtrate lines were isolated from the rest of the filter system during the cleaning sequence. The filters were typically operated while a cleaning solution was flowing through them to help remove solids from the membranes. Once the filters were cleaned, the cleaning solutions were drained from the filters. 
SRNL-STI-2011-00466

Revision 0

\subsection{Operation}

A primary objective of this task was to develop the logic of the control system for operating multiple filters in the field. Two primary tests with salt simulant were planned to accomplish the objective. The first was to determine how to start multiple filters essentially simultaneously; the second, to determine how to start a second filter after the first filter had been at a quasi-steady state operation. Also, during the second test, the solids loading was increased to further challenge the dynamic response of the control system.

The duration of both tests was chosen to be 100 hours each; however, the test time was not required to be continuous since multiple starts and stops were expected to tune the control system. Previous tests of Filter \#1 were run for at least 100 hours; this duration provided ample time to achieve steady conditions.

Although continuous operation was not expected, extended (i.e., overnight and weekend) operation was intended. Therefore, the operating system had to accommodate unattended operation. Interlocks and alarms were programmed into the control system to provide equipment safety during unmanned operations using instrumentation listed in Table 1 . The interlocks would shut down the filters and the feed pump when certain parameters exceeded critical values.

\section{Run Plan}

A run plan for testing is shown in Table 2. The test equipment was thoroughly cleaned before initiating testing. Additionally, the filters were cleaned between tests to assure similar starting conditions. A water test was conducted prior to simulant testing. The water testing not only provided a means of verifying the correct operation of components and instrumentation but also allowed initial insight to control system behavior. The two tests with salt simulant were primarily intended to support the needs of the SRR personnel programming the control system. The duration and operating parameters specified in the run plan for the two tests were somewhat arbitrary and by the end of testing, numerous operating parameters, starting sequences, and control algorithms were tested. The addition of the second batch of solids was completed very late in test 2 instead of mid test. This was done to allow for better tuning of the control system prior to testing its response to the addition of the extra solids. 
SRNL-STI-2011-00466

Revision 0

Table 2. Run Plan

\begin{tabular}{|c|c|c|c|c|c|c|}
\hline \multirow[b]{2}{*}{$\begin{array}{c}\text { Task } \\
\#\end{array}$} & \multirow[b]{2}{*}{ Description } & \multirow[b]{2}{*}{ Feed } & \multicolumn{3}{|c|}{ Operating Parameters } & \multirow[b]{2}{*}{ Comments } \\
\hline & & & $\begin{array}{l}\text { Feed } \\
\text { Flow } \\
(\text { gpm) }\end{array}$ & $\begin{array}{l}\text { Pressure } \\
\text { Drop } \\
\text { (psid) }\end{array}$ & $\begin{array}{l}\text { Filtrate } \\
\text { Flow } \\
\text { (gpm) }\end{array}$ & \\
\hline 1 & Clean pump & DI water & N/A & N/A & N/A & Run bypass \\
\hline \multirow{2}{*}{2} & \multirow{2}{*}{ Clean system } & DI water + mild soap (30 gallons) & \multirow{2}{*}{$50-100$} & \multirow{2}{*}{ N/A } & \multirow{2}{*}{$5-10$} & \multirow{2}{*}{ Whole system } \\
\hline & & DI water (30 gallons) & & & & \\
\hline \multirow{3}{*}{3} & \multirow{3}{*}{ Clean filters } & DI water (30 gallons each filter) & \multirow{3}{*}{ N/A } & \multirow{3}{*}{ N/A } & \multirow{3}{*}{ N/A } & \multirow{3}{*}{$\begin{array}{l}\text { Filters only. } \\
\text { Establish suitable TMP } \\
\text { \& inlet pressure }\end{array}$} \\
\hline & & 0.5 molar nitric acid (30 gallons each) & & & & \\
\hline & & DI water (60 gallons each filter) & & & & \\
\hline 4 & Water test & DI water & $50-100$ & N/A & $5-10$ & Whole system \\
\hline 5 & $100 \mathrm{hr}$ test & $\begin{array}{l}\text { Salt + SB6 sludge }(0.6 \mathrm{~g} / \mathrm{L}))+\mathrm{MST} \\
(0.4 \mathrm{~g} / \mathrm{L})\end{array}$ & $70-100$ & 40 & 4 & Simultaneous filter start \\
\hline \multirow{3}{*}{6} & \multirow{3}{*}{ Clean filters } & DI water (30 gallons each filter) & \multirow{3}{*}{ N/A } & \multirow{3}{*}{ N/A } & \multirow{3}{*}{ N/A } & \multirow{3}{*}{$\begin{array}{l}\text { Filters only. } \\
\text { Establish suitable TMP } \\
\text { \& inlet pressure }\end{array}$} \\
\hline & & 0.5 molar nitric acid (30 gallons each) & & & & \\
\hline & & DI water (60 gallons each filter) & & & & \\
\hline \multirow{2}{*}{7} & $50 \mathrm{hr}$ test & $\begin{array}{l}\text { Salt + SB6 sludge }(0.6 \mathrm{~g} / \mathrm{L})+\mathrm{MST}(0.4 \\
\mathrm{g} / \mathrm{L})\end{array}$ & $70-100$ & 40 & 4 & Staggered filter start \\
\hline & $50 \mathrm{hr}$ test & $\begin{array}{l}\text { Salt + SB6 sludge }(1.29 \mathrm{~g} / \mathrm{L}))+ \text { MST } \\
(0.4 \mathrm{~g} / \mathrm{L})\end{array}$ & $70-100$ & 40 & 4 & Increase wt \% of SB6 \\
\hline \multirow{3}{*}{8} & \multirow{3}{*}{ Clean filters } & DI water (30 gallons each filter) & \multirow{3}{*}{ N/A } & \multirow{3}{*}{ N/A } & \multirow{3}{*}{ N/A } & \multirow{3}{*}{$\begin{array}{l}\text { Filters only. } \\
\text { Establish suitable TMP } \\
\text { \& inlet pressure }\end{array}$} \\
\hline & & 0.5 molar nitric acid (30 gallons each) & & & & \\
\hline & & DI water (60 gallons each filter) & & & & \\
\hline 9 & Clean system & DI water & $50-100$ & N/A & $5-10$ & Whole system \\
\hline
\end{tabular}

\section{Sample Plan}

Samples of feed, concentrate and filtrate were taken at various stages of simulant testing to assess the performance of the filters. The feed and concentrate samples were subjected to particle size distribution (PSD) and solids concentration analysis to verify solids integrity and concentration. The filtrate was measured for turbidity to assure that solids were removed by the membranes.

\section{Work Control}

Test activities were controlled by work instructions, subject to SRNL departmental Document Control oversight. Starting the system was performed manually but once the filters were up to speed, the control system took over operation. A typical test would begin by assuring the appropriate feed tank level and setting the starting valve positions. The filtrate lines were initially isolated to route all flow through the concentrate lines. After feed flow was established, the filtrate lines were vented to remove air from the filter housing and collapse the filter membranes in preparation for starting the filter motors. Filtrate flow was started by slowly opening the manual control valve in the filtrate lines. The filter motors were started when filtrate flow was detected by the flow meter in the filtrate line. 


\subsection{Simulant}

\subsubsection{Sludge Simulant}

The slurry simulant is described in Herman, D. T., et al. "Recipe for Simulated Sludge Batch 6DS for Rotary Filter Testing,” SRNL-TR-2009-00111, 2009. The recipe simulates a Savannah River Site (SRS) SB 6 simulant but does not include Resource Recovery and Conservation Act (RCRA) metals or halides. The simulant recipe is based upon the recipe in SB6-D 8-17-2009. Optima Chemical was contracted to fabricate the simulant. The simulant was the same as used in the 1000-hour vendor test.

The weight percent for all three RCRA metals (barium, chromium, and lead) totaled $0.37 \%$ and is considered to be bounded by the elimination of $U$ which represented over $4 \%$ of the original recipe target and is normalized out of the recipe. The halide salts (sodium chloride and sodium fluoride) were replaced by sodium nitrate on a molar basis.

The anion and cation compositions of the feed simulant for SB 6-DS are summarized in Table 3.

Table 3. Concentration of Anion/Cation Content of Sludge Batch 6 Feed Simulant

\begin{tabular}{|c|c|c|}
\hline Component & Calcined Solids Wt \% & Calcined Solids Wt \% \\
\hline & Target & Actual \\
\hline $\mathrm{Al}^{1}$ & 16.181 & 15.8 \\
\hline $\mathrm{Ca}$ & 1.147 & 1.08 \\
\hline $\mathrm{Ce}$ & 0.085 & 0.08 \\
\hline $\mathrm{Cu}$ & 0.085 & 0.10 \\
\hline $\mathrm{Fe}$ & 17.743 & 18.02 \\
\hline K & 0.021 & 0.24 \\
\hline $\mathrm{La}$ & 0.074 & 0.08 \\
\hline $\mathrm{Mg}$ & 0.552 & 0.55 \\
\hline $\mathrm{Mn}$ & 5.982 & 6.31 \\
\hline $\mathrm{Na}$ & 19.305 & 17.77 \\
\hline $\mathrm{Ni}$ & 2.231 & 2.30 \\
\hline $\mathrm{S}$ & 0.712 & 0.28 \\
\hline $\mathrm{Si}$ & 1.232 & 1.52 \\
\hline $\mathrm{Zn}$ & 0.053 & 0.06 \\
\hline $\mathrm{Zr}$ & 0.234 & 0.22 \\
\hline Sum & 65.64 & 64.4 \\
\hline Slurry density g/mL & $1.12 \pm 0.05$ & 1.12 \\
\hline Total Solids, wt \% & $18.17 \pm 2 \%$ & 16.7 \\
\hline Insoluble Solids, wt \% & $14 \pm 1 \%$ & 10.4 \\
\hline \multicolumn{3}{|l|}{ Anions } \\
\hline Nitrite, $\mathrm{NO}_{2}^{-}$ & $8807 \pm 10 \%$ & 11100 \\
\hline Nitrate, $\mathrm{NO}_{3}^{-}$ & $6096 \pm 10 \%$ & 6470 \\
\hline Phosphate, $\mathrm{PO}_{4}{ }^{3-}$ & $27 \pm 25 \%$ & $<100$ \\
\hline Sulfate, $\mathrm{SO}_{4}{ }^{2-}$ & $904 \pm 25 \%$ & 1060 \\
\hline
\end{tabular}

${ }^{1} \mathrm{The} \mathrm{Al} \mathrm{wt} \%$ has not been adjusted to account for replacement of $\mathrm{Ba}, \mathrm{Cr}$, and $\mathrm{Pb}$. The weight percent for all three totaled $0.37 \%$ and is considered masked by the elimination of $U$ which represented over $4 \%$ of the original recipe target. Uranium was normalized out of this recipe. 


\subsubsection{Supernate Simulant}

Soluble salts were added to the simulated sludge to produce a simulated supernate of 5.6 molar (M) sodium. Table 4 shows the target composition of the supernate. The bulk supernate composition was a representative SRS salt solution containing 5.6 M sodium.

Table 4. Bulk Supernate Composition

\begin{tabular}{|l|l|}
\hline Component & Concentration (M) \\
\hline Free $\mathrm{OH}^{-}$ & 1.33 \\
\hline $\mathrm{NaNO}$ & \\
\hline $\mathrm{NaAl}(\mathrm{OH})_{4}$ & 2.6 \\
\hline $\mathrm{NaNO}_{2}$ & 0.429 \\
\hline $\mathrm{Na}_{2} \mathrm{SO}_{4}$ & 0.134 \\
\hline $\mathrm{Na}_{2} \mathrm{CO}_{3}$ & 0.521 \\
\hline Total Na & 0.026 \\
\hline
\end{tabular}

\subsubsection{MST}

The MST used in the testing was the same material (Harrell Industries Lot \#102209) currently used in the Actinide Removal Process (ARP) at SRS.

\subsubsection{Feed}

The particle size distribution of the sludge and MST is shown as Figure 6. The graph is an average of 3 different measurements. Particle size was also measured between tests and after testing was complete. There was very little change in the particle size distribution between all three measurements.

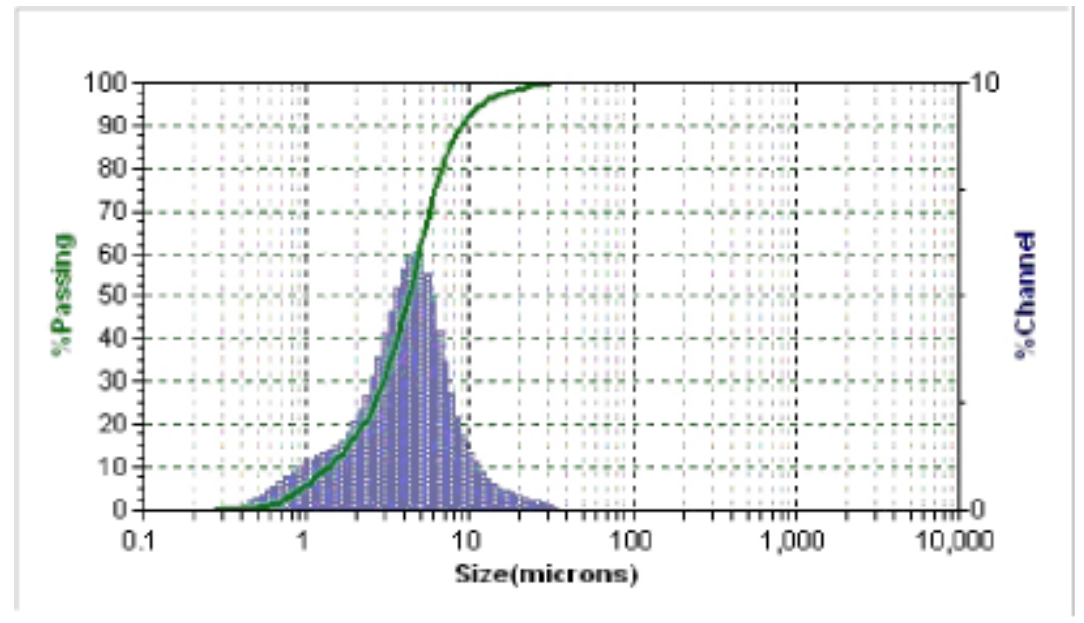

Figure 6. Particle Size Distribution of Initial Feed

\subsection{Results and Discussion}

\subsection{System Performance}

In the SCIX deployment, the filters will be operated with a fixed output. Therefore, the filtration rate was fixed and the other system parameters, primarily system pressure and the resulting pressure drop across the filter membranes, were altered to meet the filtration rate goal. Graphs of 
the pressure drop and filtration rates for Test 1 and Test 2 are shown in Figure 7 and Figure 8 . Note that during Test 1, the simulated salt solution without sludge simulant was the feed until approximately 111 hours of the elapsed test time. The sudden change in filtration rate and pressure drop after that time is due to the introduction of the $0.6 \mathrm{~g} / \mathrm{L}$ sludge simulant solids and $0.4 \mathrm{~g} / \mathrm{L} \mathrm{MST}$.

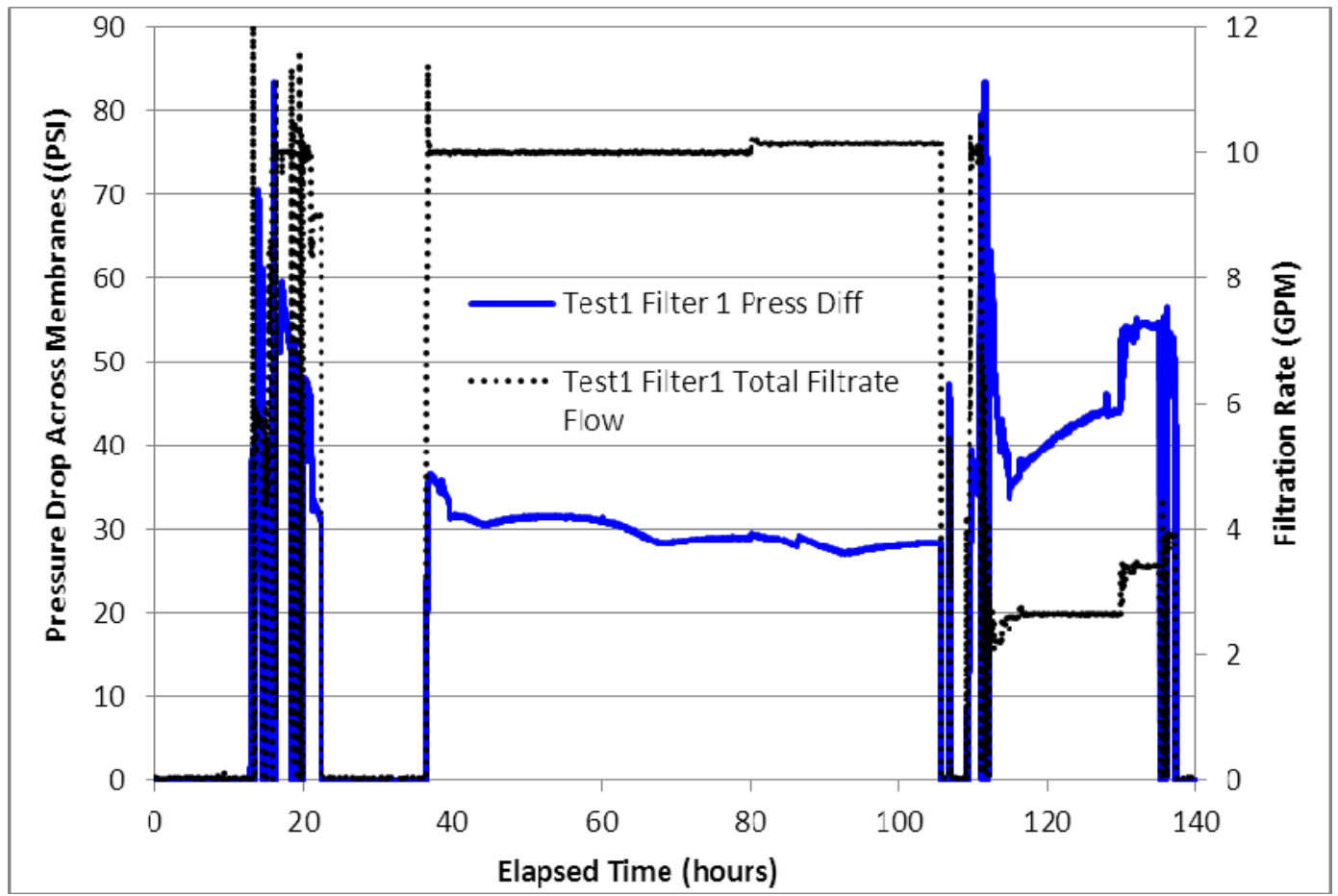

Figure 7. Pressure Drop and Filtration Rate during Test 1

Test 2 (Figure 8) utilized the same feed as the end of Test 1, specifically, the simulated salt solution with $0.6 \mathrm{~g} / \mathrm{L} \mathrm{SB} 6$ simulant and $0.4 \mathrm{~g} / \mathrm{L} \mathrm{MST}$. At the end of the test, the amount of sludge was increased to $1.29 \mathrm{~g} / \mathrm{L}$. 


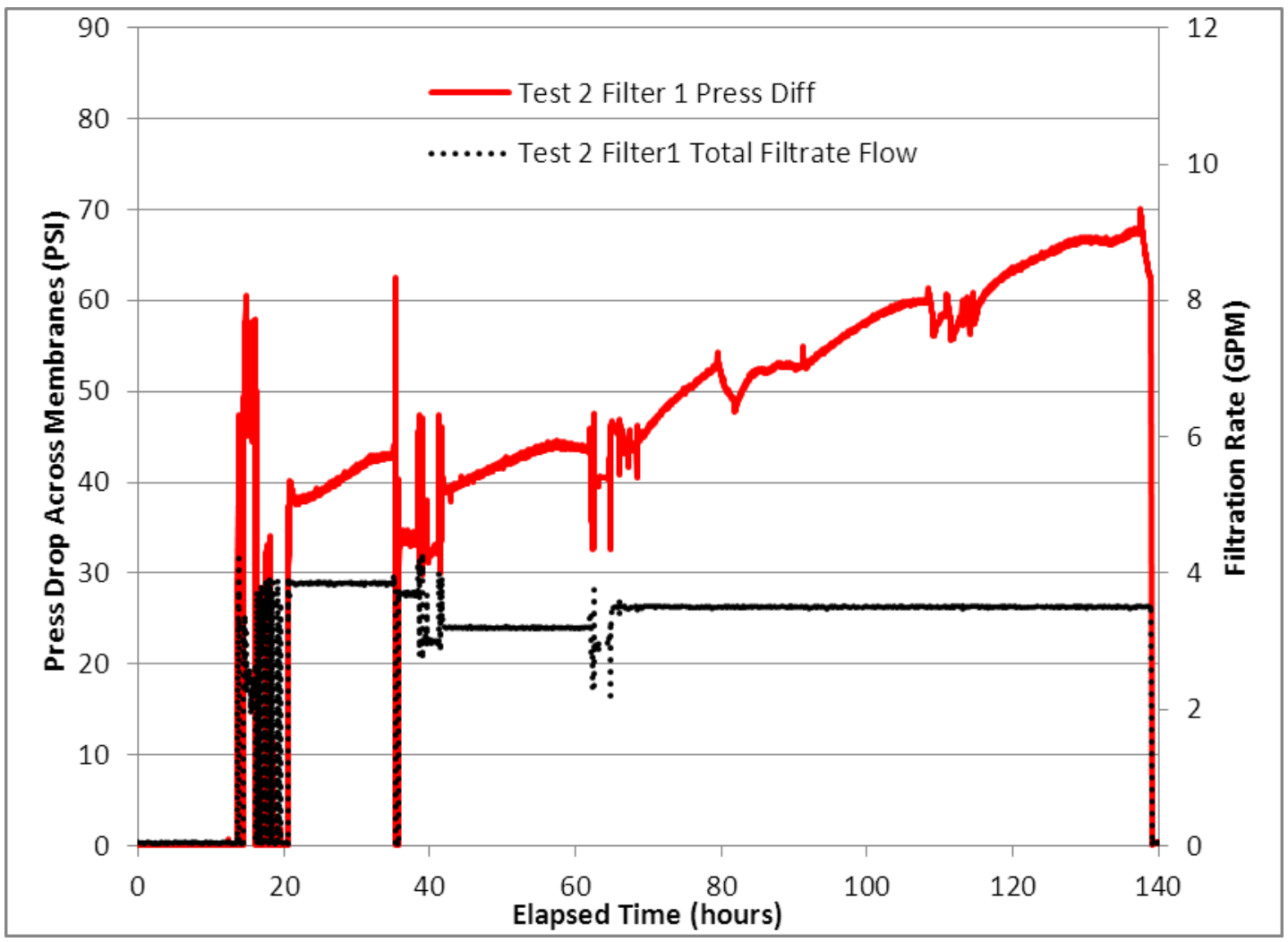

Figure 8. Pressure Drop and Filtrate Flow during Test 2

The pressure drop required to achieve the filtration rate set point for both tests was greater than expected. During Test 1 Filter \#1 showed evidence of blocked filter media. This was evident due to the reduced production (Filter \#2 was almost four times that of Filter \#1) as compared to the historic water flux performance as well as a large discrepancy between filtration rates of Filter \#1 and Filter \#2.

During both tests, the filters were primarily run at a reduced rotational speed. Graphs of the filter operational speed for Test 1 and Test 2 are Figure 9 and Figure 10 respectively. Historically, the filters have been operated at approximately $1200 \mathrm{rpm}$. Two issues required the reduction of the filter speed during the two tests. During Test 1, the vibration amplitude was very significant at full speed, due to approaching a resonant frequency in the support structure. Operating at reduced speed for the filters while the test stand was being stiffened and motor to filter alignment improved kept the vibration to a manageable level. Secondly, operating the filters at full speed added to the heat load of the system and exceeded the system cooling capacity of the facility. The filters had to be run at reduced speed to maintain the temperature of the process fluid. 


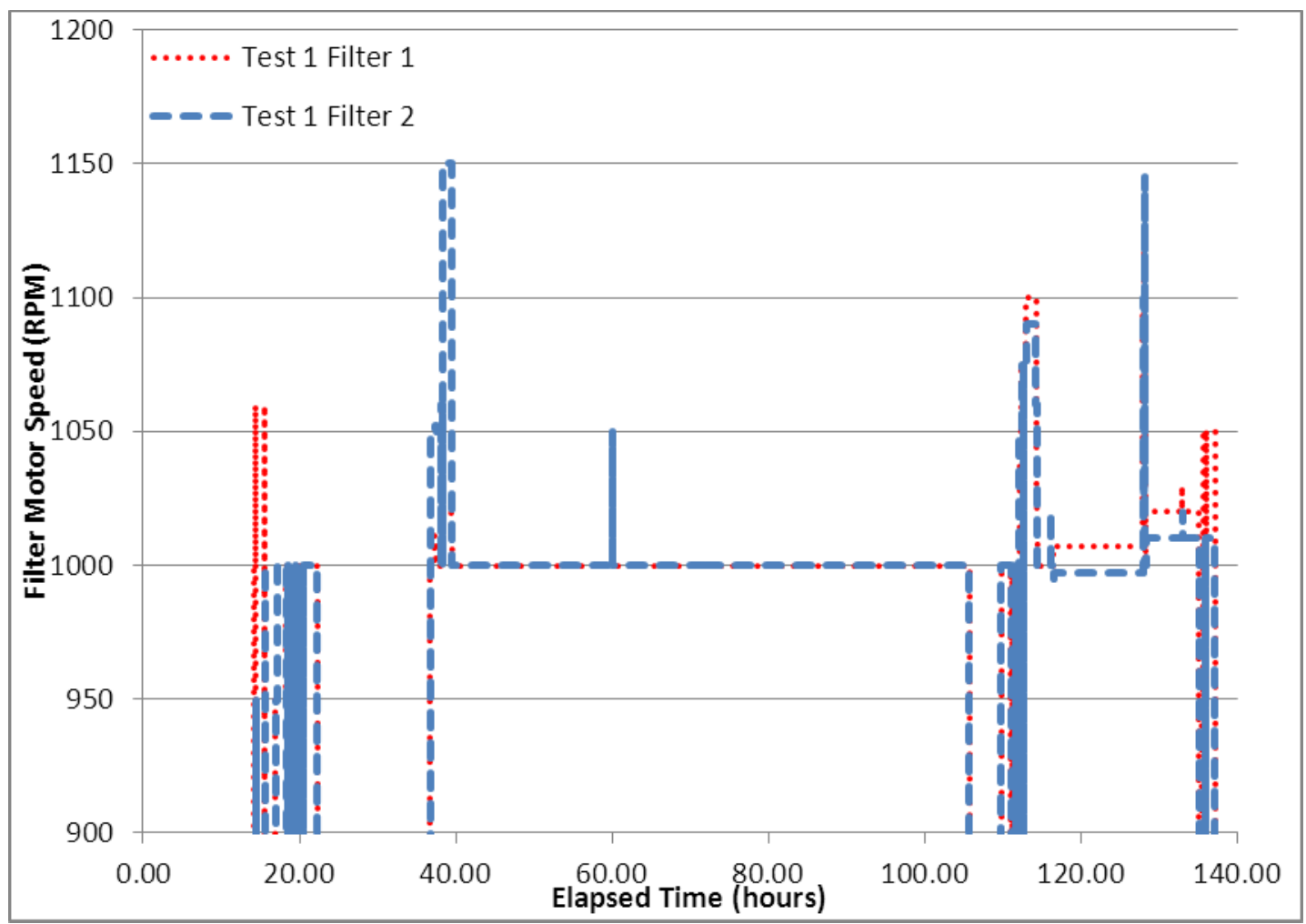

Figure 9. Rotational Speed of Filters during Test 1

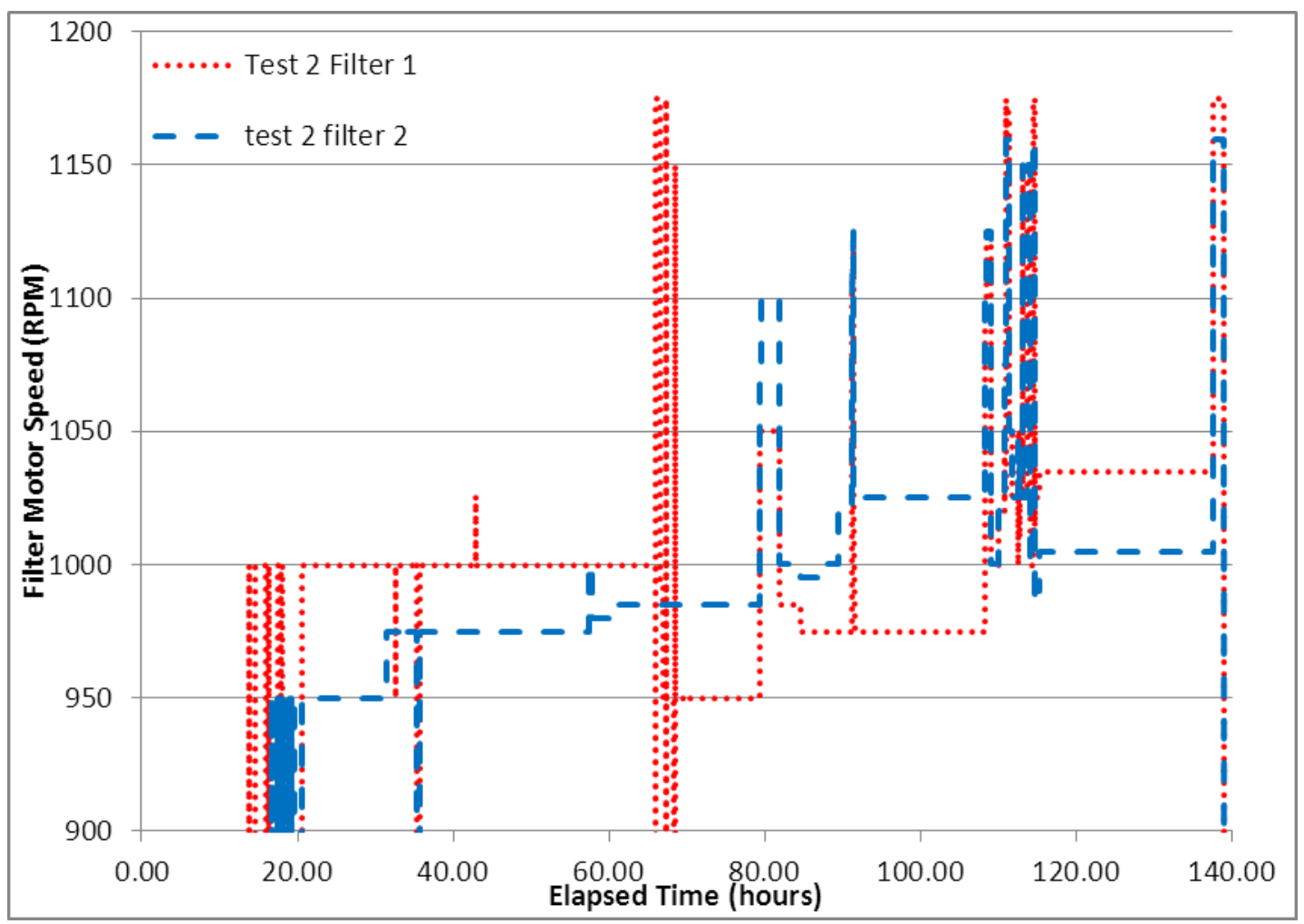

Figure 10. Rotational Speed of Filters during Test 2 
Increasing the speed of the rotors resulted in a significant reduction in the pressure drop across the filters. It also resulted in a marked increase in feed temperature. As can be observed in Figure 11, the decrease in pressure drop directly corresponded to the increase in temperature resulting from the increase in rotor speed. The change in viscosity due to the change in temperature was the dominant effect on pressure drop.

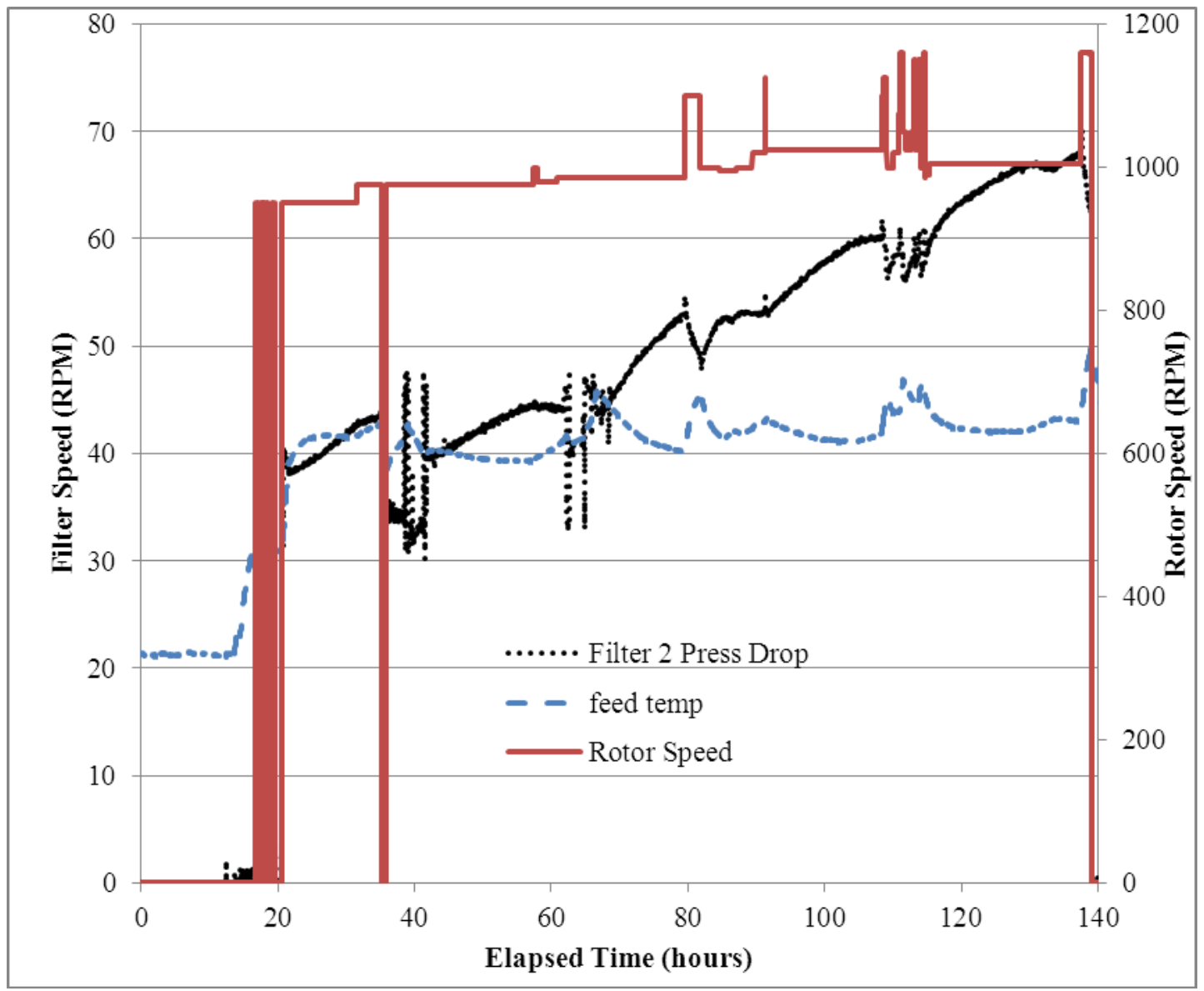

Figure 11. Test 2 Filter 2 - Effect of Increasing Rotor Speed

It is anticipated that an increase in rotor speed would aid in the prevention of filter cake buildup and; therefore, maintain a higher filtration rate. The impact of temperature dominated any effect of rotor speed change to filtration rate in this set of tests.

\subsubsection{Control Logic}

During the SCIX process, the rotary filters will be providing feed to the ion exchange columns. The ion exchange columns operate most efficiently with a constant feed rate. The control system for the rotary filters has been designed to adjust filter parameters to provide a constant filtrate rate. The goal of the control system was to be able to adjust to gradual changes in filter conditions, such as fouling of the disks, as well as dynamic changes such as filter startup or shutdown.

As previously discussed, the control system for the dual filter used a personal computer based DELTA-V architecture and was supplied by SRR Process Controls Engineering. The details of the control logic development are documented in a separate report. 
The control system communicated with equipment and instrumentation through either digital or analog I/Os. The operator communicated to the control system through the user interface. Figure 12 is a photograph of the interface screen.

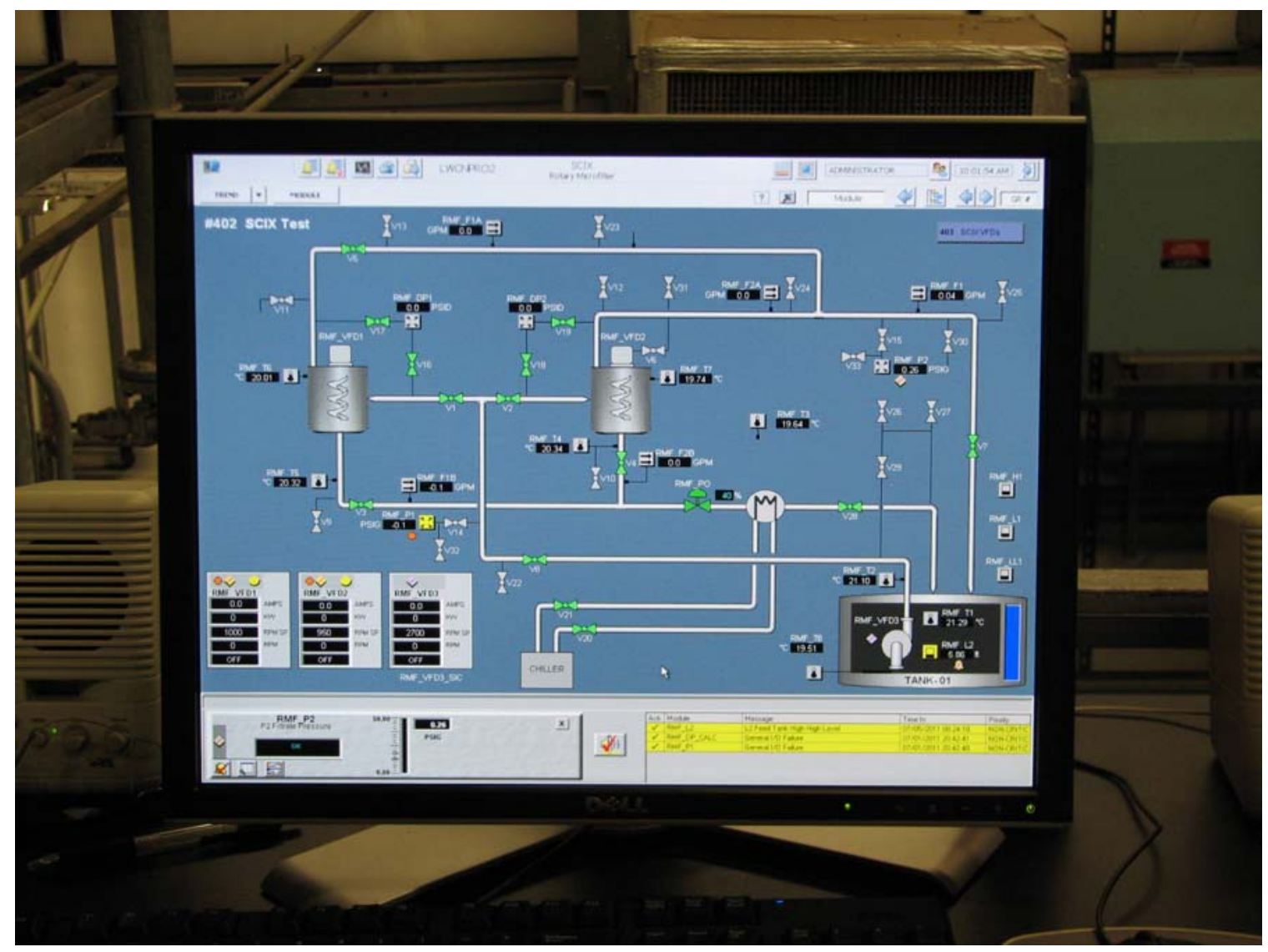

Figure 12. Dual Filter System User Interface

The operator would interact with the system through this interface and would input desired set points, primarily the filtrate production rate. The operating system was programmed in such a manner that adjusting two primary parameters, the concentrate flow control valve position and the feed pump speed, would dictate the driving pressure required to obtain the filtrate set point.

While the control logic was able to respond to gradual system changes, step changes initially caused problems. If a large change was made to a set point, the control logic altered the system variables to respond. The system would drive parameters such as pump speed or valve position until the set point condition was met or the parameter was maximized/minimized. For example, if an increase in filtrate demand was entered, the control logic would respond by altering the concentrate valve position. The valve position would continue to close until the new set point for filtrate demand was reached. If the system response was not fast enough, the valve would close entirely resulting in a loss of flow and consequential trip of the system due to lack of concentrate flow. Figure 13 illustrates set point changes resulting in the shutdown of the system. 


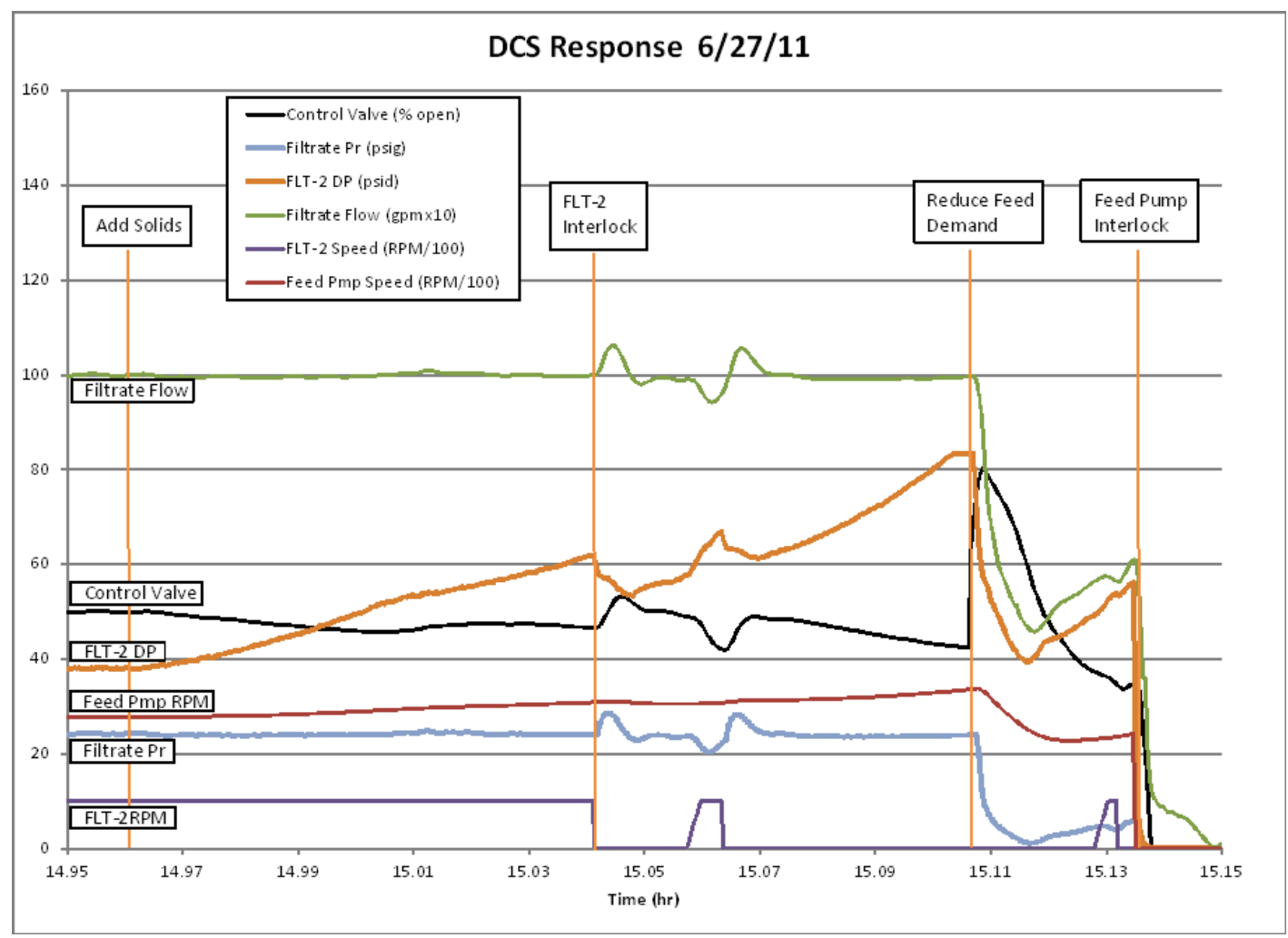

Figure 13. DCS Response to Parameter Change Prior to Tuning

The control logic was tuned to respond to dramatic changes by altering several parameters without causing the system to shut down. This was accomplished by setting limits to the amount of adjustments that could be made to the response parameters. For example, the control valve position was limited to $20 \%$ open to prevent a complete closure of the valve and resulting system shutdown. Other parameters were then altered, such as pump speed, to allow the system to achieve the new set point. An example of the tuned system response is illustrated in Figure 14. 


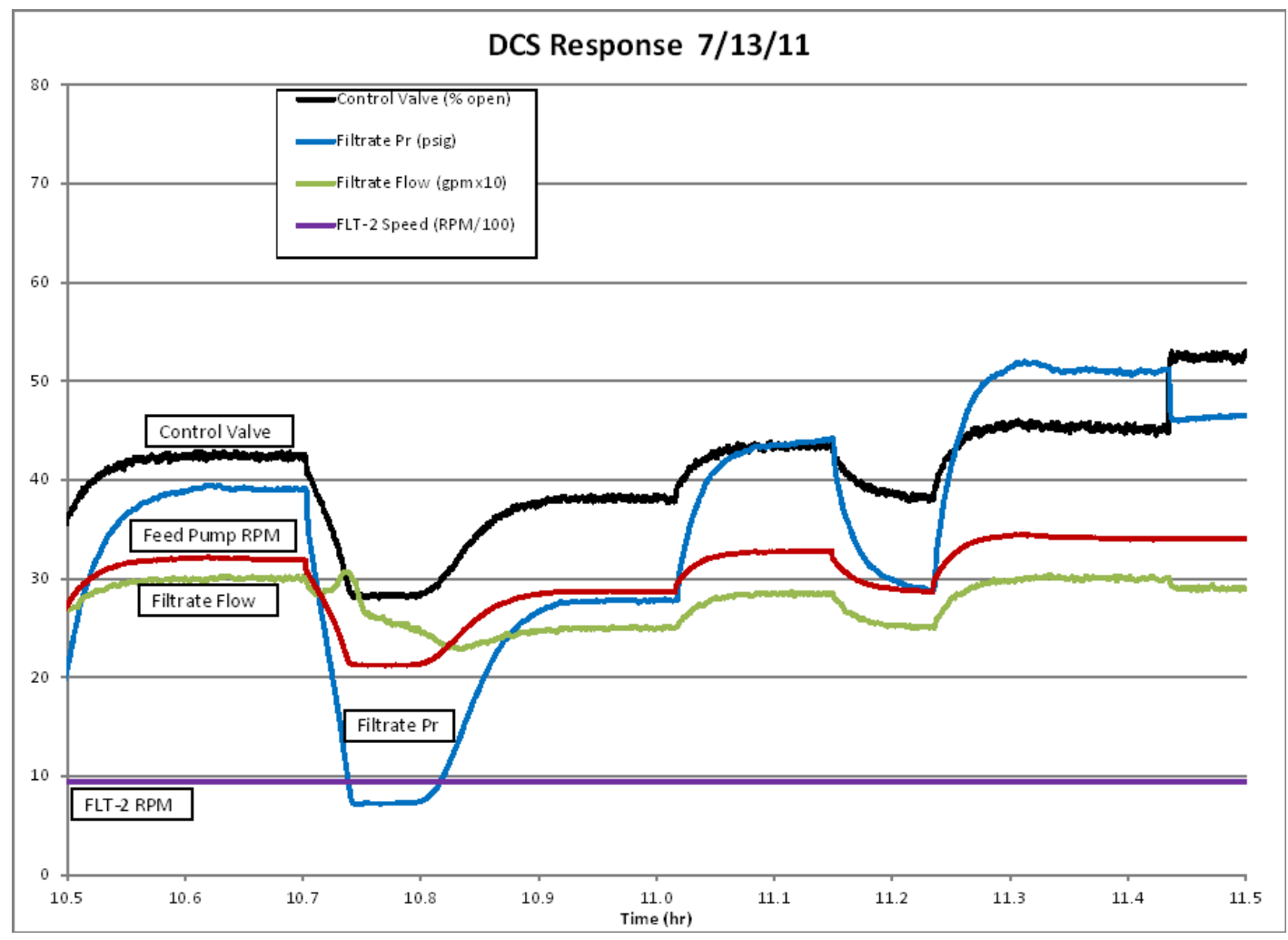

Figure 14. DCS Response to Parameter Change after Tuning

Late in Test 2, the amount of insoluble solids was increased from $0.6 \mathrm{~g} / \mathrm{L}$ to $1.29 \mathrm{~g} / \mathrm{L}$. The addition was much later than outlined the original run plan (solids addition at 50 hours) as it was decided to delay the additional solids until the completion of the tuning of the control system. Once the control system tuning was satisfactory, the filter was run at steady conditions and the solids were added. The intent was to observe the reaction of the control system to an anticipated change in the system. Once the solids were added, no change was observed in filter performance and; therefore, no response was required from the control system.

\subsubsection{Turbidity}

Per the run plan, filtrate samples were obtained throughout testing to determine filtrate quality. The results of the sample measurements are shown in Table 5. All filtrate sample turbidities were below 0.25 Nephelometric Turbidity Unit (NTU) indicating excellent filtrate quality. 
Table 5. Turbidity Results

\begin{tabular}{|c|c|c|c|c|c|}
\hline Test & Date & Sample Label & $\begin{array}{c}\text { Turbidity } \\
\text { (NTU) }\end{array}$ & $\begin{array}{l}\text { Wt\% } \\
\text { SB6 } \\
\text { Added } \\
\end{array}$ & $\begin{array}{l}\text { Wt\% } \\
\text { MST } \\
\text { Added } \\
\end{array}$ \\
\hline N/A & $8 / 1 / 2011$ & StablCal Solution $<0.1$ NTU Jul 12 & 0.05 & N/A & N/A \\
\hline N/A & $8 / 1 / 2011$ & StablCal Standard 20 NTU Mar 13 & 20.7 & N/A & N/A \\
\hline N/A & $8 / 1 / 2011$ & StablCal Standard 200 NTU Sep 13 & 196 & N/A & N/A \\
\hline Pretest & $6 / 20 / 2011$ & RMF Salt Solution, No solids & 0.02 & 0 & 0 \\
\hline 1st $100 \mathrm{hr}$ test & $6 / 23 / 2011$ & Filtrate from FLT-1, No solids in Feed & 0.02 & 0 & 0 \\
\hline 1 st $100 \mathrm{hr}$ test & $6 / 23 / 2011$ & Filtrate from FLT-2, No solids in Feed & 0.02 & 0 & 0 \\
\hline 1 st $100 \mathrm{hr}$ test & $6 / 27 / 2011$ & Filtrate from FLT-1, No solids in Feed & 0.02 & 0 & 0 \\
\hline 1 st $100 \mathrm{hr}$ test & $6 / 27 / 2011$ & Filtrate from FLT-2, No solids in Feed & 0.02 & 0 & 0 \\
\hline 1 st $100 \mathrm{hr}$ test & $6 / 27 / 2011$ & FLT-1 Filtrate, 0.6 g/L SB6+0.4 g/L MST & 0.02 & 0.06 & 0.04 \\
\hline 1st $100 \mathrm{hr}$ test & $6 / 27 / 2011$ & FLT-2 Filtrate, 0.6 g/L SB6+0.4 g/L MST & 0.02 & 0.06 & 0.04 \\
\hline 1 st $100 \mathrm{hr}$ test & $6 / 28 / 2011$ & FLT-1 Filtrate, 0.6 g/L SB6+0.4 g/L MST & 0.06 & 0.06 & 0.04 \\
\hline 1 st $100 \mathrm{hr}$ test & $6 / 28 / 2011$ & FLT-2 Filtrate, 0.6 g/L SB6+0.4 g/L MST & 0.08 & 0.06 & 0.04 \\
\hline 2nd $100 \mathrm{hr}$ test & 7/5/2011 & FLT-1 Filtrate, 0.6 g/L SB6+0.4 g/L MST & 0.21 & 0.06 & 0.04 \\
\hline 2nd $100 \mathrm{hr}$ test & $7 / 5 / 2011$ & FLT-2 Filtrate, 0.6 g/L SB6+0.4 g/L MST & 0.1 & 0.06 & 0.04 \\
\hline 2nd $100 \mathrm{hr}$ test & $7 / 6 / 2011$ & FLT-1 Filtrate, 0.6 g/L SB6+0.4 g/L MST & 0.02 & 0.06 & 0.04 \\
\hline 2nd $100 \mathrm{hr}$ test & $7 / 6 / 2011$ & FLT-2 Filtrate, 0.6 g/L SB6+0.4 g/L MST & 0.02 & 0.06 & 0.04 \\
\hline 2nd $100 \mathrm{hr}$ test & $7 / 7 / 2011$ & FLT-1 Filtrate, 0.6 g/L SB6+0.4 g/L MST & 0.02 & 0.06 & 0.04 \\
\hline 2nd $100 \mathrm{hr}$ test & $7 / 7 / 2011$ & FLT-2 Filtrate, 0.6 g/L SB6+0.4 g/L MST & 0.02 & 0.06 & 0.04 \\
\hline 2nd $100 \mathrm{hr}$ test & $7 / 8 / 2011$ & FLT-1 Filtrate, 0.6 g/L SB6+0.4 g/L MST & 0.02 & 0.06 & 0.04 \\
\hline 2nd $100 \mathrm{hr}$ test & $7 / 8 / 2011$ & FLT-2 Filtrate, 0.6 g/L SB6+0.4 g/L MST & 0.02 & 0.06 & 0.04 \\
\hline 2nd $100 \mathrm{hr}$ test & $7 / 9 / 2011$ & FLT-1 Filtrate, 0.6 g/L SB6+0.4 g/L MST & 0.02 & 0.06 & 0.04 \\
\hline 2nd $100 \mathrm{hr}$ test & $7 / 9 / 2011$ & FLT-2 Filtrate, 0.6 g/L SB6+0.4 g/L MST & 0.02 & 0.06 & 0.04 \\
\hline 2nd $100 \mathrm{hr}$ test & $7 / 10 / 2011$ & FLT-1 Filtrate & 0.02 & 0.06 & 0.04 \\
\hline 2nd $100 \mathrm{hr}$ test & $7 / 10 / 2011$ & FLT-2 Filtrate & 0.02 & 0.06 & 0.04 \\
\hline 2nd $100 \mathrm{hr}$ test & $7 / 11 / 2011$ & RMF Filtrate from FLT-1 & 0.02 & 0.06 & 0.04 \\
\hline 2nd $100 \mathrm{hr}$ test & $7 / 11 / 2011$ & RMF Filtrate from FLT-2 & 0.02 & 0.06 & 0.04 \\
\hline 2nd $100 \mathrm{hr}$ test & $7 / 14 / 2011$ & Filtrate from FLT-1, $1.29 \mathrm{~g} / \mathrm{L} \mathrm{SB} 6$ & 0.02 & 1.29 & 0.04 \\
\hline 2nd $100 \mathrm{hr}$ test & $7 / 14 / 2011$ & Filtrate from FLT-2, $1.29 \mathrm{~g} / \mathrm{L} \mathrm{SB} 6$ & 0.02 & 1.29 & 0.04 \\
\hline N/A & $8 / 1 / 2011$ & StablCal Solution $<0.1$ NTU Jul 12 & 0.02 & N/A & N/A \\
\hline N/A & $8 / 1 / 2011$ & StablCal Standard 20 NTU Mar 13 & 20.9 & N/A & N/A \\
\hline N/A & $8 / 1 / 2011$ & StablCal Standard 200 NTU Sep 13 & 196 & N/A & N/A \\
\hline
\end{tabular}

\subsubsection{Vibration}

Casing vibrations were collected off the rotary microfilter units during dual rotary filter system testing. Figure 15 shows the measurement points. Sensors were arranged orthogonal at each elevation for recording information in two radial directions. A portable machinery analyzer (CSI model 2120-2) and general purpose accelerometers (Wilcoxin Research 742) were the primary tools used during monitoring. A speed series was conducted at the end of filter tests with a Data Signal Processing Instrument (ADRE 408 DSPi) and Velometers ${ }^{\circledR}$ (Bently Nevada 330500) to collect additional waveforms and generate spectra at different speeds. 


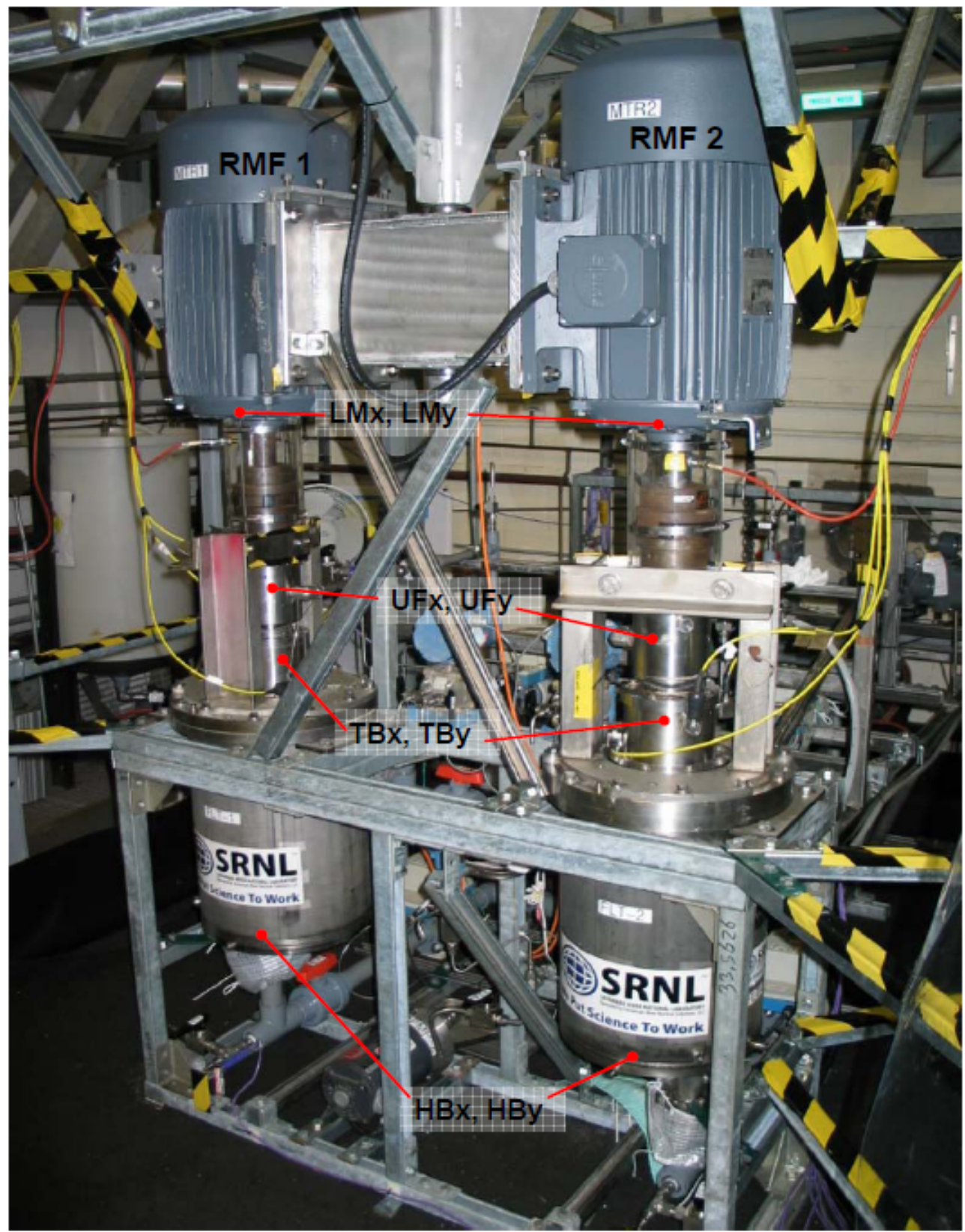

Figure 15. Vibration Monitoring Point for Dual Rotary Microfilter System

Spectrum cascade plots, or more simply, cascade plots for Filter \#1 are shown in Figure 16 through Figure 19 during startup and shutdown of the equipment. The full spectrum cascade plots show a series of vertical peaks on different spectra. The fundamental, or first harmonic, appears around $16.125 \mathrm{~Hz}$ (967.5 rpm). The frequency becomes visible in the plot around 600 rpm and the peak amplitude is fairly constant as the machine speed increases to $960 \mathrm{rpm}$. When the $1 \mathrm{X}$ forcing frequency, typically caused by a combination of runout, shaft bow and unbalance, reaches this frequency, the vibration amplitudes grow significantly and harmonics which track 
running speed are generated. These vibration frequencies are evident on the diagonal lines (1X, $2 \mathrm{X}, 3 \mathrm{X}$ ) of the forward and reverse precession frequencies. The series of vertical peaks were witnessed to 960 revolutions per minute then disappeared, suggesting a sudden change in rotor system stiffness possibly by a rub, change in balance, or other form of resonance.

Sidebands are also evident in the cascades. These sum and difference frequencies are produced when one signal modulates another and can occur by nonlinearities and asymmetries in rotor systems or during rapid changes in machine accelerations or decelerations.

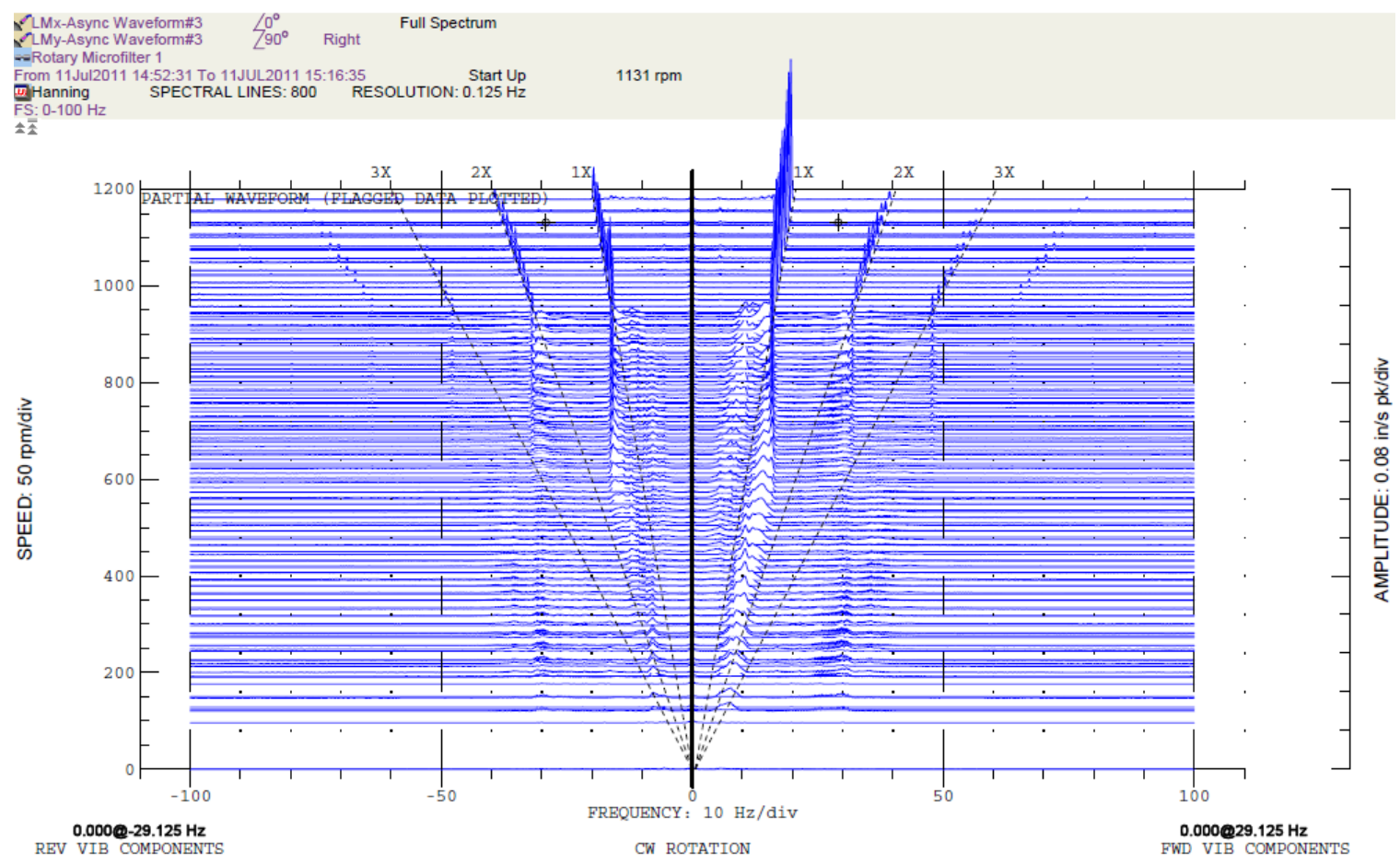

Figure 16. Cascade Plot of Motor Vibration for Filter \#1 
SRNL-STI-2011-00466

Revision 0

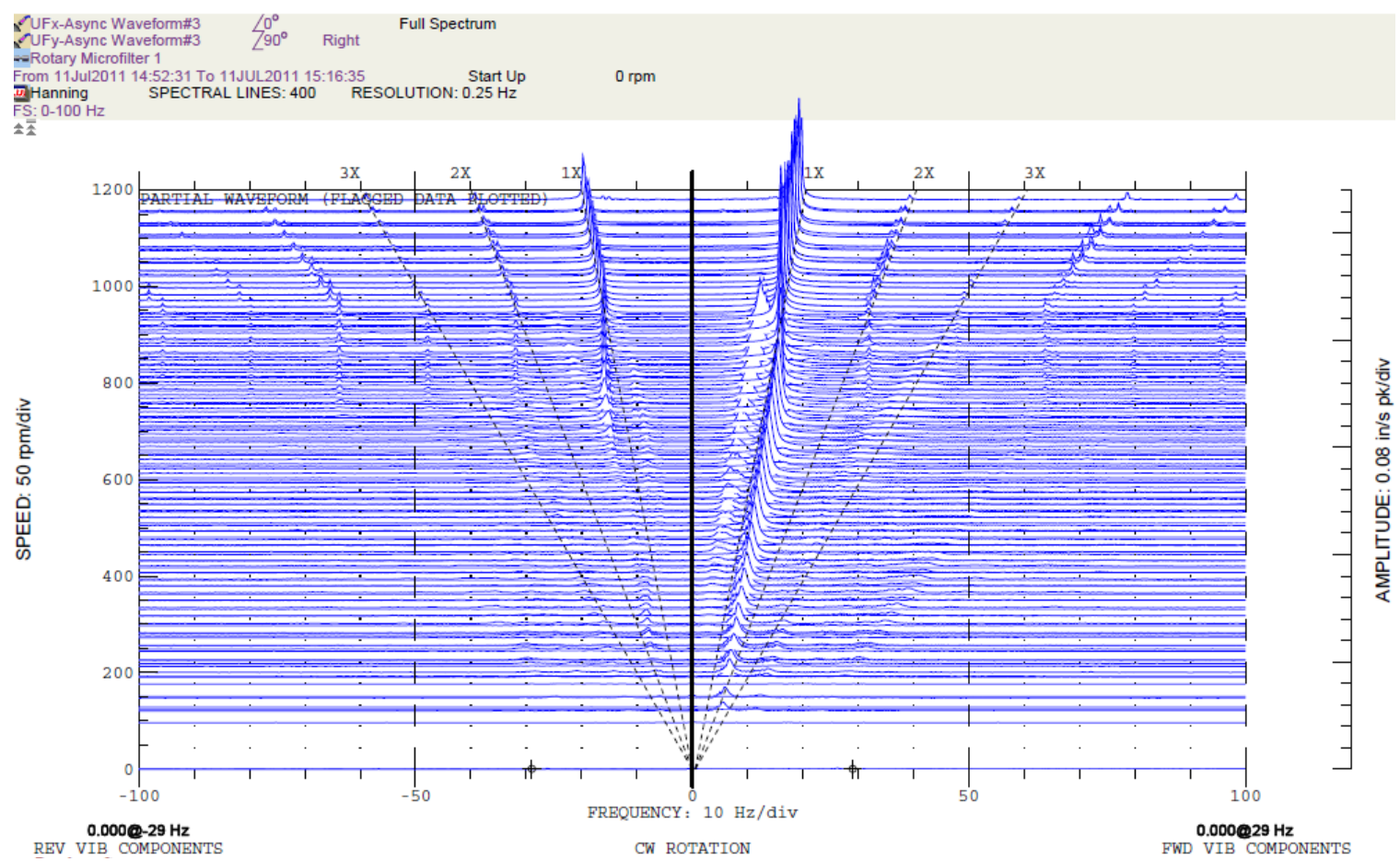

Figure 17. Cascade Plot of Rotary Union Vibrations for Filter \#1

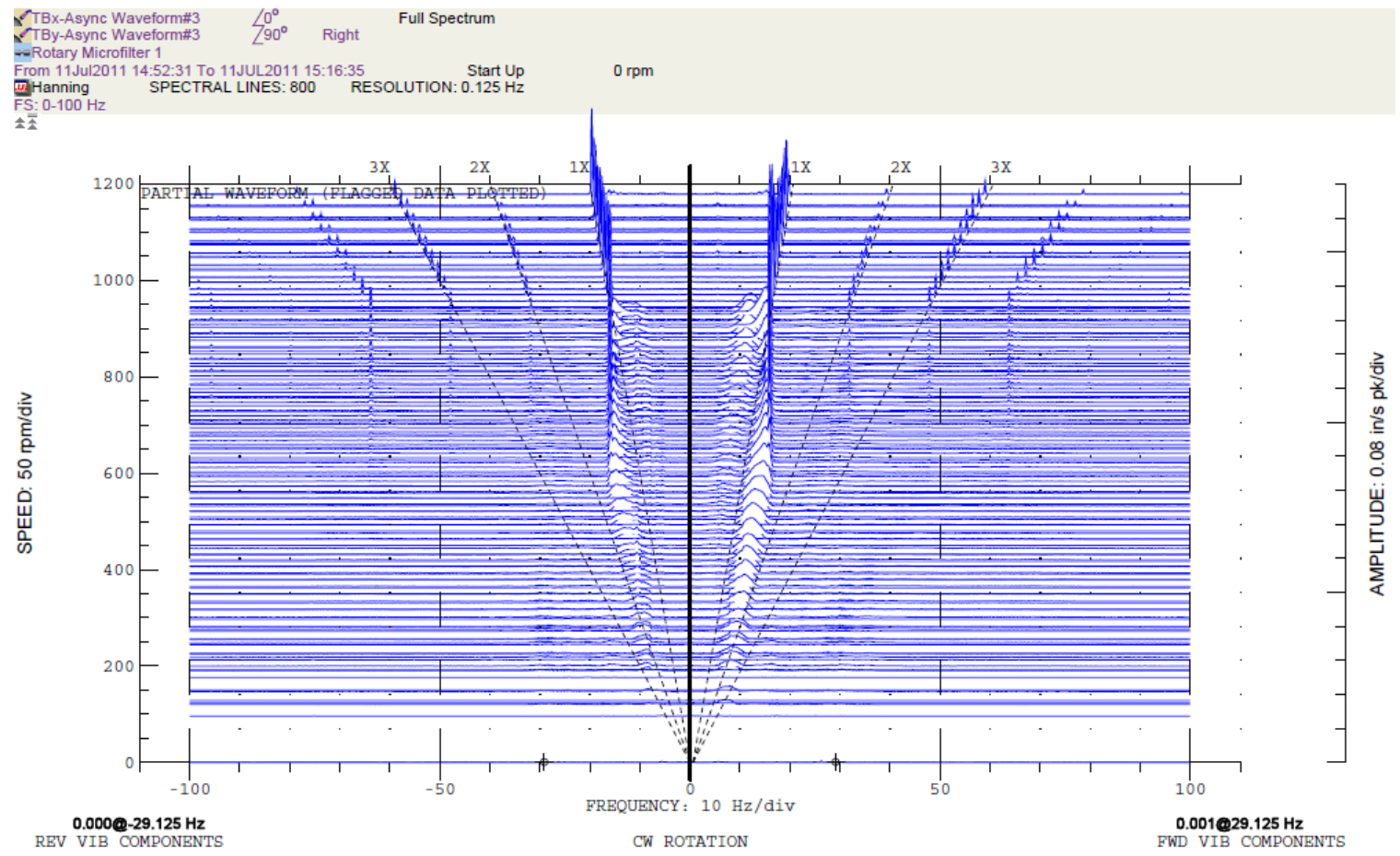

Figure 18. Cascade Plot of Gas Seal Housing Vibrations for Filter \#1 


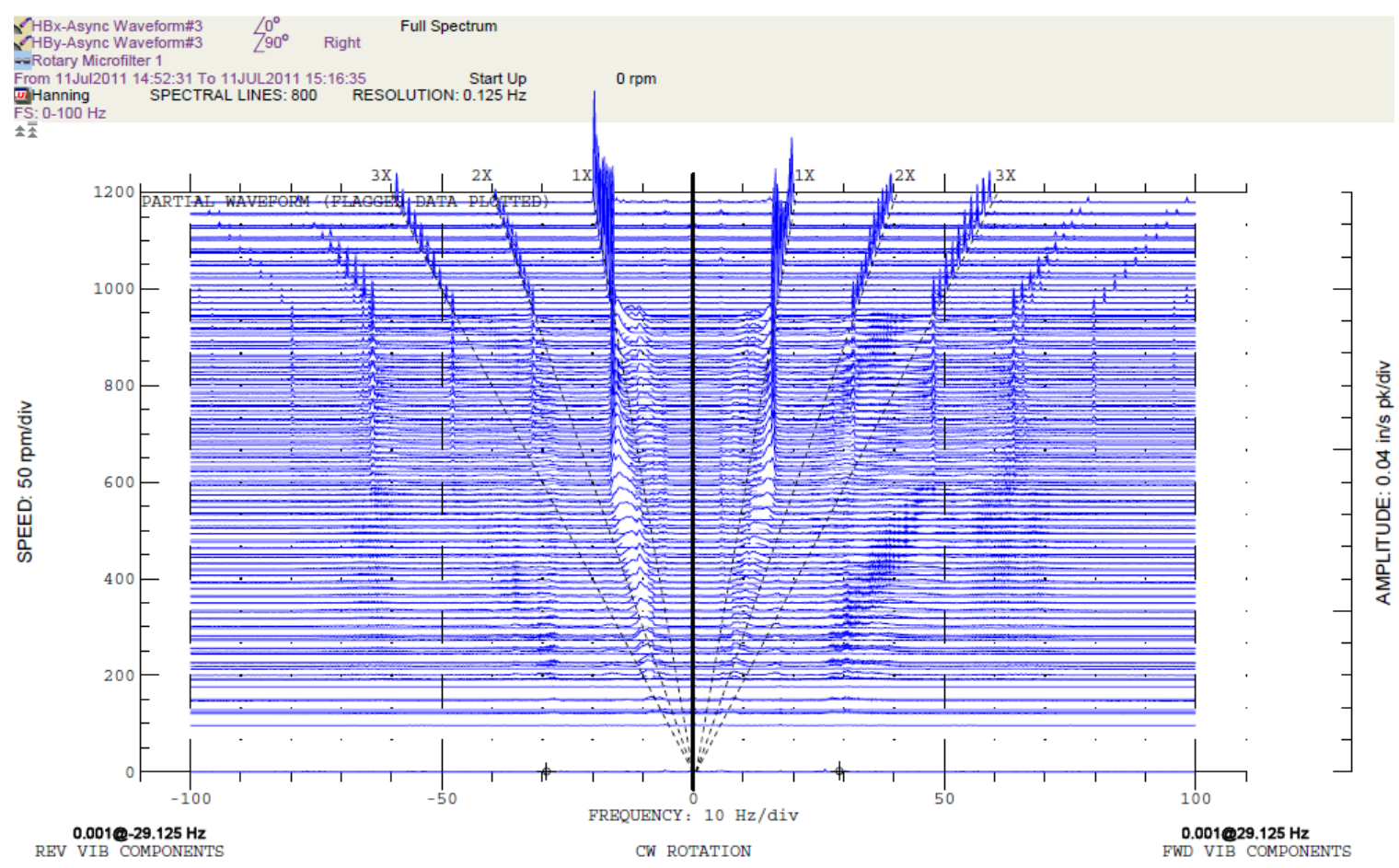

Figure 19. Cascade Plot of Rotor Housing Vibrations for Filter \#1

Cascade plots for Filter \#2 are presented in Figure 20 through Figure 23. A vibration pattern similar to Filter \#1 is observed in these data plots. This suggests the cause of the vibration is common in the design of the filter, or being caused by the equipment set up. The reverse precession seen in Figure 23 for rotary microfilter housing 2 is worth mentioning and could be due to misalignment at the motor coupling. 
SRNL-STI-2011-00466

Revision 0

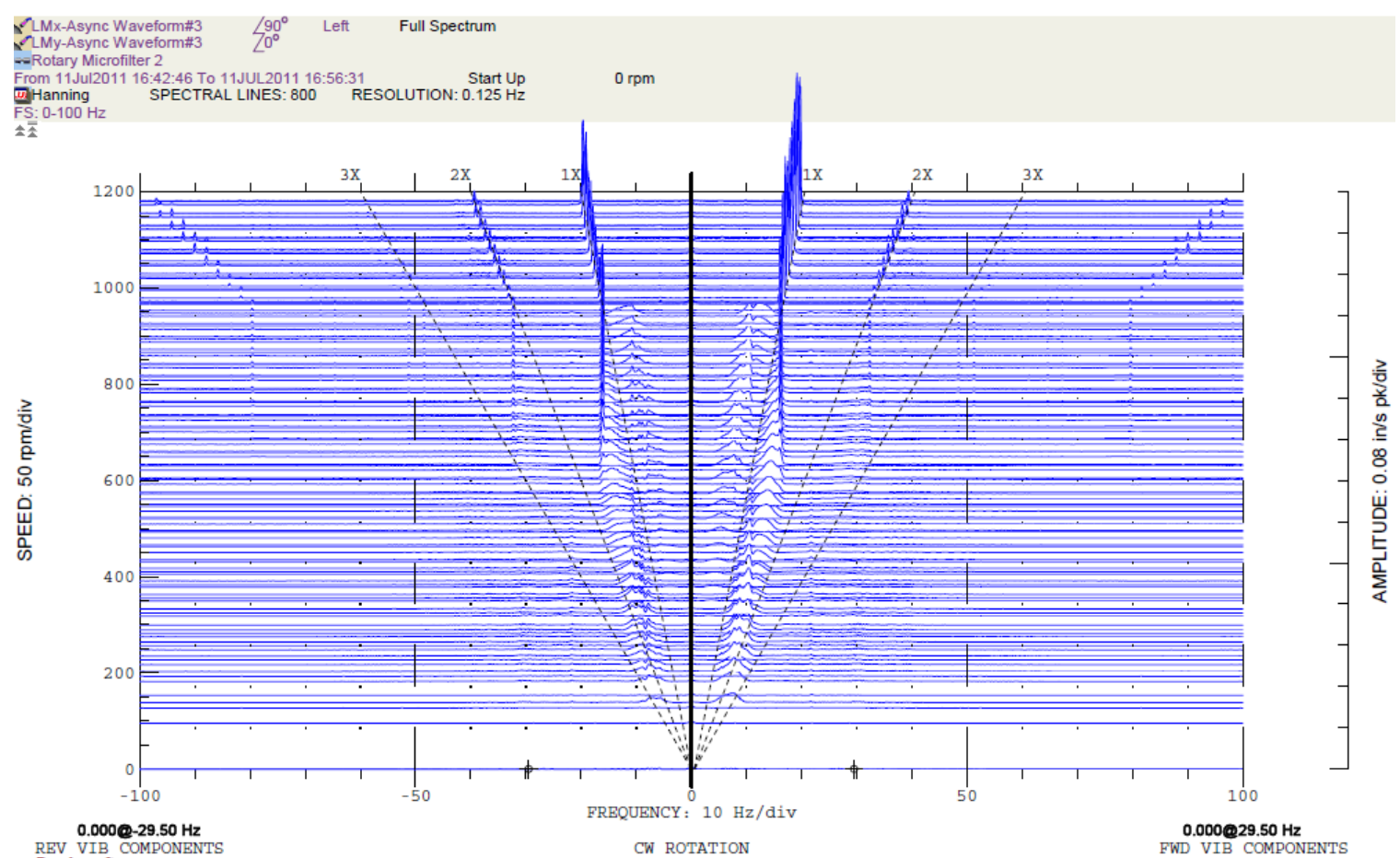

Figure 20. Cascade Plot of Motor Vibrations for Filter \#2

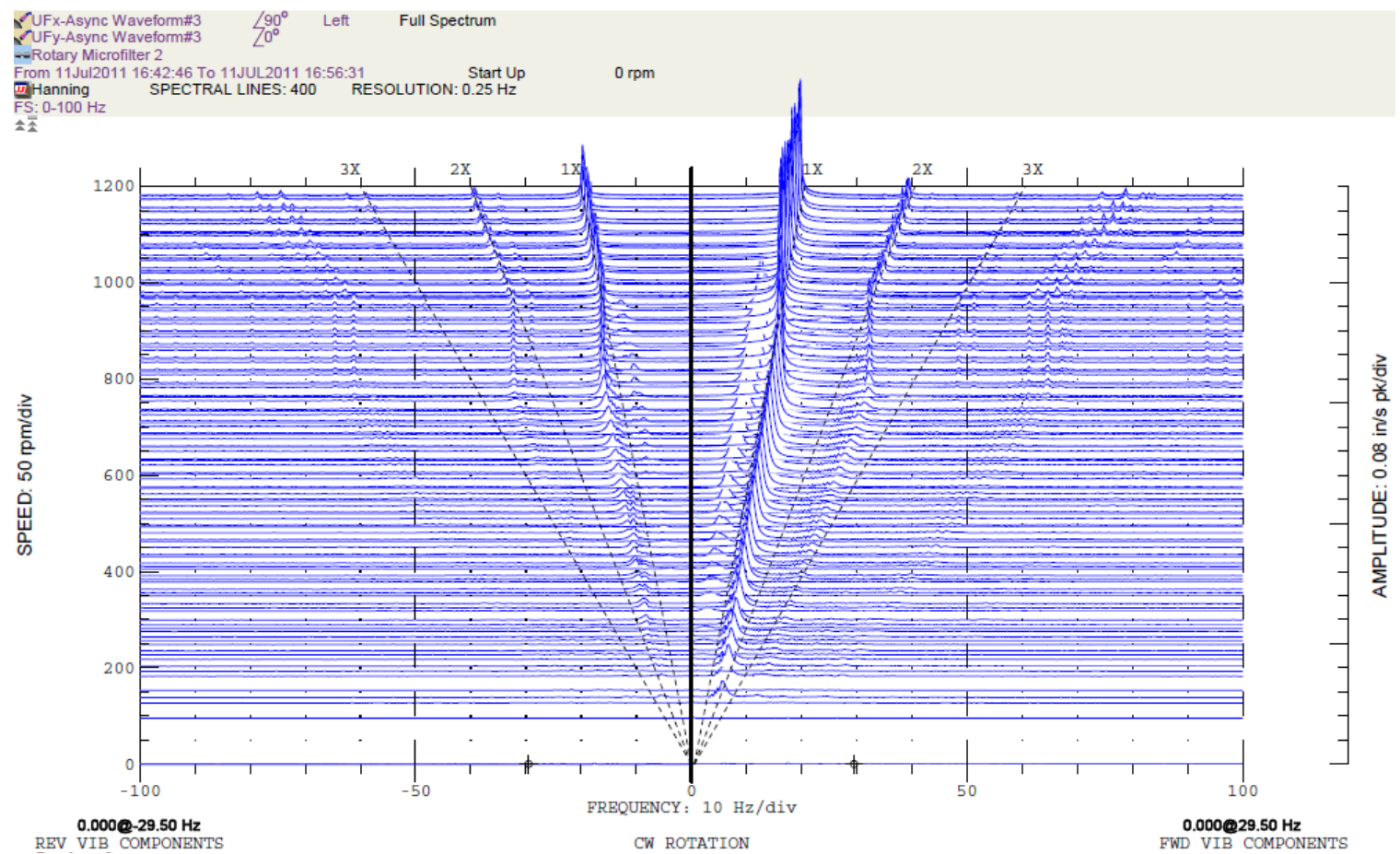

Figure 21. Cascade Plot of Rotary Union Vibrations for Filter \#2 
SRNL-STI-2011-00466

Revision 0

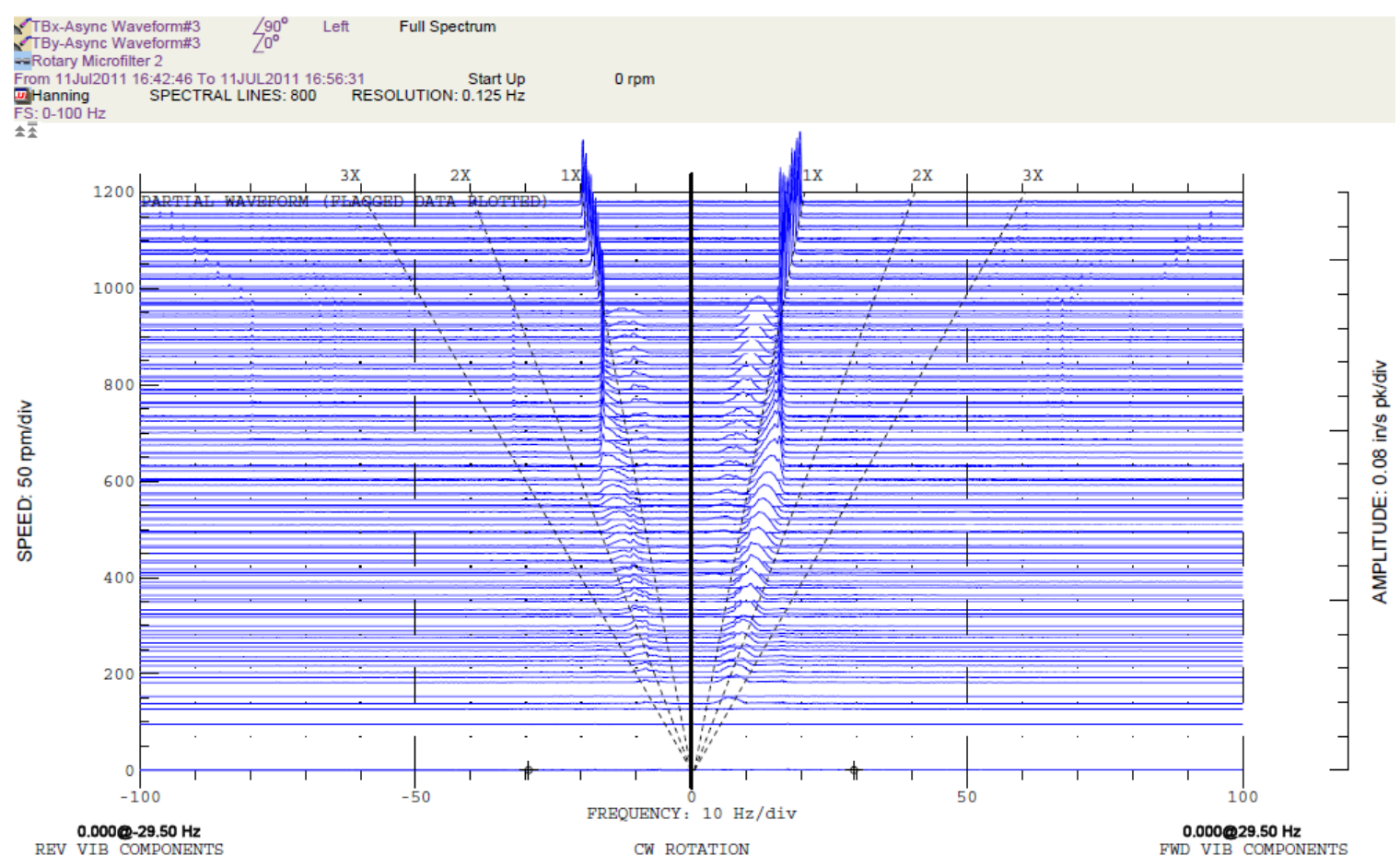

\section{Figure 22. Cascade Plot of Gas Seal Housing Vibrations for Filter \#2}

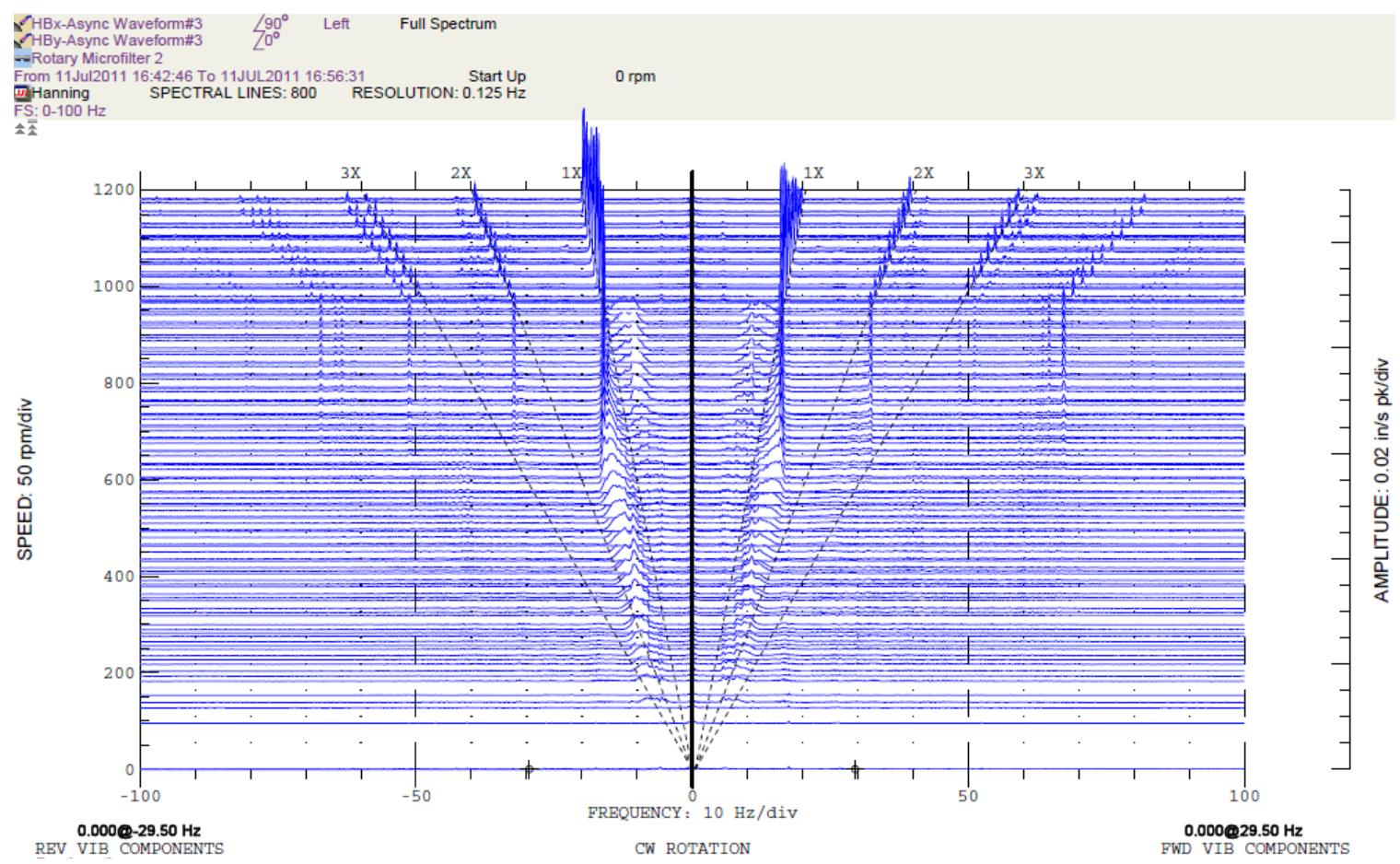

Figure 23. Cascade Plot of Rotor Housing Vibrations for Filter \#2

Several polar plots are presented in Figure 24 through Figure 31. Polar plots are most commonly used to locate the direction of the heavy spot for balancing purposes and with eddy current/proximity probes that measure displacement. Use of this plot format can also help in 
identifying system natural frequencies with casing vibration measurements. Plots from the rotary microfilter speed series display loops around $630 \mathrm{rpm}, 970 \mathrm{rpm}$ and $1020 \mathrm{rpm}$. These loops identify phase changes which is indicative of resonance in a system. Whether the resonance is associated with a rotor critical or structural is hard to distinguish with casing measurements. A relative motion measurement would have helped in the evaluation but there was not enough free space on the shaft to install the probes in the test system.

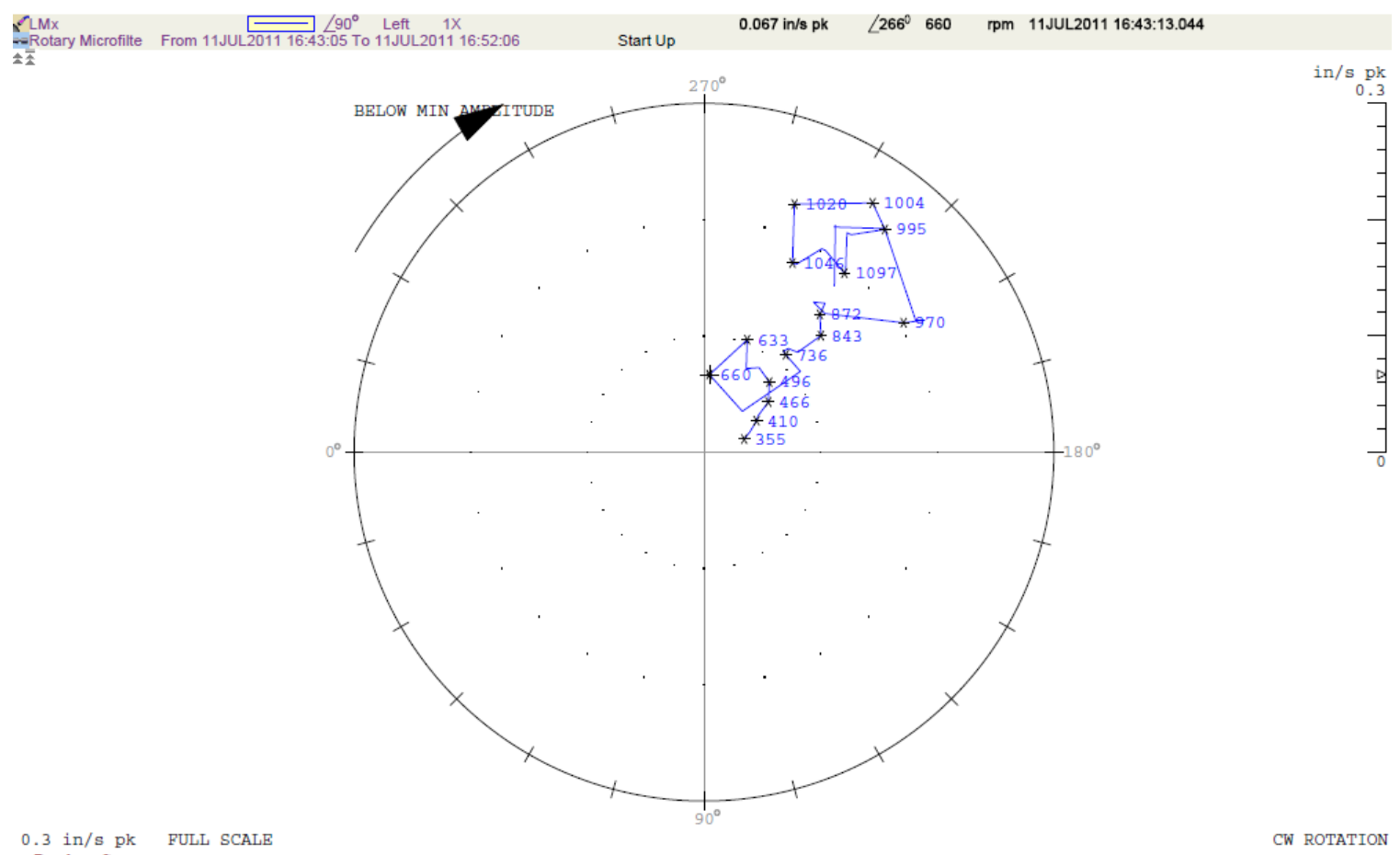

Figure 24. Polar Plot of Lower Motor Showing System Resonances in the X Direction 
SRNL-STI-2011-00466

Revision 0

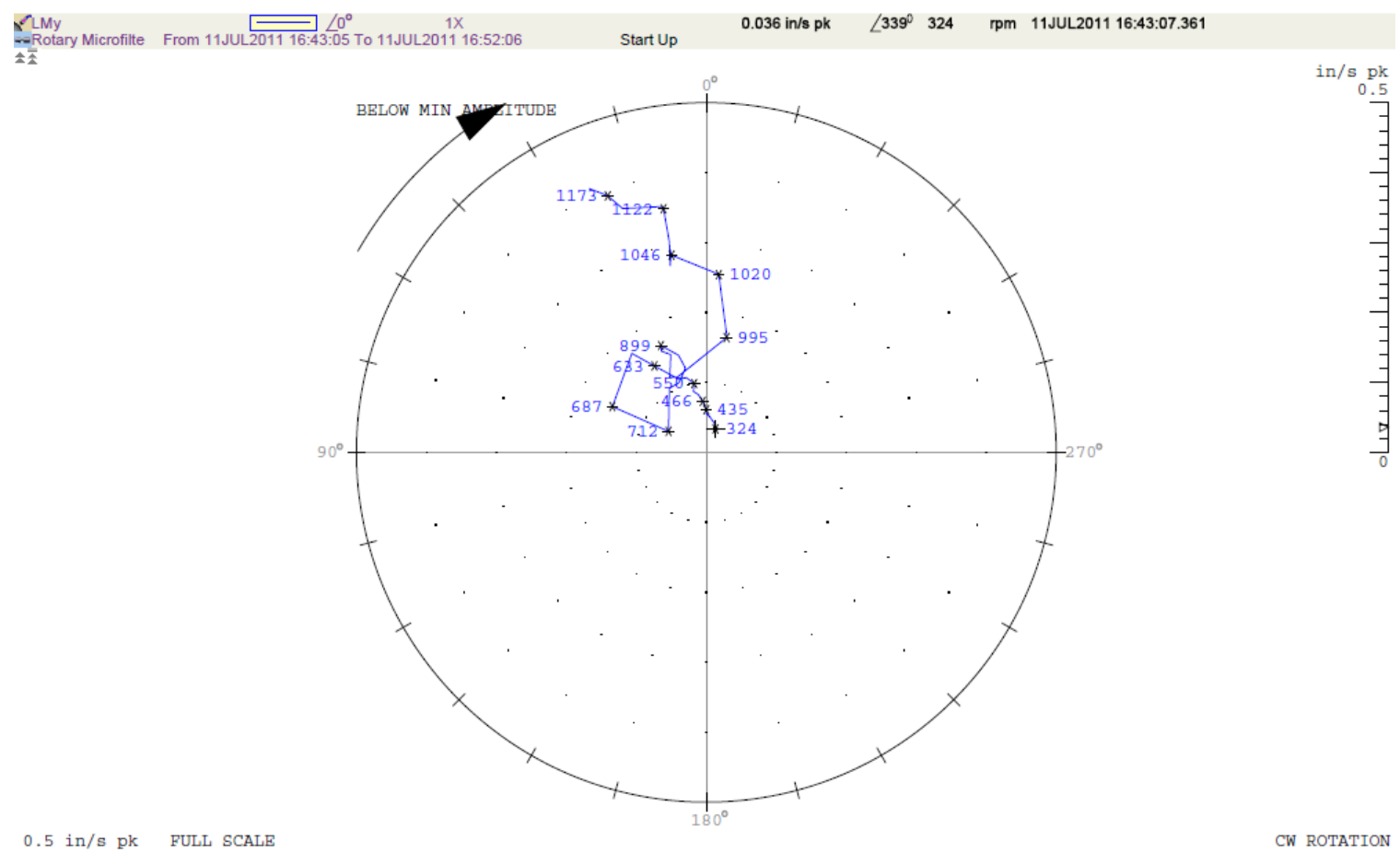

Figure 25. Polar Plot of Lower Motor Showing System Resonances in the Y Direction

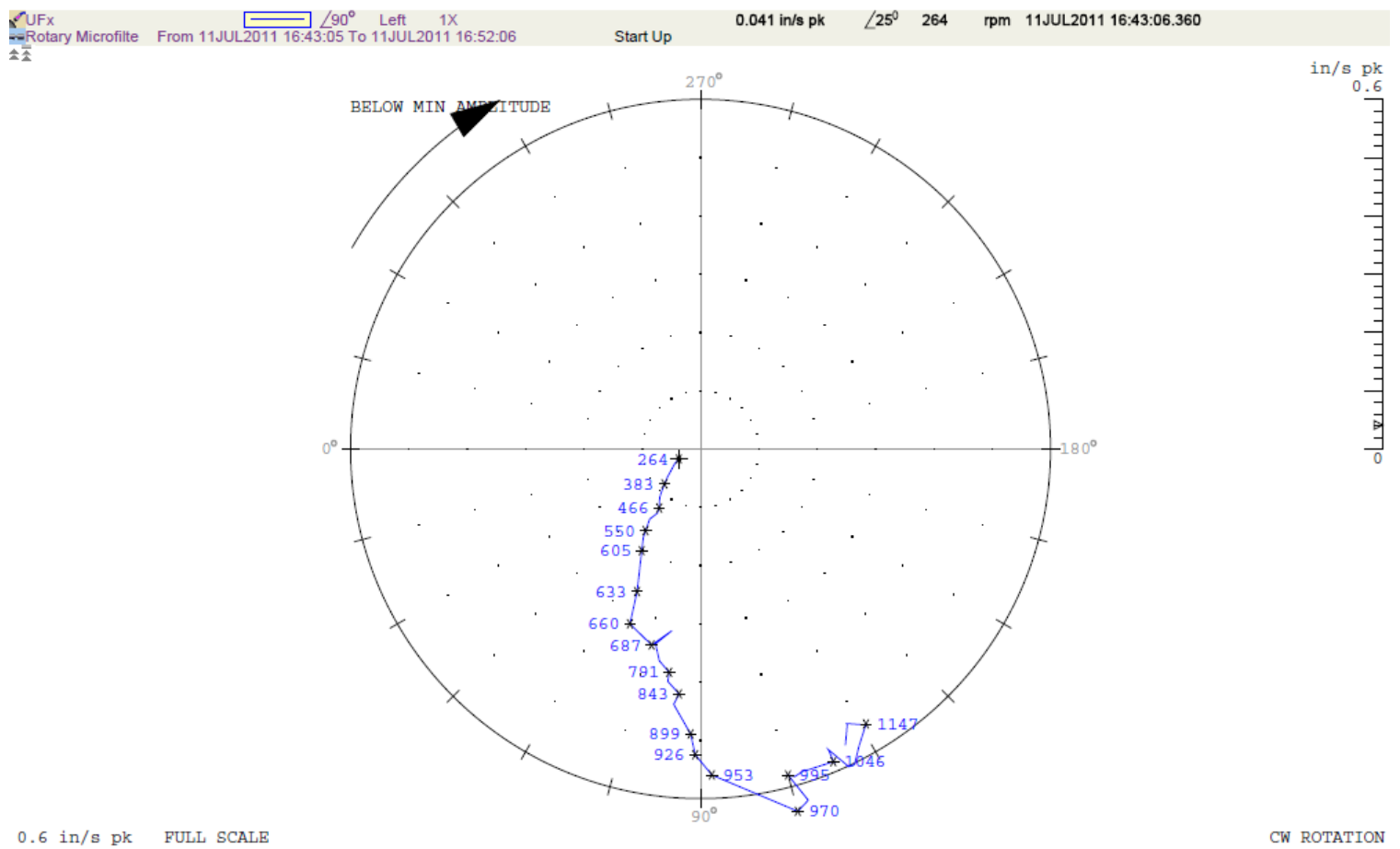

Figure 26. Polar Plot of Rotary Union Showing System Resonances in the X-Direction 
SRNL-STI-2011-00466

Revision 0

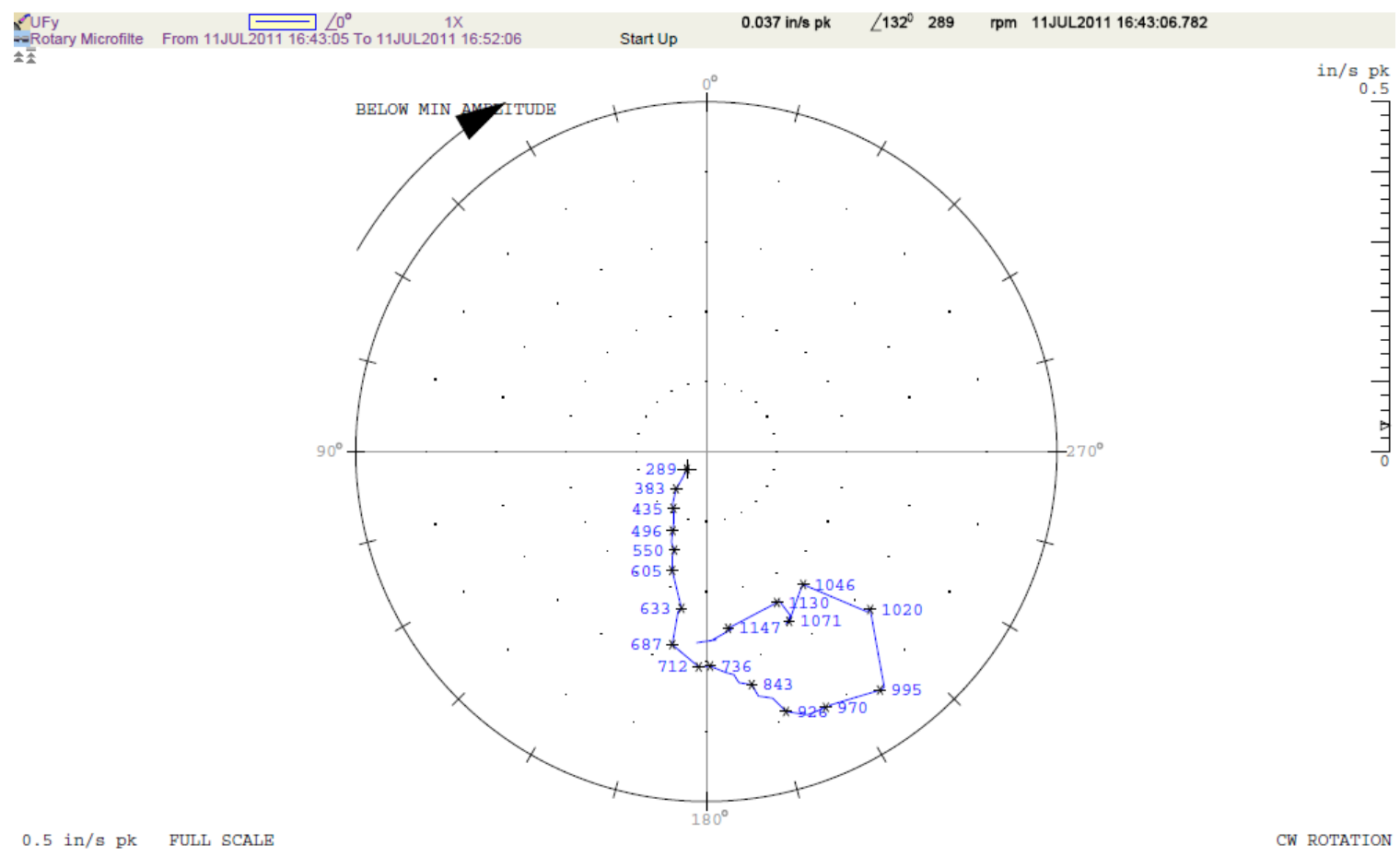

Figure 27. Polar Plot of Rotary Union Showing System Resonances in the Y Direction

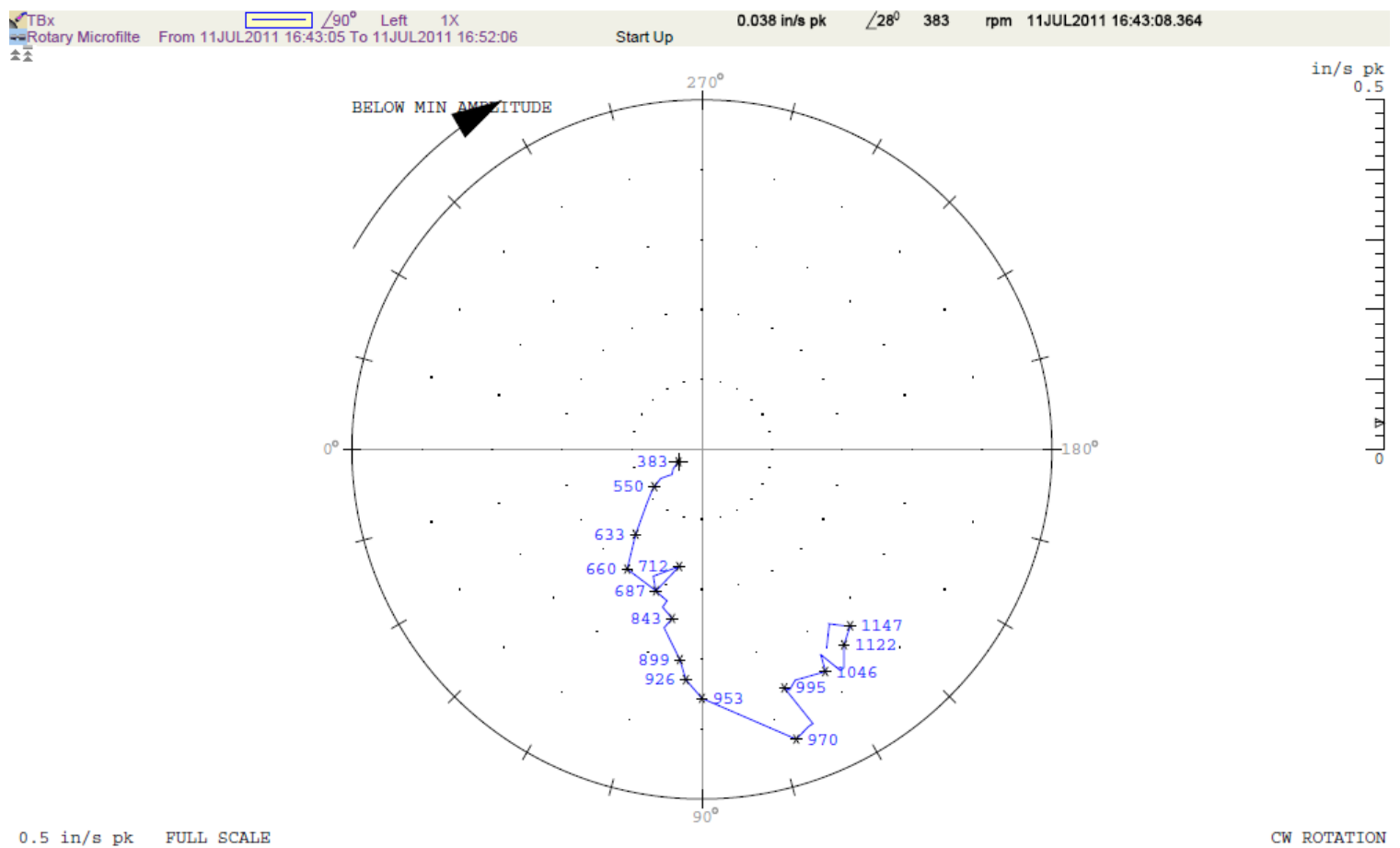

Figure 28. Polar Plot of Gas Seal Housing Showing System Resonances in the X Direction 
SRNL-STI-2011-00466

Revision 0

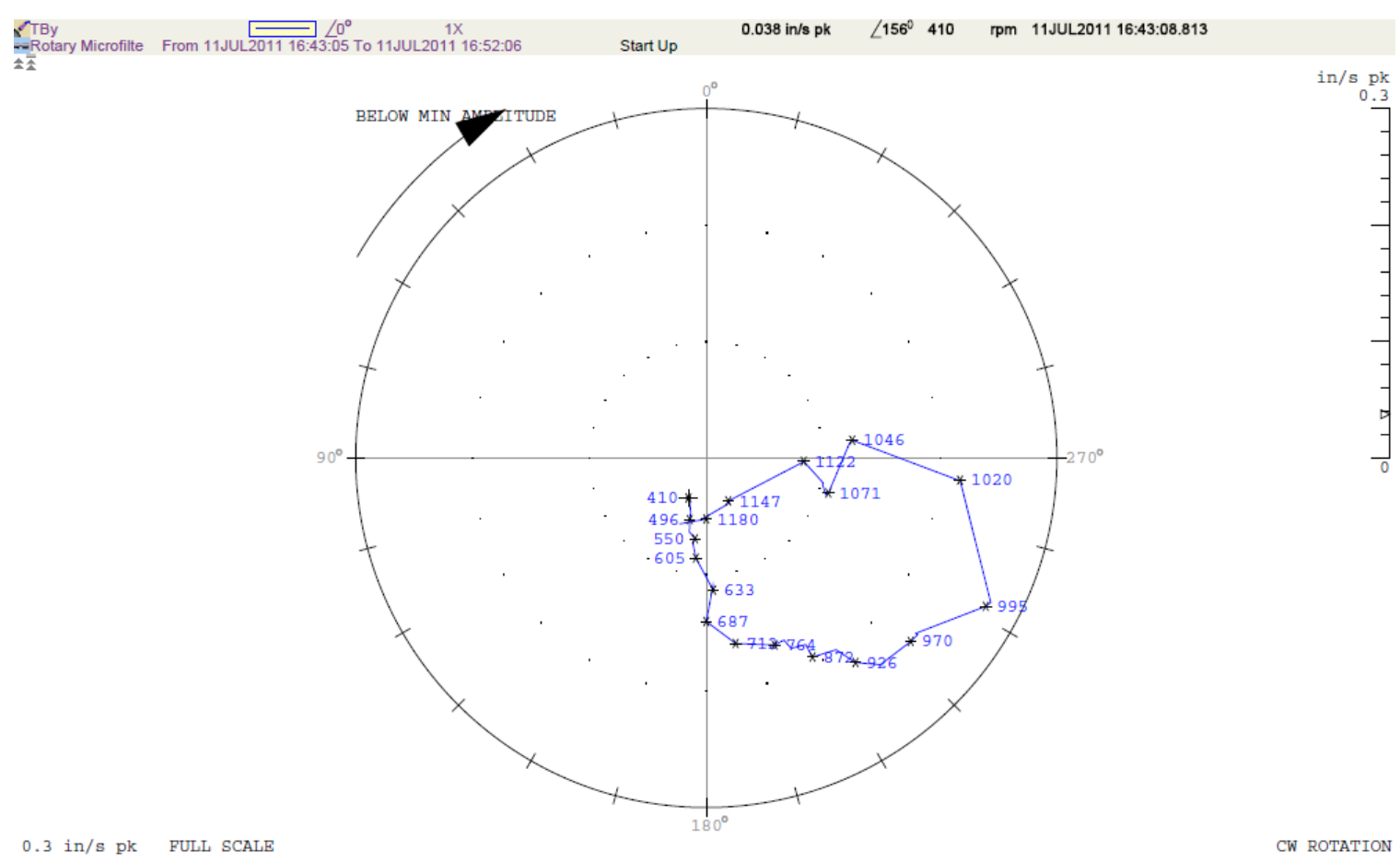

Figure 29. Polar Plot of Gas Seal Housing Showing System Resonances in the Y Direction

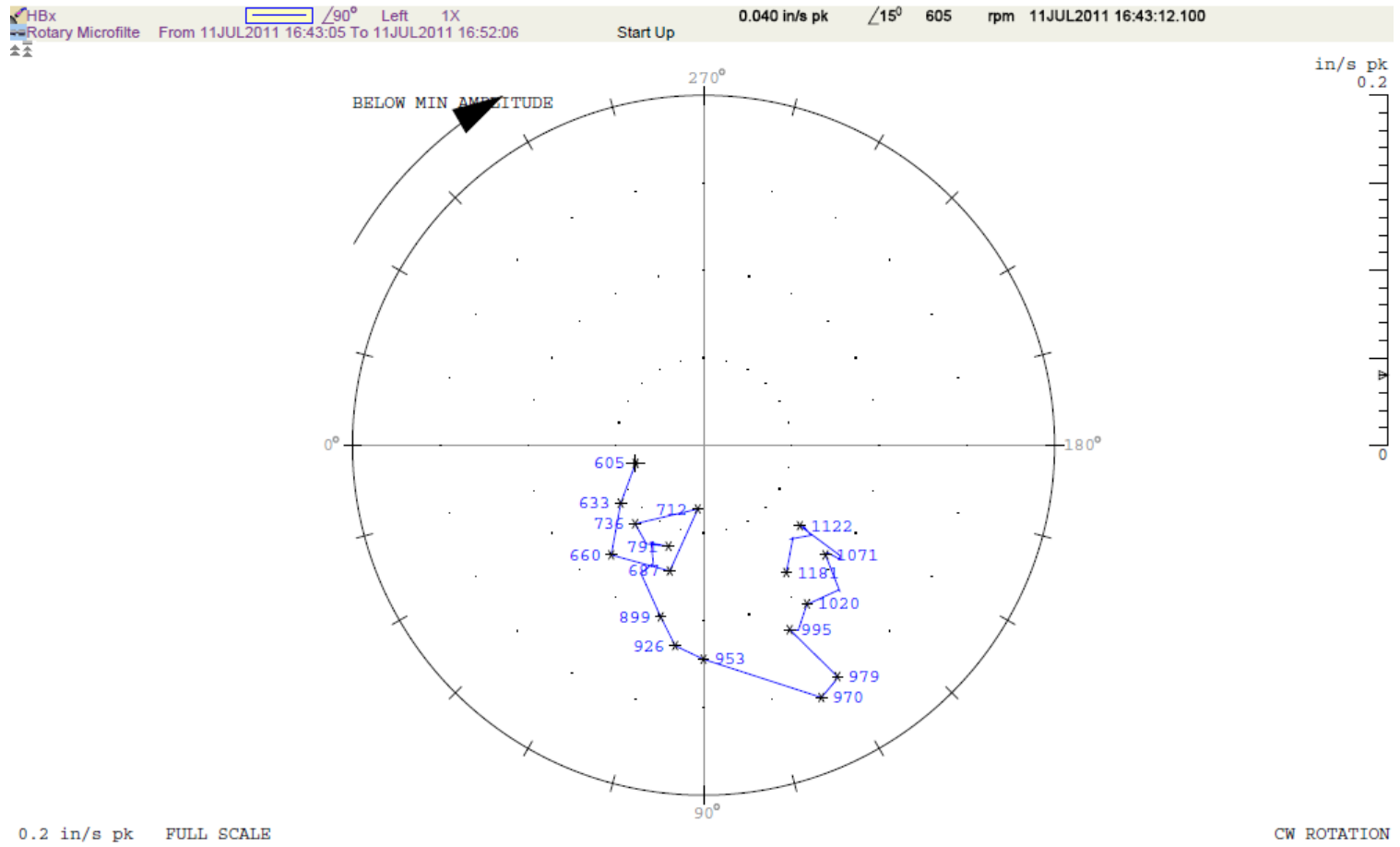

Figure 30. Polar Plot of Rotor Can Housing Showing System Resonances in the X Direction 


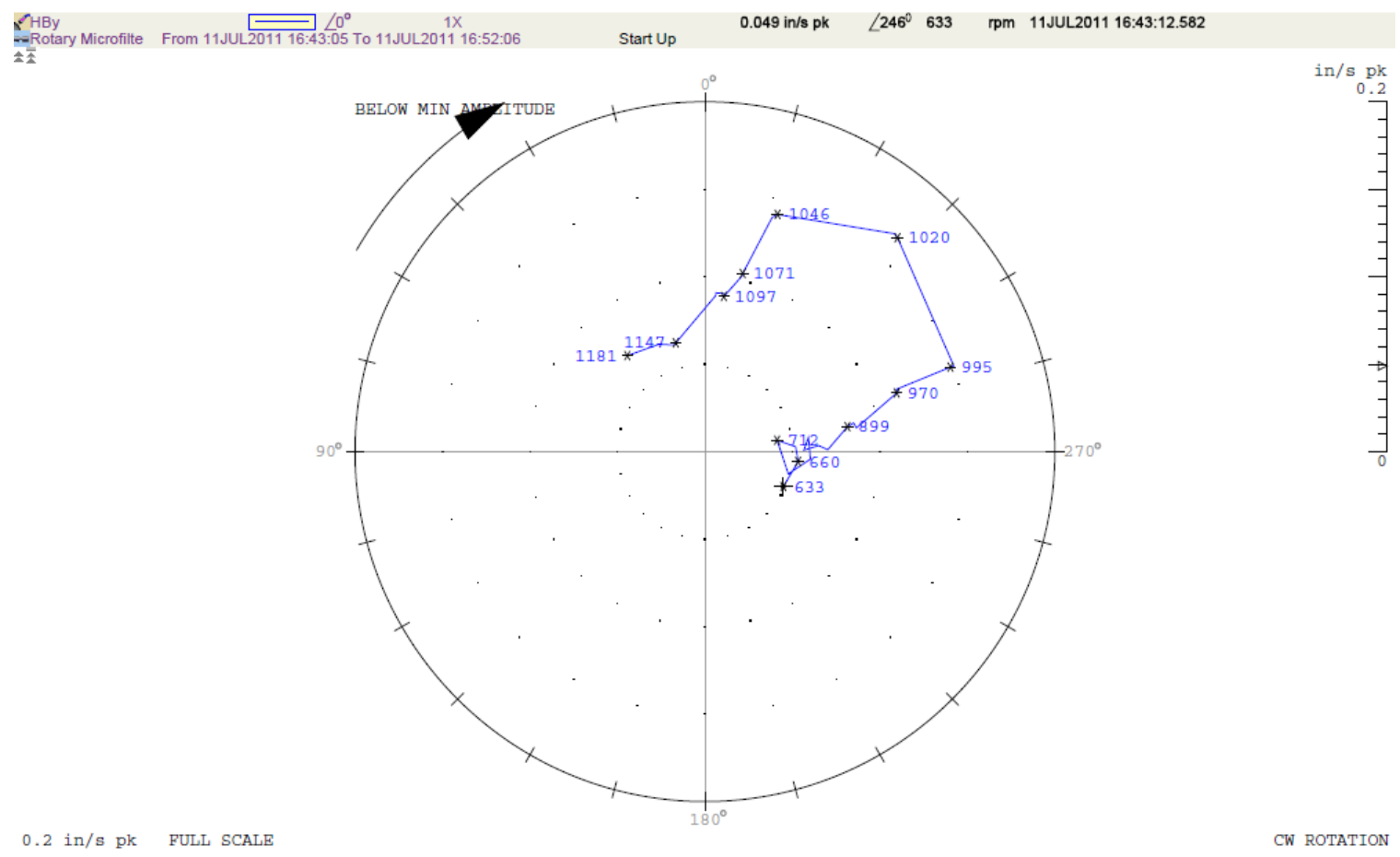

Figure 31. Polar Plot of Rotor Can Housing Showing System Resonances in the Y Direction

The following can be deduced from the vibration data:

- The data identified critical speeds. Whether it corresponds to the resonance frequency of a rotor radial vibration mode that is excited by rotor unbalance or a resonance in the mounting structure is uncertain based upon the measurements. Use of proximity probes is required to differentiate between the two.

- Two resonance frequencies appear to exist.

- The vibrations grew to unacceptable amplitudes in the current equipment set up. An evaluation of the final equipment mount will be required to maximize the lifetime of the filters.

- Journal bearing rub within the filter housing may be present based on the reverse vibration components seen in the cascade plot and higher speeds.

- The sidebands seen in the tracking frequency harmonics indicate there are rapid changes in machine accelerations or decelerations at higher speeds. This behavior can increase the stress on machine components and lead to equipment reliability issues.

- Misalignment may have existed at the motor coupling on Filter \#2 at the time the speed series was run based on the reverse vibration component.

During the vibration measurements, it was observed that backlash may be occurring from the motor-to-filter shaft coupling supplied by the vendor. The current coupling is a Lovejoy Jaw coupling with an Ethylene-Propylene Diene Monomer (EPDM) spider. ${ }^{\text {a }}$

\subsubsection{System Temperature}

Throughout testing, process temperature was a concern. The system used a closed feed loop with 180 gallons of feed. A $16 \mathrm{~kW}$ chiller, in conjunction with a $10.7 \mathrm{~kW}$ heat exchanger, was used on

\footnotetext{
${ }^{a}$ Note the spider on Filter \#1 was starting to split and tear. The couplings, including spiders, used in this testing were not new and had been used in previous testing.
} 
the concentrate line but was found to be inadequate when the ambient temperature was over approximately $80^{\circ} \mathrm{F}$ with the filters operating at a reduced speed. A $4.5 \mathrm{~kW}$ supplemental chiller was added with cooling coils applied directly to the feed tank. This modified set-up proved to be marginally effective for cooling of the system.

The filters produce a great deal of heat as the applied mechanical energy is dissipated in the form of heat due to fluid friction and shearing. The two motors are rated at approximately $15 \mathrm{~kW}$ each. Additionally, the circulation pump energy is also imparted to the fluid due to fluid friction in the piping. The pump motor is rated at $4 \mathrm{~kW}$. Thus, the total mechanical energy imparted to the fluid can be as much as $34 \mathrm{~kW}$ with the rotors and feed pump operating at full speed. Note that the motor efficiency is less than $100 \%$, and some energy from the motor body will be dissipated to the surroundings. However, as an example and assuming that all the energy is imparted to the fluid, it was calculated that at a flow rate of $70 \mathrm{gpm}$ and $28 \mathrm{~kW}$ of work being performed at the reduced rpm, a fluid temperature rise of $2.8^{\circ} \mathrm{F}$ resulted for a single pass of feed through the system. Since the test was a closed loop with limited volume, the filters were required to be operated at reduced speed to maintain the temperature in the feed tank below alarm and interlock values.

\subsection{Operational Issues and Improvements}

\subsubsection{Motor to Filter Alignment}

The amount of vibration on the filter is the single most important factor in filter lifetime. For this testing, locking the filter in the proper aligned position was extremely challenging. The filter mounting did not allow the securing of one direction while the other was adjusted. Misalignment of the motor and filter resulted in a significant amount of vibration during operation. Fine adjustment was not designed into the support system which did not provide the alignment necessary for minimal vibration. In spite of the use of a laser alignment system, aligning the motor to the filter was accomplished with great effort, and differences of 0.010 ” were common.

Filter vibration would change noticeably during a test as the system temperature changed. It was presumed that the increase in temperature during operation moved the motor relative to the filter and changed the alignment. This will most likely carry over to deployment, where operational, as well as atmospheric changes in temperature will affect the alignment of the motor and filter sets.

To facilitate proper alignment, the filter should ideally be tied directly to the motor. The motor mount design should include independent fine adjustment and the shaft design should provide enough room for the mounting of alignment equipment.

\subsubsection{Start Up}

The first 100-hour test using simulant resulted in lower than desired flux after the solids were added. This low flux was a result of maintaining a sustained pressure drop across the filter disks prior to the start of the filter motor. It is believed that this allowed a significant amount of solids to collect on the filter disks creating a buildup of a large filter cake. As reported previously ${ }^{\mathrm{v}}$, it is much more difficult to break up an established filter cake than it is to prevent the filter cake formation. Ideally, the filter should be initiated by starting the rotor as soon as possible to prevent the buildup of filter cake. 
During the startup of the second 100-hour test, additional care was taken to start the rotor as quickly as possible after initiating feed flow. This resulted in a higher initial flux that continued for the duration of the testing.

To optimize filter startup in a multi-filter configuration, the system should allow each filtrate line to be hydraulically isolated to prevent deadheading filters that are started later in the startup sequence. As currently planned, each filter will be started up manually. After all filters have been started, operation will be turned over to the automated control system. If the deployed configuration does not include automated valves for each filtrate line, the filters will be deadheaded during startup and an excessive filter cake will be formed. An automated isolation valve that can be manipulated during start-up will allow each filter to remain isolated while the others are being started. Each valve would open just as the corresponding filter would start up to prevent extended dead heading of the filter.

\subsubsection{Disk Reverse Flow}

During an interruption of the testing, Filter \#1 was removed and inspected. It was observed that the filter disks had undergone a reverse pressurization at some point during the testing. The membranes were no longer sitting flat on the disks and appeared very similar to the disks from the reverse pressurization testing. ${ }^{\mathrm{x}}$ A photo of a disk from the reverse pressure testing is shown as Figure 32.

A photo of a disk from Filter \#1 after the first 100 hours of testing is shown as Figure 33. The membrane was no longer sitting flat on the disk support structure and showed a deformation similar to that seen in Figure 32 though not to the same extent.

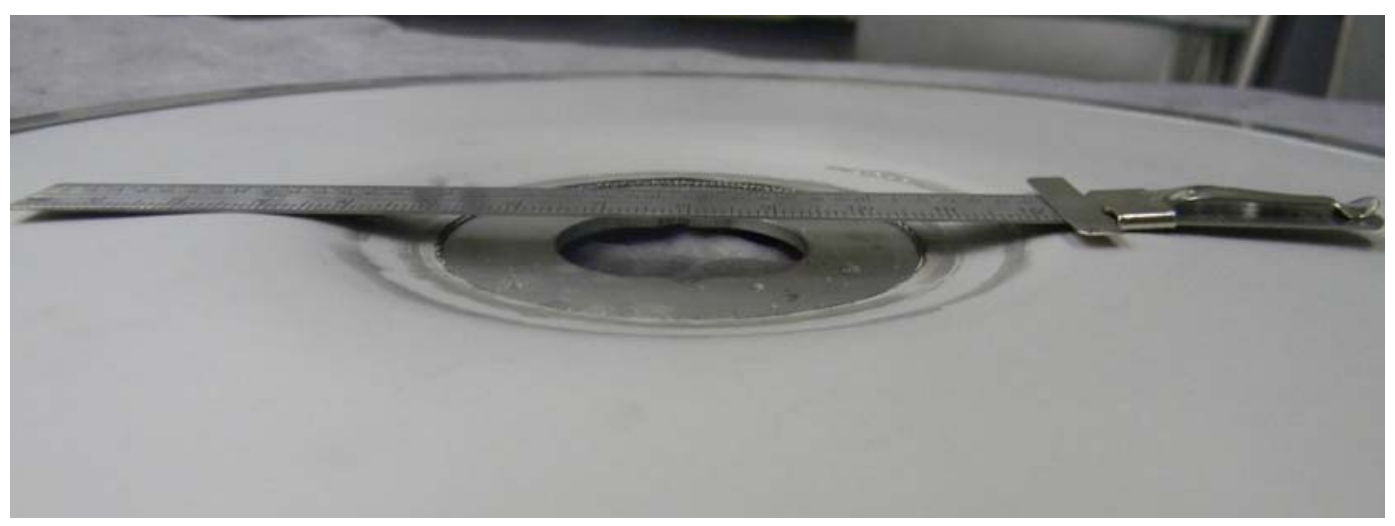

Figure 32. Filter Disk from Reverse Pressure Testing ${ }^{\mathrm{x}}$ 


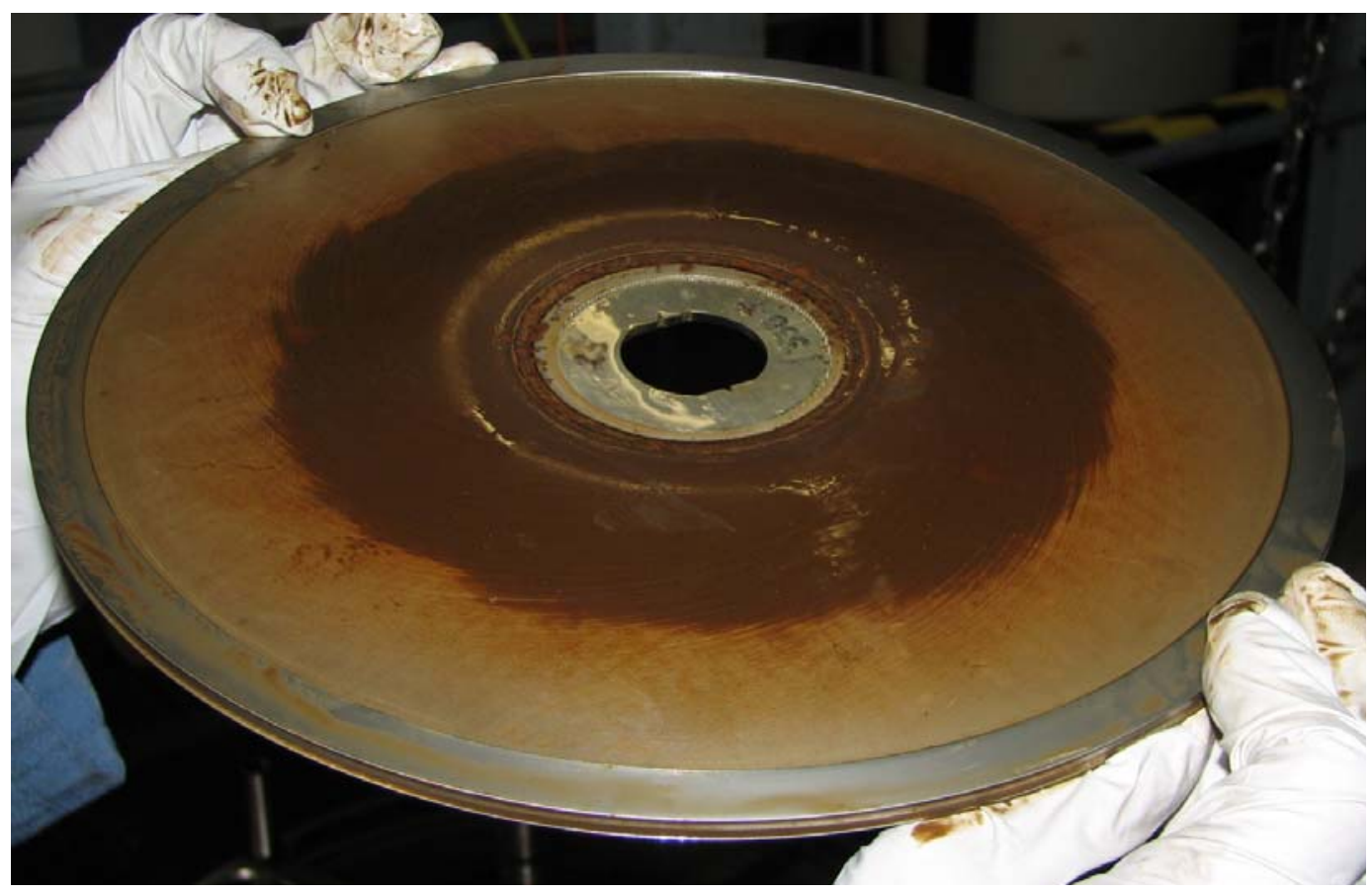

Figure 33. Disk from Filter 2 (old filter) with Evidence of Reverse Flow

Two probable causes exist for the deformations. The first potential cause of a reverse flow through the disks severe enough to deform the membranes would be a vacuum pulled on the filter chamber as the filter housing gravity drained into the feed tank. The filter housing may have been vented through the filtrate line resulting in the reverse flow through the disks. This is the more likely cause and is consistent with the movement of the stationary seal face in the rotary union of Filter \#2 discussed in 3.2.4.

The second potential cause would be operation (spinning) of the disks with no feed pressure. On one occasion during testing of the control system, the feed pump tripped off by an interlock but the filters continued to operate. The filters continued to spin for approximately two minutes before being turned off. This situation would have resulted in a reverse flow through the disks as the centrifugal force expelled filtrate from the disks back to the housing. This is considered less likely based on the authors' experience operating filters in the past and observations made during the reverse pressurization testing.

\subsubsection{Gravity Drain}

During a restart of the filter, filtrate leaked from the rotary union of Filter \#2. The system was shut down and the rotary union was removed and disassembled. A picture of the cause of the leak (Figure 34) shows the concentric O-ring that seals the stationary face of the mechanical seal in the rotary union housing extruded.

Up to this point, the system had been running without incident. Prior to the start of Test 2, the system was shut down without isolating the filtrate lines as previously discussed. The hypothesis is the gravity drain of the feed from the filter housing, pulled a vacuum on the filtrate line and resulted in the stationary seal face being drawn inward. This resulted in the condition shown in Figure 34. 


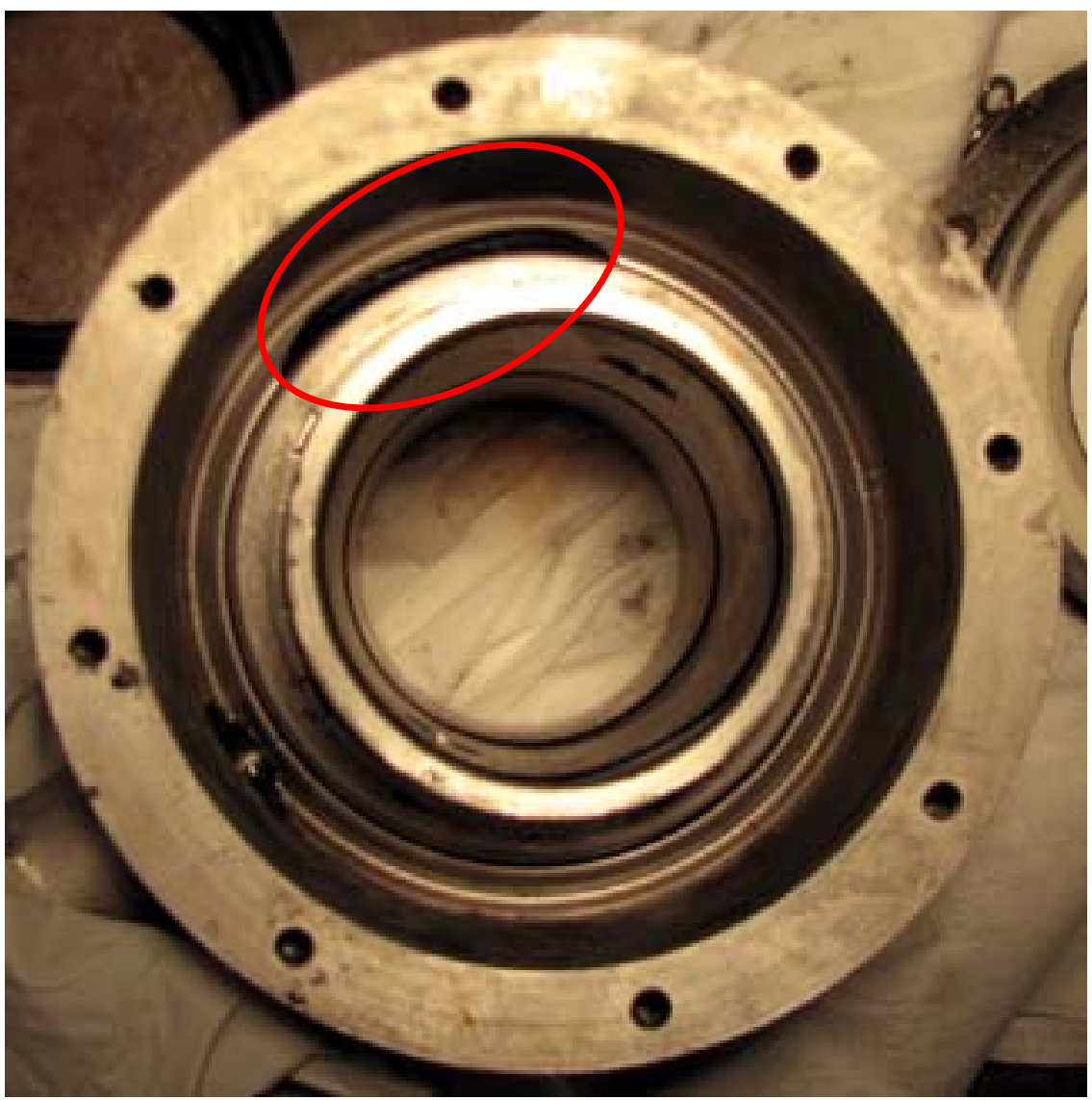

Figure 34. Leak Path from Rotary Union

\subsubsection{Rotary Union}

\subsubsection{Flexible Filtrate Line}

The system was originally plumbed with a hard pipe connected to the rotary union based on SRR input on the deployment design. This configuration was run for the first 100-hour test. Historical setups of the RMF had always used a flexible line to connect the rotary union to hard piping to dampen vibration. Approximately 60 hours into testing, evidence of wear on the carbon seal face and the passage of minute quantities of filtrate were observed on the rotary union of Filter \#2. A line of material, carbon and salt solution residue, was observed on the bearing support structure (Figure 35). The line was formed over time as the material passed the seal face and was eventually slung from the rotating parts of the rotary union to form a visible black line on a nearby support structure. 


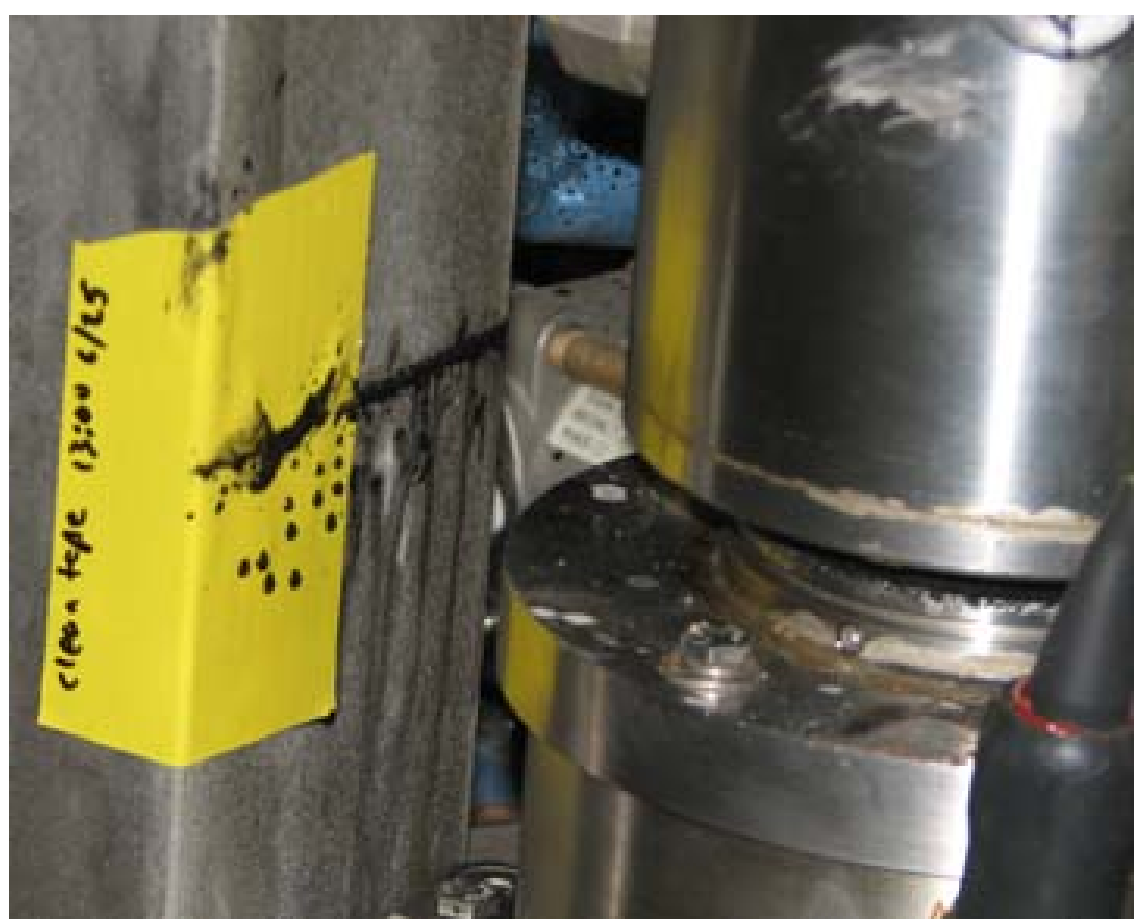

Figure 35. Rotary Joint of Filter \# 2 with Evidence of Salt and Carbon Discharge

In addition, the rotary union from Filter \#1 had dried salt traces from both weep holes indicating minute quantities of fluid passage from the rotary union seals.

Prior to the second 100-hour test, the hard pipe to the rotary unions were replaced with stainless steel flexible lines (Figure 36). The flexible lines were used to dampen and isolate vibration to the rotary union. The lines in the test are approximately three feet long. This line length was used simply due to availability. Previous tests used flexible lines of approximately one foot. 


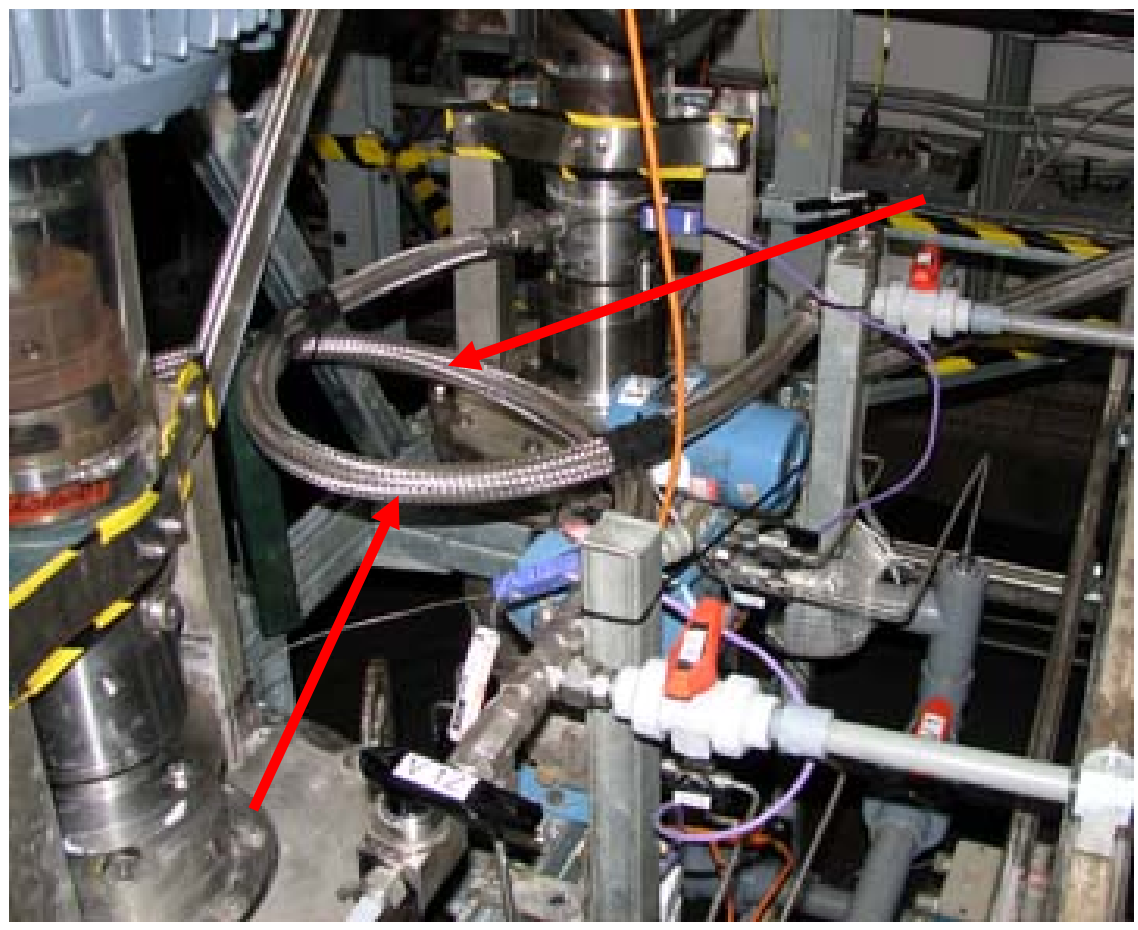

Figure 36. Flexible Lines between Rotary Unions and Filtrate Piping

The rotary union on Filter \#2 was rebuilt with new seals between Test 1 and Test 2. With the flexible lines installed for the second test, the line of salt and carbon was not observed. The rotary union from Filter \#1 also did not have any additional dried salt traces, indicating that the material weep across the seal faces had been minimized. No changes occurred to the Filter \#1 rotary union between tests. The passage of filtrate across the seal faces ceased after the flexible line was installed. No active leak was observed on either rotary union for the remainder of testing.

\subsubsection{Rotary Union Movement}

Twice during initial testing, flow dropped significantly for one of the filters. The reason was due to the misalignment of the discharge port in the shaft with the inner hole of the rotary union. The misalignment occurred because the set screws holding the position of the rotary union on the shaft had become loose. The inner sleeve rotated and blocked flow out of the shaft. Figure 37 shows the discharge of the rotary union to the shaft. The inner hole in the rotary union sleeve behind the spring in the center of the photo should show the shaft discharge port. The rotary union has rotated and; therefore, only the side of the shaft is shown in through the inner sleeve hole. 


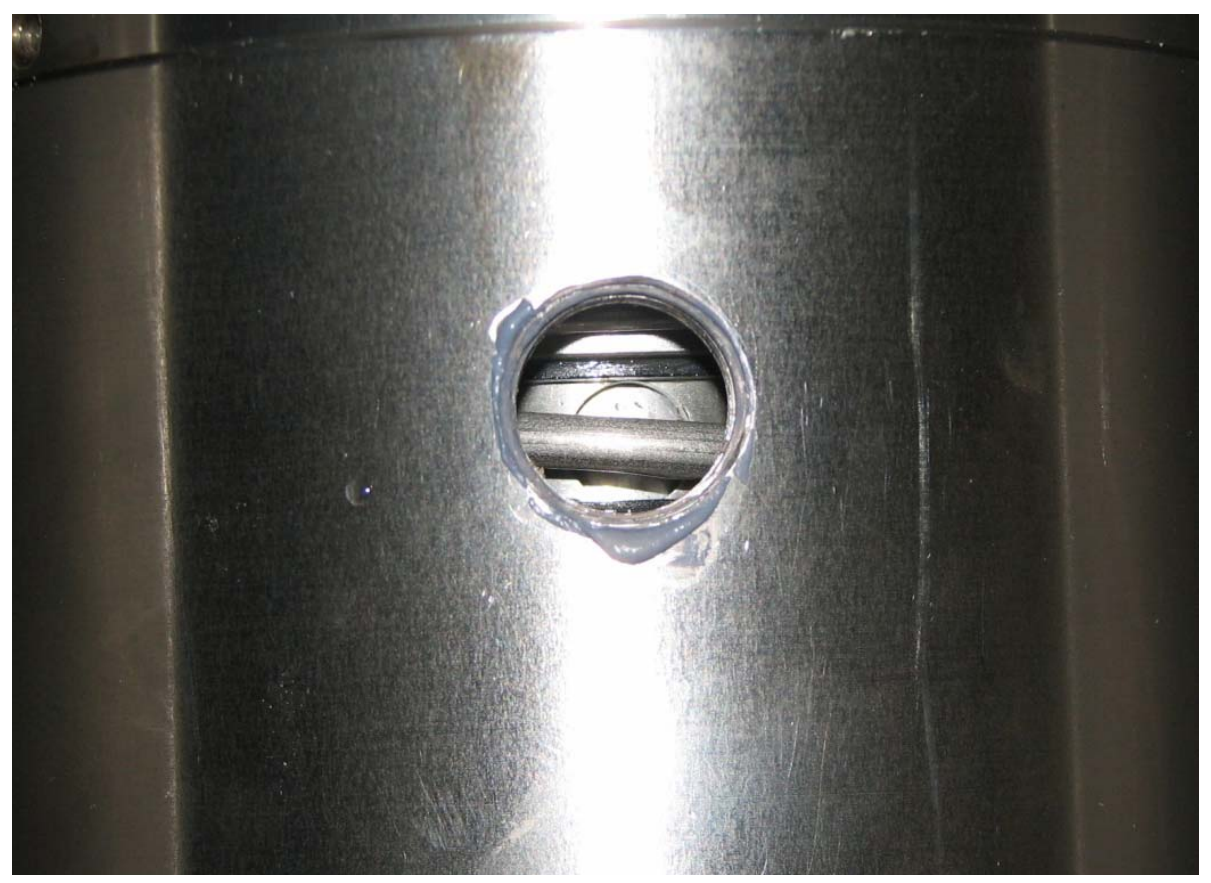

Figure 37. Rotary Union Connection Showing Blocked Shaft Discharge

In one instance, a misalignment occurred by the tightening of a pipe connection leading to the rotary union. The connection was tightened due to a minor leak. The rotary union was hard piped to the pipe connection and the torque applied to the connection forced the rotary union to move on the shaft. This and the other instances of misalignment were reported to the vendor and they have since changed the location and size of the set screws. The previous design of two set screws, internal and centered on the rotary union sleeve, replaced the small set screws on the top of the rotary union. An access port, added for installation and removal, was coupled with a flat added to the shaft for set screw anchorage.

SRNL recommended to the vendor the inclusion of a position indicator to aid in proper alignment of the rotary union inner sleeve and the shaft discharge port. Locating those holes is currently challenging and is accomplished by looking through the access ports on the rotary union. This will be very challenging in a remote facility if the union requires replacement.

\subsubsection{Filtrate Valve}

The control valve used in testing was the valve selected by SRR for use in deployment. The 2" control valve was manufactured by Fisher, part number NPS 2 EZ 667 size 45 DVC6010 SS. The Fisher EZ valve body was a stainless steel, single port, globe-style design. The 667 actuator was a spring-opposed, reverse-acting diaphragm actuator that provided automatic operation of the valve. Controlling the actuator was a DVC 6010 digital valve controller using the Foundation Fieldbus communicating protocol. Dry filtered air was provided to the valve controller from the facility process air supply at $125 \mathrm{psig}$. The controller regulated the supply pressure to $30 \mathrm{psig}$ for the actuator.

The control valve was used to regulate filtrate flow rate and it performed effectively throughout testing. The control algorithms were designed to keep the valve operating in the middle of its range, $40-50 \%$ open, for smooth, predictable response. Flow rate through the valve typically varied from 55 to $95 \mathrm{gpm}$, but occasionally exceeded $130 \mathrm{gpm}$. Pressure upstream of the valve 
typically varied from 60 to 100 psig, and the maximum pressure of the system (dead head pressure of the feed pump) was 143 psig. The downstream pressure was approximately atmospheric given the flow resistance through the heat exchanger and the vertical drop to the feed tank.

\subsubsection{Filter Draining}

Prior to rinsing and cleaning the filters, the system was drained to remove simulant. The filters were also drained between sequential cleaning solutions. The filters were emptied through a drain line in each respective concentrate line. Air vents were opened on the feed line and the concentrate lines to facilitate gravity draining. In spite of vents available to both filters, Filter \#1 consistently retained approximately five gallons in the filter housing. A cause for this retention was never established. No issues were encountered for draining Filter \#2.

\subsubsection{Acid Cleaning}

The filters were cleaned in situ with $0.5 \mathrm{M}$ nitric acid prior to filter testing, between Test 1 and Test 2 (Filter \#2 only was cleaned in situ between Test 1 and Test 2), and after all tests were completed. Due to binding of the filter shaft, Filter \#1 was disassembled, inspected, and cleaned by hand between Test 1 and Test 2 . The binding was a result of shimming the bottom of the filter to the filter tank. The need for the shims posed an early filter design issue that has been resolved in the current design. The Filter \#1 disks were replaced with spare disks when, during inspection, they were found to be deformed due to back pressure (reference section 3.2.3).

Cleaning the filters involved pumping a sequence of fluids through the filters; a batch of DI water, a batch of $0.5 \mathrm{M}$ nitric acid and finally two batches of DI water to remove any residual acid (the $\mathrm{pH}$ of the last DI water batch was measured to verify the neutral condition). The batches were approximately 30 gallons each. Each cleaning fluid was pumped into the filters through the feed line with a dedicated pump, through the filter membranes and out the filtrate line. The discharge from the filtrate line was routed back to the cleaning solution tank to continuously circulate the cleaning fluid. The feed and filtrate lines were isolated from the rest of the filter system during the cleaning sequence. The filters were typically operated while a cleaning solution was flowing through them to help remove solids from the membranes. Operation was limited to less than one minute.

An improvement in the performance of Filter \#2 resulted from the cleaning between tests. Table 6 shows the improvement in the filtrate flow from the end of the first 100 hour test to the beginning of the second 100 hour test for similar operating conditions. The Filter \#1 disks were replaced between Test 1 and 2 and therefore a comparison could not be made.

Table 6. Filter \#2 Filtration Improvement from Acid Cleaning

\begin{tabular}{|c|c|c|c|c|c|c|}
\hline \multirow[b]{2}{*}{ Test } & \multirow[b]{2}{*}{$\begin{array}{l}\text { Run Time } \\
\text { (hrs) }\end{array}$} & \multirow[b]{2}{*}{$\begin{array}{c}\text { Filtrate } \\
\text { Flow (gpm) }\end{array}$} & \multirow[b]{2}{*}{$\begin{array}{l}\text { Improvement } \\
\text { (\%) }\end{array}$} & \multicolumn{3}{|c|}{ Operating Conditions } \\
\hline & & & & $\begin{array}{c}\text { Feed } \\
\text { Temperature } \\
\text { (C) }\end{array}$ & $\begin{array}{c}\text { Differential } \\
\text { Pressure } \\
\text { (psid) }\end{array}$ & $\begin{array}{l}\text { Filter Speed } \\
\text { (rpm) }\end{array}$ \\
\hline $1^{\text {st }} 100$ & 83.0 & 1.52 & - & 40.8 & 40.5 & 997 \\
\hline $2^{\text {nd }} 100$ & 10.3 & 1.82 & 20 & 41.6 & 41.5 & 950 \\
\hline
\end{tabular}




\subsubsection{Loss of a Single Filter}

One issue highlighted during testing was the difficulty in determining the condition of individual filters without individual filter instrumentation. Current deployment plans include the use of instrumentation on the inlet and filtrate headers. Without individual instrumentation, the condition of each filter will be unknown. The consequence in being unable to determine individual filter performance would be potentially to run a filter to failure instead of identifying an issue with a single filter and being able to isolate or repair that filter.

\subsubsection{Bearing Temperature}

Monitoring the temperature of the individual bearings may provide insight into the condition of an individual filter. The precursor to bearing failure is expected to be elevated temperature. Plugging of one filter would reduce filtrate flow in that filter. Reduced filtrate flow would result in low cooling and lubrication to the rotary union seals resulting in elevated temperatures.

During the testing, a sharp increase in bearing temperature for Filter \#1 was observed on several occasions. The temperature would spike rapidly and would then return to a temperature consistent with the system and Filter \#2 bearing temperature. This was only observed during startup of the system. Figure 38 shows three separate occurrences during Test 2.

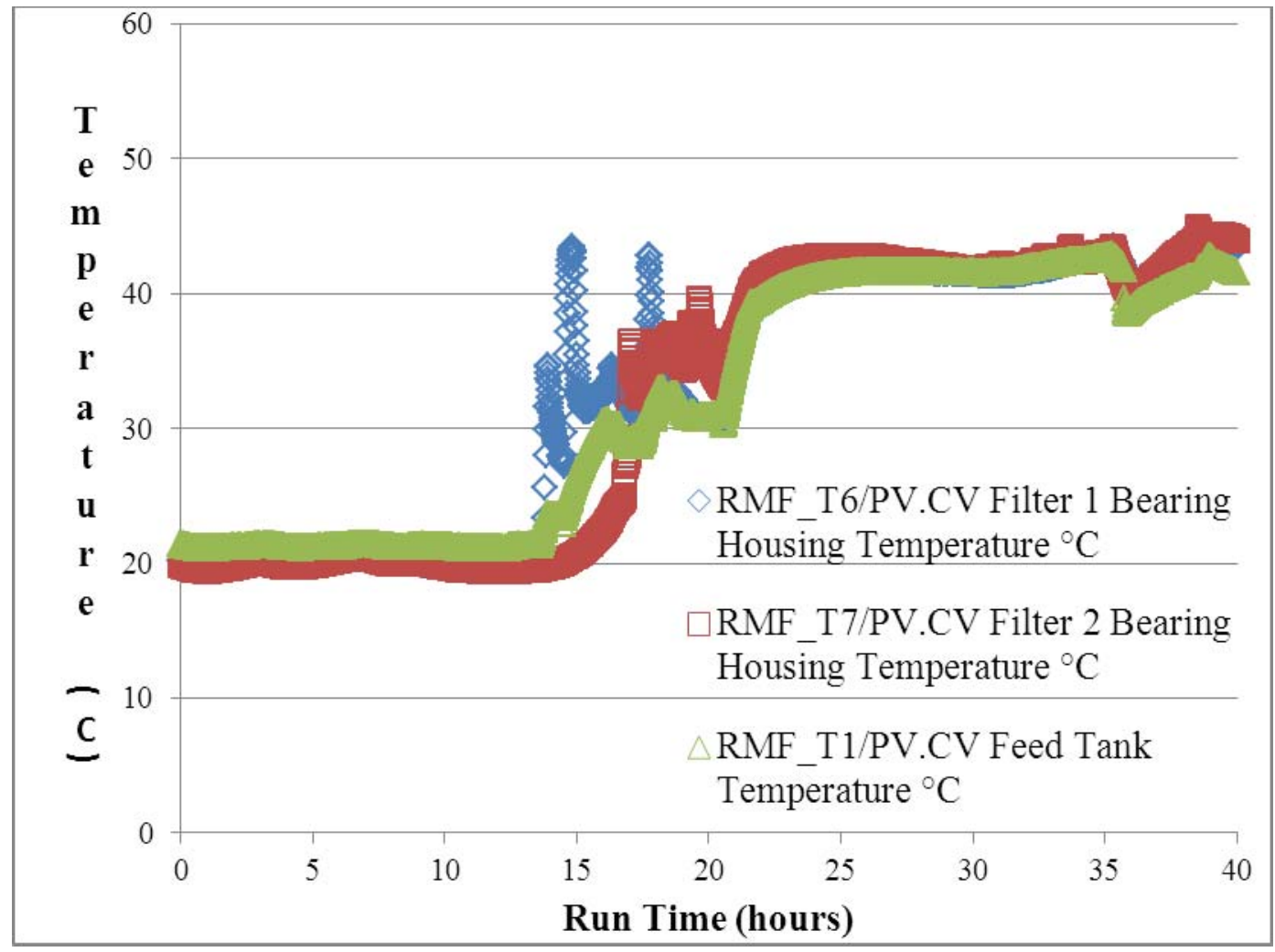

Figure 38. Filter Main Bearing Temperatures for the First 40 Hours of Test 2

\subsubsection{Filtrate Flow Meter}

Towards the end of testing, a discrepancy was noticed in the total filtrate flow rate as measured by the 1-1/2" Krohne magnetic flow meter. The output of the Krohne was compared to the 
combined output of the two $1 / 2$ " ABB magnetic flow meters in the separate filtrate lines to quantify the discrepancy. The discrepancy occurred at flow rates less than four gpm. The 1-1/2" Krohne had a maximum range of $240 \mathrm{gpm}$ and the $1 / 2$ ” ABB meters had a maximum range of approximately $30 \mathrm{gpm}$; therefore, the ABB flow meters were more accurate at low flow rates. Figure 39 shows the discrepancy of the Krohne as a percent of reading throughout the range of measured filtrate flow. Below 3.5 gpm, the reading becomes very inaccurate.

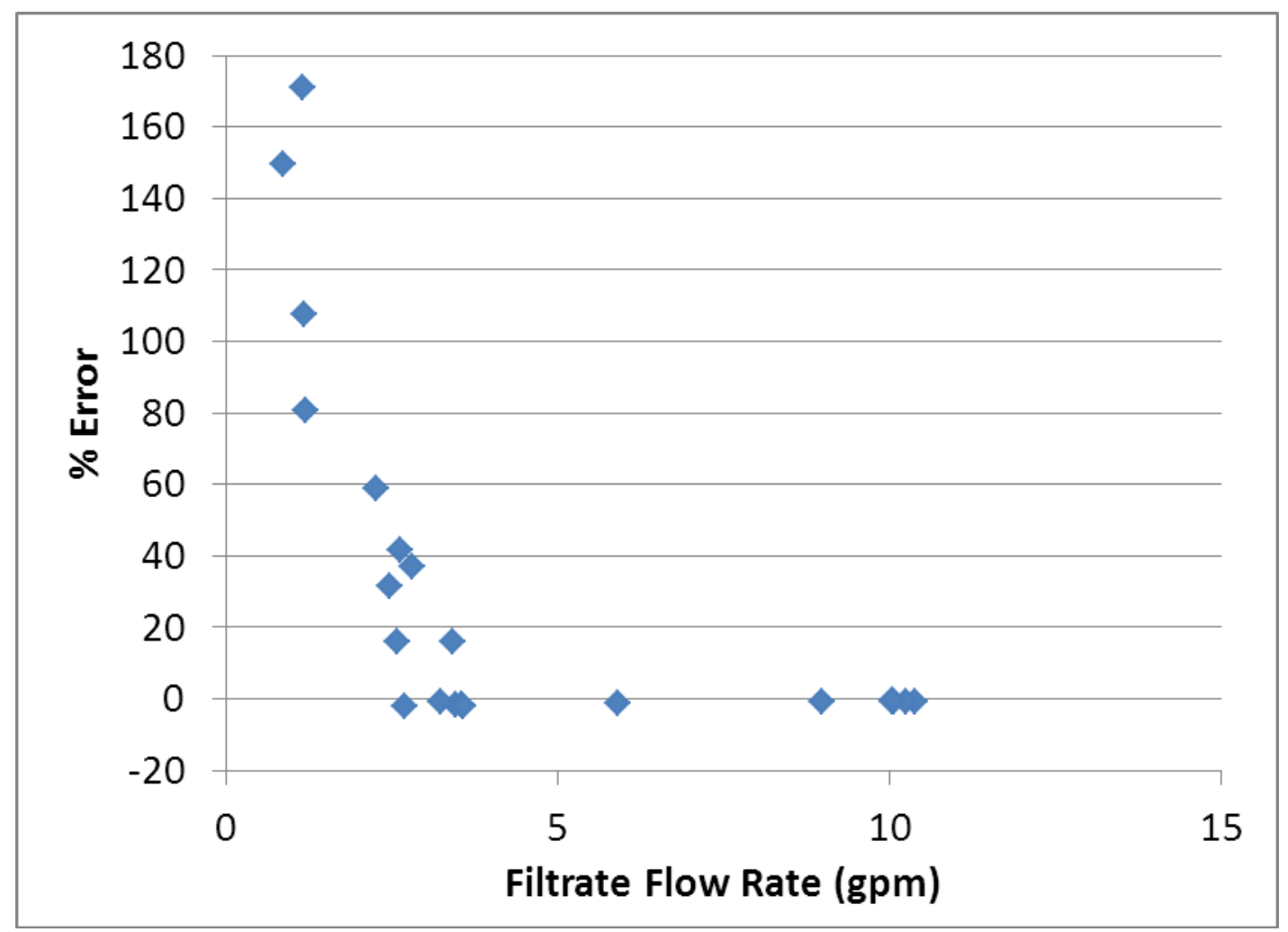

Figure 39. Filtrate Flow Rate Discrepancy of 1-1/2" Meter

In anticipation of this problem, a 1" Krohne flow element was installed in the combined filtrate line. However, the element was never used since the flow rate discrepancy was noticed only towards the end of testing when filtrate set points were intentionally low. In addition, only one Krohne transmitter was available, which would require the elements to be re-wired. The accuracy of the 1" element (0-95 gpm range) is expected to be better than the 1-1/2" element. On the tank top, the filtrate flow rate from four filters is expected to be relatively high ( 10 gpm) where this discrepancy should not be seen. However, flow rate alarms or interlocks at low flow set points may be affected by this discrepancy, in which case the 1" Krohne flow element should be considered instead of the 1-1/2” flow element.

\subsection{Conclusions}

SRNL installed and tested two hydraulically connected RMF units. Both units were successfully controlled by a control scheme written in DELTA-V architecture by SRR Process Control Engineering personnel. The control system was tuned to provide satisfactory response to changing conditions during the operation of the multi-filter system. This was done by limiting parameter ranges to prevent unwanted results. The control system demonstrated stability through 
the startup and shutdown of one of the filter units. Filters were brought online through a manual startup and then turned over to the automated system for control.

The test installation, which was based on the configuration of independent filter and motor mounts proved to be troublesome for vibration. Significant stiffening of the filter and motor mounts was required to minimize the vibration. The use of a flexible line is highly desired at the outlet of the rotary union. Isolating the vibration from the rotary union will significantly improve the lifetime of the seals.

The equipment selected for deployment, including the concentrate discharge control valve, the pressure transmitters, and flow meters, performed well. Automation of the valve control integrated well with the control scheme and when used in concert with the other control variables, allowed automated control of the dual RMF system. The one area of concern with the instrumentation was the lower operating range of the 1-1/2" flow meter. At flow rates less than 3 gpm, the performance of the flow meter was questionable. This should not be an issue in deployment where the desired flow rate will be well above the lower limitation of the meter. However, alarms and interlocks that occur at low flow rates may be affected.

Methods to monitor and isolate individual filters should be considered during deployment. Isolating the filtrate line of each filter will minimize the premature buildup of solids on the filter disks. Several tests have shown that the method of filter startup can improve performance lifetime of the filters. The ability to diagnose issues with individual filters can allow isolation prior to failure. Thus filters may be cleaned or repaired instead of requiring complete replacement if the condition continues unnoticed.

The installation must factor in air inlet for draining the filter that does not allow a reverse flow through the current filter disks. The reverse flow may cause deformation of the disks or may damage other components of the filters themselves.

\subsection{Recommendations}

As a result of this testing, SRNL makes the following recommendations for the final design:

- Ensure the deployment mount ties the drive motors and filter together

- Include a thermocouple for filter bearings

- Ensure the discharge of the rotary union is connected to the system piping by a flexible line

- Incorporate an automatic valve in the individual filtrate lines

- Investigate a new motor to filter coupling

- Evaluate the use of the laminated filter disk for deployment

The installation should securely couple the drive motors and filter together to minimize vibration.

The design mount should allow for easy alignment and tying the drive motor to the filter to prevent the individual units moving out of phase and magnifying the detrimental effect of vibration. Proper alignment will be important to the lifetime of the filter. During testing, excessive vibration was experienced due to misalignment of the drive motor to the filter. 
A relative motion series should be completed on the filter with the final shaft configuration to check for resonances. Resonances were identified in the test system but it could not be determined if they were associated with a rotor critical or the support structure.

The shaft should be of sufficient length to allow for shaft-to-shaft alignment at the motor coupling and sufficient space for the installation of proximity probes.

Additional testing should be performed to rule out misalignment based on nonlinear thermal growth between motor and RMF as system changes temperatures.

Thermocouples should be mounted to the bearing housings of the filters to provide an indication of bearing health. Since no indication of individual filter performance is in the current deployment design, SRNL recommends monitoring the condition of the bearings. The greatest 8failure concern will be the seizing of the bearings in a filter.

The discharge of the rotary union should be connected to the system piping by flexible line to extend the lifetime of the rotary union seals. The component that is greatly affected by vibration is the rotary union. Connection to a hard piping was demonstrated during the first 100 hours of testing and shown to decrease the lifetime of the rotary union seals. Attaching flexible line between the rotary union and the rest of the piping system allows the union to float on the shaft and thereby absorb vibration.

The vendor has updated the design of the rotary joint by changing set screw locations. The performance of and the ability to access the new set screw locations should be verified.

Incorporate an automatic valve in the filter filtrate lines to allow isolation of individual filters and aid in filter startup. The ability to isolate the filtrate lines will allow for individual startup of the filters as well as the ability to isolate a damaged or unneeded filter. Filtrate line isolation is also necessary to prevent reverse flow through the filter disks.

A new motor to filter shaft coupling should be investigated. The current Lovejoy Jaw coupling appears to be exhibiting backlash and the EPDM spider on Filter \#1 contained splits and tears at the end of testing.

SRNL recommends that the use of the laminated filter disks, developed under DOE-EM research programs, ${ }^{\mathrm{xi}}$ be investigated for deployment with the rotary filter. Removing the limitations of the floating membrane would significantly simplify the startup, control and cleaning of the rotary filters by eliminating the need for a positive pressure while starting the filter rotors. Additionally, by being able to start the filters with minimal flow prevents deadheading the filters and the buildup of filter cake prior to rotor startup. The laminated disks also eliminate the possibility of damage to the disk membranes due to reverse flow either by mis-valving or a vacuum being pulled on the filter disks due to gravity draining of the filter housing. 
${ }^{\text {i }}$ D. T. Herman, M. R. Poirier, and S. D. Fink, "Testing of the SpinTek Rotary Microfilter Using Actual Waste,” WSRC-TR-2003-00030, Rev. 1, December 2003.

${ }^{i i}$ M. R. Poirier, D. T. Herman, S. D. Fink, R. Haggard, T. Deal, C. Stork, and V. Van Brunt, "Pilot-Scale Testing of a SpinTek Rotary Microfilter with SRS Simulated High Level Waste," WSRC-TR-2003-00071, February 3, 2003.

iii D. T. Herman, M. R. Poirier, and S. D. Fink, “Testing and Evaluation of the Modified Design of the 25-Disk Rotary Microfilter,”WSRC-STI-2006-00073, Rev. 0, August 2006.

${ }^{\text {iv }}$ D. T. Herman, D.B. Stefanko, M.R. Poirier, S.D. Fink, "Testing of a Full-Scale Rotary Microfilter for the Enhanced Process for Radionuclides Removal,” SRNL-STI-2009-00183, January, 2009.

${ }^{v}$ D. T. Herman, "Rotary Filter 1000 Hour Sludge Washing Test," SRNL-STI-2011-00008, January, 2011.

${ }^{v i}$ Task Technical Request (TTR) HLE-TTR-2010-0021.

${ }^{v i i}$ D. A. Shedd, C. L. Houchens, "Process Control Development and Testing for the Dual Rotary Micro Filter System,” SRR-SCIX-2011-00085, September, 2011.

viii D. T. Herman, “Rotary Filtration System,” M-SPP-A-00102, Rev. 2, October 4, 2004.

${ }^{\text {ix }}$ D.T. Herman, “Rotary Filtration System,” M-SPP-A-00110, March 16, 2009.

${ }^{x}$ M. D. Fowley, D. T. Herman, "Backpressure Testing of Rotary Microfilter Disks,” SRNL-STI2010-00790, April, 2011.

${ }^{x i}$ D. T. Herman, “Development of a Laminated Disk for the SpinTek Rotary Microfilter,” SRNLSTI-2011-00279, May, 2011. 